\title{
Taxonomy and phylogeny of Eosemionotus Stolley, 1920 (Neopterygii: Ginglymodi) from the Middle Triassic of Europe
}

\author{
Adriana López-Arbarello, Toni Bürgin, Heinz Furrer, and Rudolf Stockar
}

\begin{abstract}
Over 80 years the actinopterygian genus Eosemionotus was known from a single species, E. vogeli, from the German Muschelkalk (Anisian). A second species was published in 2004, E. ceresiensis, from the upper Besano Formation (lowermost Ladinian) of Monte San Giorgio, Switzerland. New excellently preserved specimens recovered from the Cassina and Sceltrich beds (Meride Limestone; Ladinian) in this latter area, triggered a new study. Consequently, three new species are established: $E$. diskosomus, E. sceltrichensis, and E. minutus, including differential diagnoses for the five species, which differ in body proportions, relative position of the fins, the morphology of several skull bones, squamation pattern, and some meristic characters (e.g., number of premaxillary teeth, and branchiostegal rays). The cladistic analysis retrieved Eosemionotus as the oldest Macrosemiidae within the order Semionotiformes (Ginglymodi). The monophyly of the genus and its sister-group relationships with the other macrosemiids are among the best supported nodes with high Bremer, jackknife and bootstrap values, and numerous synapomorphies. The pattern of phylogenetic relationships between the five species of Eosemionotus indicates that the Muschelkalk species $E$. vogeli originated through dispersal from the Tethys into the Germanic Basin, most probably across the Silesian-Moravian or the East Carpathian gates before the late Anisian. This very speciose genus, so far almost restricted to the Middle Triassic, has also been reported from localities in Eastern Switzerland, the Netherlands, Spain, Slovenia, and China. Pending the taxonomic and phylogenetic study of these other material of Eosemionotus, the origin of the genus in the Western or Eastern Tethys remains enigmatic.
\end{abstract}

Adriana López-Arbarello. Department of Earth and Environmental Sciences, Palaeontology and Geobiology and GeoBio-Center, Ludwig Maximilian University, Richard-Wagner-Strasse 10, D-80333 Munich, Germany. a.lopez-arbarello@Irz.uni-muenchen.de Toni Bürgin. Naturmuseum, Rorschacher Strasse 263, CH-9016 St. Gallen, Switzerland. toni.buergin@naturmuseumsg.ch

http://zoobank.org/A385EC82-19BE-4EC8-B82B-DE2FA8428E83

López-Arbarello, Adriana, Bürgin, Toni, Furrer, Heinz, and Stockar, Rudolf. 2019. Taxonomy and phylogeny of Eosemionotus Stolley, 1920 (Neopterygii: Ginglymodi) from the Middle Triassic of Europe. Palaeontologia Electronica 22.1.10A 1-64. https://doi.org/ $10.26879 / 904$

palaeo-electronica.org/content/2019/2383-systematics-of-eosemionotus

Copyright: February 2019 Palaeontological Association.

This is an open access article distributed under the terms of the Creative Commons Attribution License, which permits unrestricted use, distribution, and reproduction in any medium, provided the original author and source are credited.

creativecommons.org/licenses/by/4.0/ 
Heinz Furrer. Paläontologisches Institut und Museum der Universität Zürich, Karl Schmid-Strasse 4, CH8006, Zürich, Switzerland. heinz.furrer-paleo@bluewin.ch

Rudolf Stockar. Museo cantonale di storia naturale, Dipartimento del territorio del Cantone Ticino, Viale Carlo Cattaneo 4, CH-6901 Lugano, Switzerland. rudolf.stockar@ti.ch

Keywords: Semionotiformes; Macrosemiidae; new species; Middle Triassic; cladistic analysis; palaeobiogeography

Submission: 10 July 2018 Acceptance: 17 December 2018

\section{INTRODUCTION}

The genus Eosemionotus Stolley, 1920, has been among the poorly understood Triassic neopterygian taxa. Although it is widely distributed in Middle Triassic localities of Europe, only two species have been named so far within this genus: the type species, E. vogeli (Fritsch, 1906), from the Middle Muschelkalk (late Anisian) of Förderstedt bei Bernsburg (Germany), and E. ceresiensis Bürgin, 2004, from the uppermost Besano Formation (earliest Ladinian) of Monte San Giorgio (Switzerland). Bürgin (2004, p. 248), however, indicates the presence of at least four additional morphospecies in Middle Triassic deposits of Monte San Giorgio. The genus has been reported from Middle Triassic localities in Eastern Switzerland (Bürgin et al., 1991; Bürgin, 1999; Herzog, 2003), the Netherlands (Oosterink and Poppe, 1979), Spain (Cartanyà, 1999; Fortuny et al., 2011), Slovenia (Hitij et al., 2010; Miklavc et al., 2016) and China (Jin, 2006; Sun et al., 2009), too. Although the named species have been described in some detail, the systematic position of Eosemionotus has been puzzling (Schultze and Möller, 1986; Bürgin, 2004), and the taxon has never been included in a cladistic analysis. The genus has been considered morphologically similar to the Permian Acentrophorus (Bürgin, 2004) and has been classified within the Semionotidae of Woodward (1890; Stolley, 1920; Schultze and Möller, 1986) or in its own family Eosemionotidae (Bürgin et al., 1991; Bürgin, 2004). The present paper is aimed to complete a detailed morphological and systematic study of the Triassic neopterygian Eosemionotus, including a cladistic analysis to solve its phylogenetic relationships. The study is based on recently collected and extraordinarily well-preserved specimens of Eosemionotus from the Meride Limestone (Ladinian) of Monte San Giorgio (Switzerland; Figure 1), as well as the type and referred material of $E$. vogeli and E. ceresiensis.

\section{METHODS}

The fossil material was mechanically prepared with the aid of vibrotools (Chicago Pneumatic CP9361 air scribe with Krantz W795 modified head bearing Krantz W797 pointed steel chisels) and sharpened steel needles. The specimens were studied under stereomicroscopes Leica Wild MZ6 and M80 equipped with a camera lucida. The drawings were made using a camera lucida, and the photographs were taken with a Nikon D40 digital camera equipped with a Nikon AF-S micro $60 \mathrm{~mm}$ objective. The same protocols have been used in López-Arbarello et al. (2016).

Skull bones and cephalic sensory canals are named according to the use of most authors in actinopterygians (Grande and Bemis, 1998; Grande, 2010; López-Arbarello, 2012; Giles et al., 2017; López-Arbarello and Sferco, 2018). The bones carrying the infraorbital sensory canal anterior to the orbit are referred to as 'anterior infraorbitals' following Wenz (1999), Wenz (2003), and LópezArbarello and Codorniú (2007). Fringing fulcra are named according to Patterson (1982). Scutes, unpaired, and paired basal fulcra are identified according to López-Arbarello and Codorniú (2007). The relative position of the fins and the scale counts are expressed in a pterygial formula where $D, P, A$, and $C$ indicate the number of scale rows between the first complete row behind the pectoral girdle and the insertion of the dorsal, pelvic, anal, and caudal fins respectively, and $T$ is the total number of scale rows between the pectoral girdle and the caudal inversion (Westoll, 1944).

The systematic nomenclature follows LópezArbarello (2012) and López-Arbarello and Sferco (2018). The signs attached to the entries in the synonymy list follow Matthews (1973). The specific diagnoses presented here are the result of firsthand examination of the type and referred material, and detailed comparisons with the other species of the genus. 

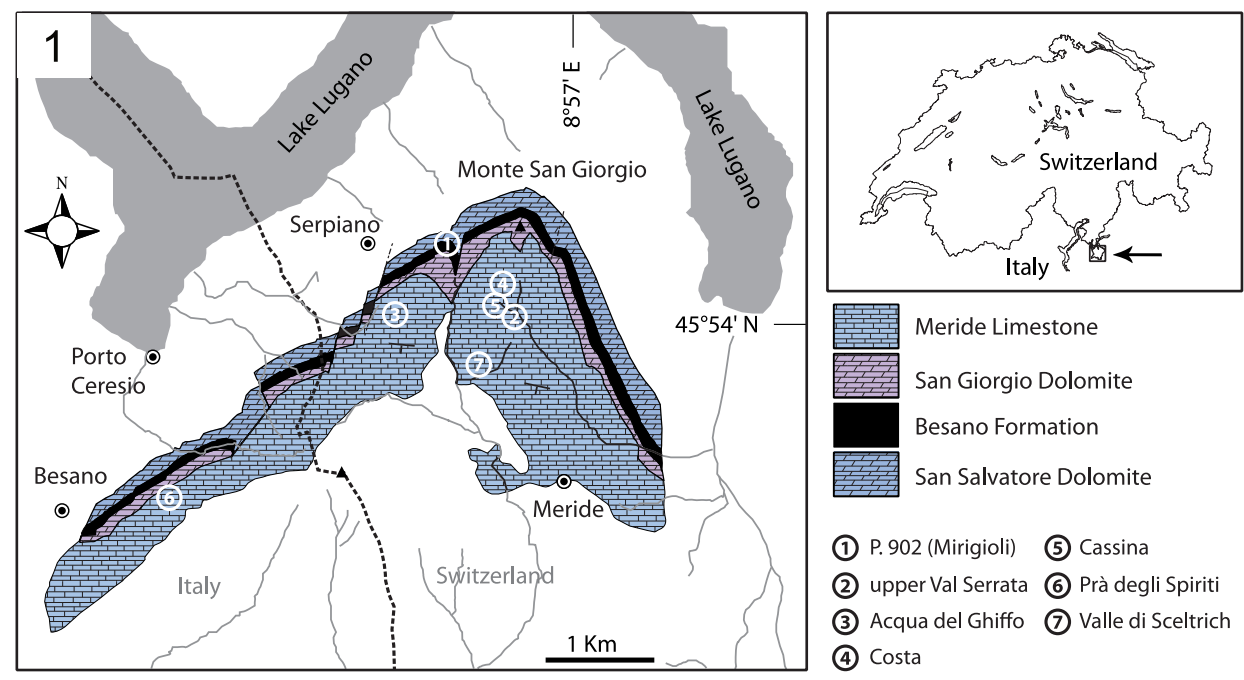

(1) P. 902 (Mirigioli) (5) Cassina

(2) upper Val Serrata (6) Prà degli Spiriti

(3) Acqua del Ghiffo (7) Valle di Sceltrich

(4) Costa

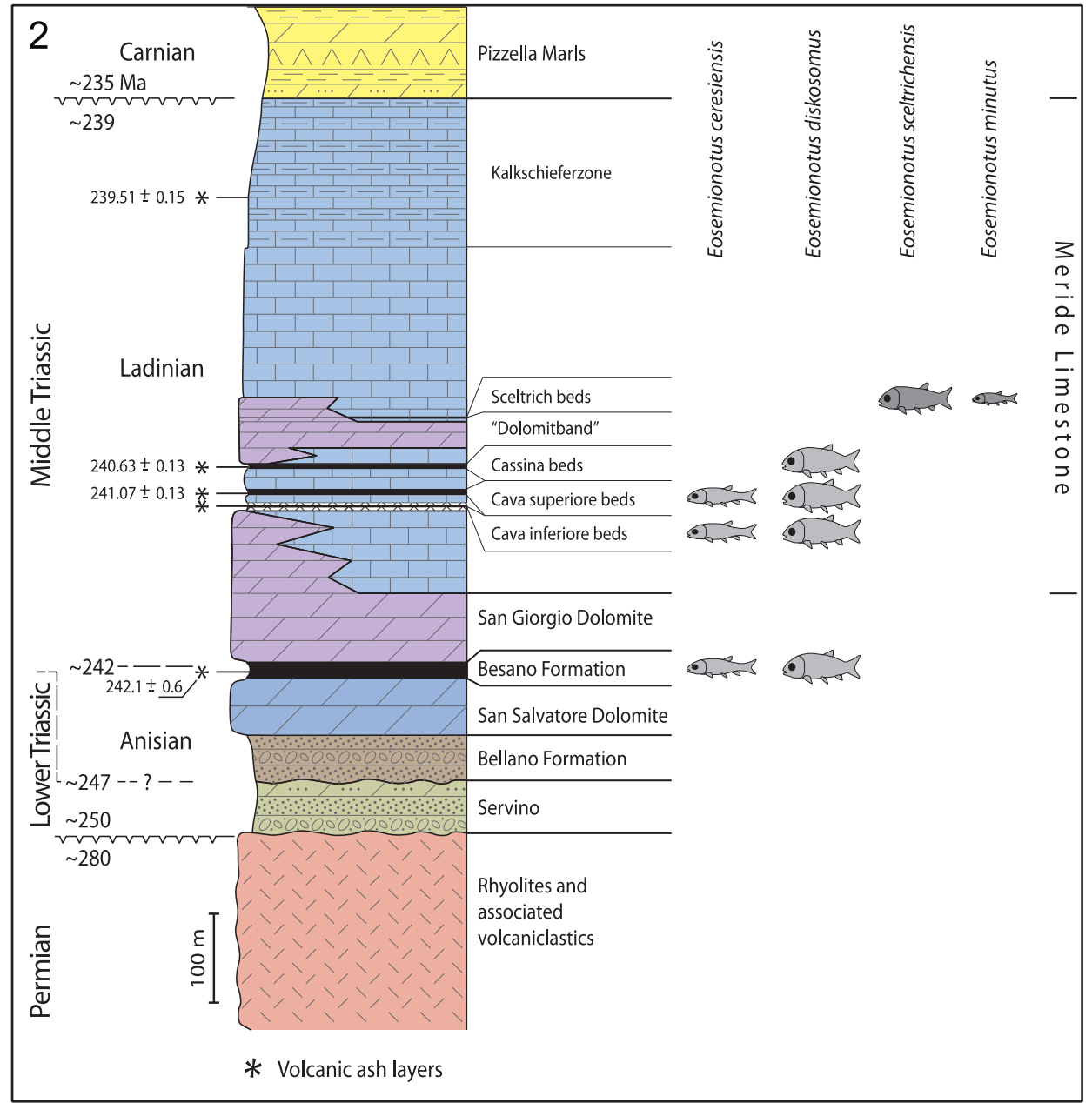

FIGURE 1. Geographic (1) and stratigraphic (2) location of the new species. 1, geological map of the Monte San Giorgio area showing the Middle Triassic carbonate sequence and the location of the excavation sites in which specimens of Eosemionotus have been collected (modified from Stockar and Kustatscher, 2010). Location of 'Prà degli Spiriti' according to the information provided by local people through Alberto Marchi (pers. comm., 12.06.2018). 2, Middle Triassic stratigraphic units of the Monte San Giorgio area and occurrences of Eosemionotus. Stratigraphy after Commissione scientifica transnazionale Monte San Giorgio 2014, modified. U-Pb ages after Mundil et al. (2010) and Stockar, Baumgartner and Condon (2012). 
The phylogenetic relationships of the species of Eosemionotus were explored through cladistic analyses based on the data matrix recently published by López-Arbarello and Sferco (2018) with modifications (Appendix 1). Due to the presence of ginglymodian synapomorphies and the absence of halecomorph or teleost synapomorphies (see discussion), we used a subset of taxa, including the species of Ginglymodi and two holostean outgroups Amia calva and Watsonulus eugnathoides. In addition to the taxa taken from López-Arbarello and Sferco (2018), the five species of Eosemionotus, the macrosemiids Macrosemius fourneti (Thiollière, 1850) and Palaeomacrosemius thiollieri Ebert et al., 2016, and the three species of Lophionotus Gibson, 2013a, from the Late Triassic and Early Jurassic of North America are included in the new data base. The data matrix is freely available in the MorphoBank (www.morphobank.org; Project 3211).

As a result of the reduction in the taxonomic sample, many characters resulted uninformative and were therefore removed. In the light of the new anatomical information resulted from this study, some characters were modified and others have been added (see Appendix 2). Also, several meristic features used by López-Arbarello and Sferco (2018) showed significant variation between the species of Eosemionotus. Therefore, we have modified the definition of those characters, which were coded as discrete characters using ranges, and added new characters using multiple states representing the raw counts directly. In most cases however, these counts show some intraspecific variation, but the number of studied specimens was too low to make any inference about the mean value for a species. Therefore, according to the observed variation and trends, we took the minimal or maximal count for the species, depending on the applied criterion (see explanation in Appendix 2).

The new data matrix, including 50 taxa and 192 characters, was compiled using Mesquite version 3.2 (Maddison and Maddison, 2017). The cladistic analysis was performed with the software TNT (Goloboff et al., 2008) under equal weighting. Characters 130,144, 156, 160, and 188-192 were ordered a priori and character 56 was ordered a posteriori according to the trend resulted after a first iteration of the analysis. Tree search was performed with the traditional search option of TNT v. 1.1 (Goloboff et al., 2008) applying random addition sequence (RAS) and tree bisection reconnection (TBR) through 1000 replicates keeping 10 trees per replicate. TBR was also applied to all the trees retained in memory and trees are rooted in Watsonulus eugnathoides. Branch support was evaluated also with TNT applying bootstrap and jackknife expressed as absolute frequencies through 1000 replicates and calculating Bremer decay indexes for each node. The distribution of synapomorphies was analysed with TNT and using the 'trace character history' option in Mesquite version 3.2 (Maddison and Maddison, 2017).

Anatomical abbreviations. a, angular; a.io, anterior infraorbitals; apl, autopalatine; ao, antorbital; b.fu, basal fulcra; br, branchiostegal rays; chy, anterior ceratohyal; cl, cleithrum; co, coronoid; d, dentary; d.c.fu, dorsal caudal fulcra; dt, dermopterotic; e, extrascapulars; ent, endopterygoid; et, ectopterygoid; eth, median ethmoidal ossification; fr.fu, fringing fulcra; fr.p, anteromedial frontal processes; fr.pl, frontal plate; h, hyomandibula; hy, hyopohyal; iop, interopercle; I.e, lateral ethmoid; I.I, lateral line; $\mathrm{n}$, nasals; $\mathrm{m}$, maxilla; $\mathrm{mt}$, metapterygoid; op, opercle; ors, orbitosphenoid; $p$, parietal; pcl, postcleithrum; p-fr.pl, parietal-frontal plate; p.io, postinfraorbital; pit, pit for an isolated pit organ; pm, premaxilla; pop, preopercle; ps, parasphenoid; ptt, posttemporal; qj-q, quadratojugal-quadrate complex; s?, symplectic?; sa, surangular; sc, scutes; scl, supracleithrum; s.io, subinfraorbitals; sop, subopercle; vo, vomer. The labels '( $r$ )' or '(l)' after any of the abbreviations indicate right or left elements, respectively.

Institutional abbreviations. GZG, Geowissenschaftliches Zentrum der Georg-August-Universität, Göttingen, Germany; IGWuG, Institut für Geologische Wissenschaften und Geiseltalmuseum, Martin-Luther-Universität Halle-Wittenberg, Halle (Saale), Germany; MB.f., Museum für Naturkunde, Leibniz-Institut für Evolutions- und Biodiversitätsforschung an der Humboldt-Universität, Berlin, Germany; MCSN, Museo cantonale di storia naturale, Lugano, Switzerland; PIMUZ, Paläontologisches Institut und Museum der Universität Zürich, Switzerland.

\section{SYSTEMATIC PALAEONTOLOGY}

Subclass ACTINOPTERYGII Cope, 1887

Series NEOPTERYGII Regan, 1923

Super Division HOLOSTEI Müller, 1844 sensu Huxley (1861)

Division GINGLYMODI Cope, 1871 sensu Grande (2010)

Order SEMIONOTIFORMES Arambourg and

Bertin, 1958 sensu López-Arbarello (2012)

Family MACROSEMIIDAE Thiollière, 1858 Genus EOSEMIONOTUS Stolley, 1920 
v 1906 Allolepidotus Vogelii [sic] Fritsch, table 11, figures 2, 3.

v*1920 Eosemionotus Stolley, p. 68.

1926 Eosemionotus Deecke, p. 136.

1928 Eosemionotus Schmidt, pp. 358-359, figure 1010.

1938 Eosemionotus Schmidt, p. 117.

1938 Eosemionotus Obruchev, p. 586.

1966 Eosemionotus Lehman, p. 158.

1979 Eosemionotus Oosterink and Poppe, pp. 109-112, figure 31.

v 1986 Eosemionotus Schultze and Möller, pp. 118119.

v 1991 Eosemionotus Bürgin et al., pp. 953-954.

v 1998 Eosemionotus Bürgin, p. 5.

1999 Eosemionotus Schultze and Kriwet, p. 246.

v 1999 Eosemionotus Bürgin, pp. 492-494.

1999 Eosemionotus Poyato-Ariza et al., pp. 507, 532.

1999 Eosemionotus Cartanyà, p. 546, figure 11.

v 2003 Eosemionotus Herzog, pp. 46-51.

v 2004 Eosemionotus Bürgin, pp. 240-241, 247248.

2006 Eosemionotus Jin, p. 34, 42; table 2.

2009 Eosemionotus Sun et al.: figure 1.

v 2010 Eosemionotus Stockar, figure 6d-e.

2010 Eosemionotus Hitij et al., pp. 42-45, plate $1 \mathrm{e}$.

2011 Eosemionotus Fortuny et al., p. 76.

2016 Eosemionotus Miklavc et al., p. 27, figure 5.

Emended diagnosis. Small holosteans characterized by the following autapomorphies: presence of distinctive rod-like anteromedial frontal processes; slender cleithra, without a medial wing; a series of distinctly large caudal fulcra embracing body lobe dorsally.

Additional combination of characters: dermal bones of the skull smooth or very slightly ornamented; bell-shaped frontal plate formed by the complete fusion of the two frontal bones; preorbital portion of frontals less than $1 / 3$ of total length of frontal; nasal bones well separated from each other; presence of a median ethmoidal ossification; supraorbital bones absent; quadratojugal fused to quadrate; L-shaped preopercle; high posttemporal bones, reaching or almost reaching the dorsal midline; single rounded postcleithrum; less than 10 dorsal fin rays; scales with smooth borders and surface, with peg-and-socket articulation, but no longitudinal articulation; less than 30 scales along the lateral line.
Eosemionotus vogeli (Fritsch, 1906)

Figures 2-3

v*1906 Allolepidotus Vogelii [sic] Fritsch, table 11, figures 2, 3.

v 1920 Eosemionotus Vogelii [sic] Stolley, pp. 6874, tag. 10, figures 3, 4.

1926 Eosemionotus Vogelii [sic] Deecke, pp. 136.

1928 Eosemionotus Vogelii [sic] Schmidt, pp. 358-359, figure 1010.

1938 Eosemionotus Vogelii [sic] Schmidt, p. 117.

1966 Eosemionotus Lehman, p. 158.

v1986 Eosemionotus vogeli Schultze and Möller, pp. 119-125, figures 7-11, 12a.

2004 Eosemionotus vogeli Bürgin, pp. 240-241.

Holotype. IGWuG L2, almost complete specimen preserved in right lateral view (57 mm SL). The main slab, on which the fish is preserved, is unfortunately lost (Norbert Hauschke, pers. comm. 2017), but there is a counter slab, containing the mould of the postcranium with well-preserved squamation and caudal fin (Figure 2.1).

Type horizon and locality. Karlstadt Formation (upper Anisian, Illyrian; Middle Muschelkalk) of Förderstedt bei Staßfurt, Germany.

Referred specimens. GZG.G6.1202.1-19 from the Diemel Formation (upper Anisian, Illyrian; Middle Muschelkalk) at Grebenberg bei Angerstein (Figure 2.2); MB.f. 14890, 14892, 14894, 14896, 19800 from the Heilbronn Formation, 'blaue Fischmergel' of Rüdersdorf (upper Anisian, Illyrian; Middle Muschelkalk; Siegel and Wischnewsky, 2017) Rüdersdorf bei Berlin (Figure 2.3).

Differential diagnosis. Species of Eosemionotus differing from all other known species of the genus in the following features (Table 1): opercle finely ornamented; single pair of extrascapulars; marginal row of body lobe with 6-7 scales.

Additional characters (Table 1): fusiform body (deep disk-like in E. diskosomus and E. sceltrichensis n. spp.); supraoccipital canal in parietals present (absent in E. diskosomus and E. sceltrichensis n. spp.); four premaxillary teeth (5-6 in E. ceresiensis, six in E. minutus n. sp.); maxilla shallow (notably deeper in E. diskosomus and $E$. sceltrichensis n. spp.); seven dentary teeth (10-12 in E. ceresiensis, 11 in E. minutus n. sp.); lower jaw articulation at the centre of the orbit (at the anterior border of the orbit in $E$. ceresiensis, and in $E$. diskosomus n. sp.); opercle approximately as deep as long (deeper than long in E. diskosomus, E. minutus and E. sceltrichensis n. spp.); 6-7 branchiostegals (five in $E$. diskosomus and $E$. minutus $\mathrm{n}$. spp.); four scales posterodorsal to the hinge-line (three in E. minutus n. sp., five in E. ceresiensis); 

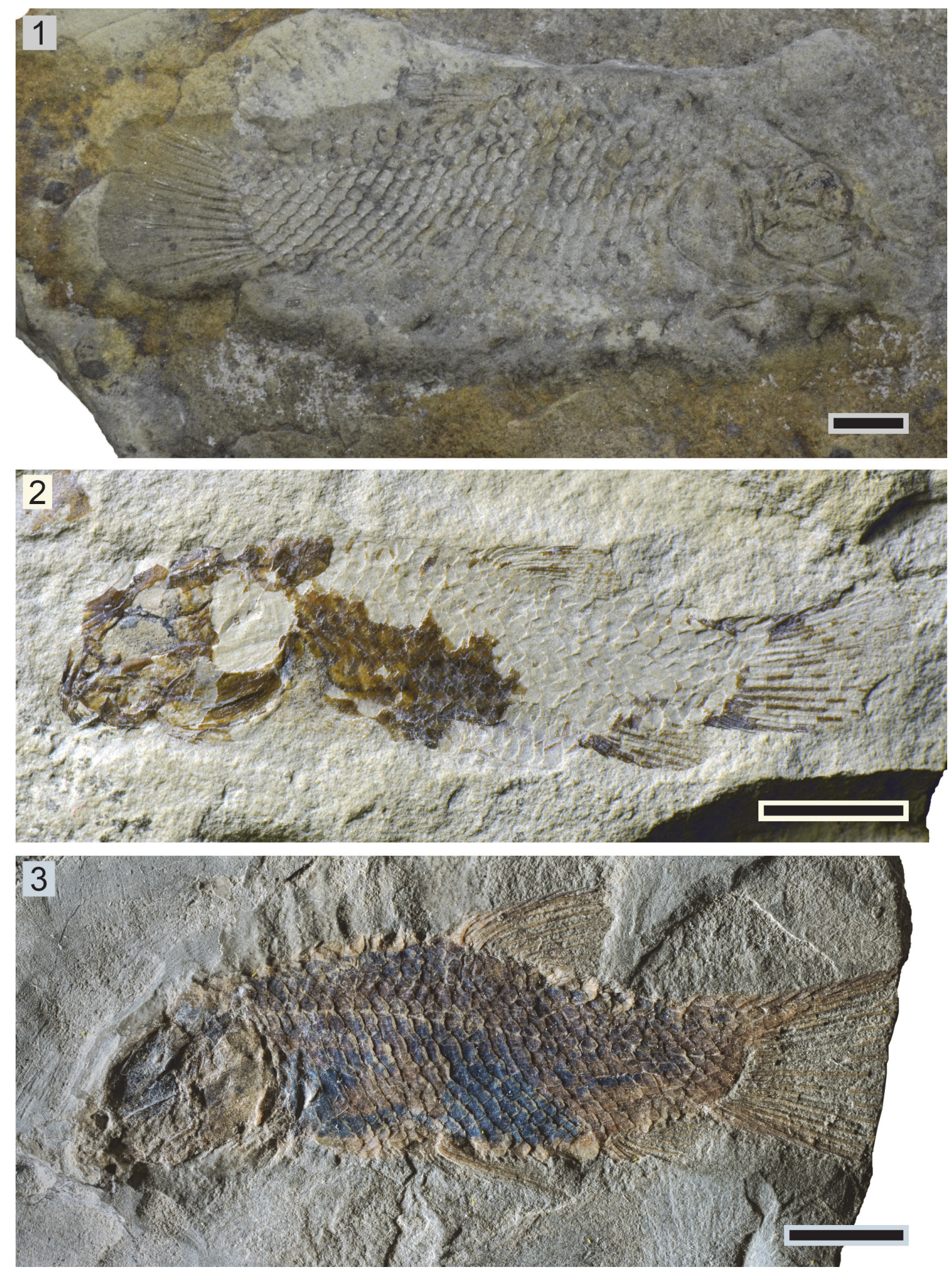

FIGURE 2. Eosemionotus vogeli. 1, holotype (IGWuG L2; $57 \mathrm{~mm} \mathrm{SL}$ ) from Förderstedt bei Staßfurt. 2, largest juvenile (GZG.G6.1202.1; $24.5 \mathrm{~mm} \mathrm{SL}$ ) amongst the specimens from Gebenberg. 3, Most complete and best-preserved specimen (MBf 14894; 30 mm SL) from Rüdersdorf bei Berlin (Photograph @ Rudolf Gold, Wien). Scale bars equal $5 \mathrm{~mm}$. 

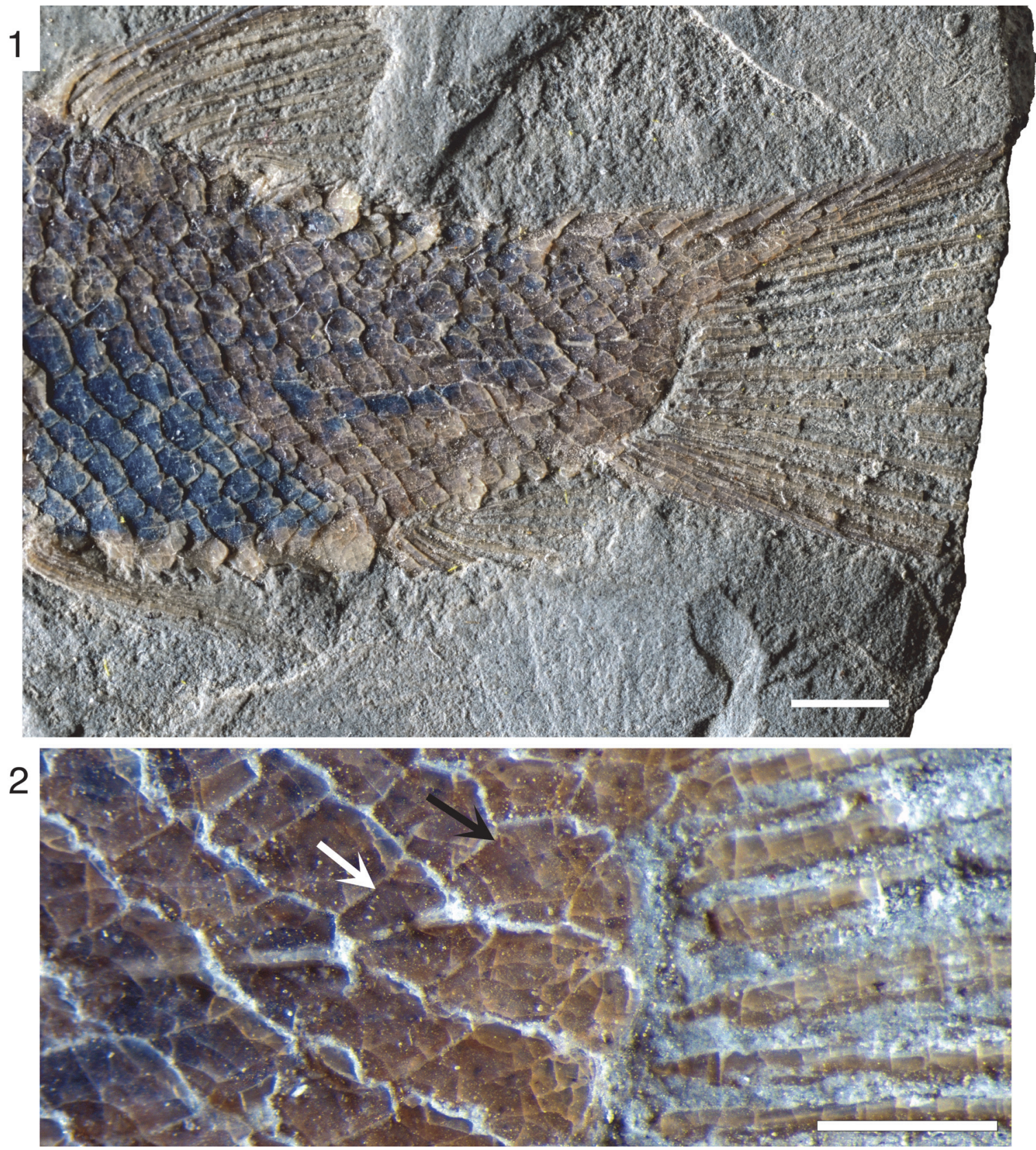

FIGURE 3. Rüdersdorf specimen MBf 14894 of Eosemionotus vogeli. 1, photograph of the posterior abdominal and caudal region showing the squamation and the pelvic, dorsal, anal and caudal fins (@ Rudolf Gold, Wien). Scale bar equals $2 \mathrm{~mm}$. 2, detailed photograph showing the most posterior portion of the lateral line. White arrow points towards the 27 th scale traversed by the lateral line; black arrow points towards the 28 th scale in this series. Scale bar equals $1 \mathrm{~mm}$.

5-6 dorsal caudal fulcra on the body lobe (four in E. diskosomus, E. sceltrichensis and E. minutus n. spp.); absence of ventral precaudal scutes (present in E. minutus and E. sceltrichensis n. spp.); dorsal precaudal scutes probably present with sharp spine-like distal ends (dorsal precaudal scutes present, but rounded in E. diskosomus $\mathrm{n}$. sp. and E. ceresiensis, or absent in E. sceltrichensis); $26-28$ vertical rows of scales along the lateral line; posterior border of some flank scales with one to three spines.

Pterygial formula: GZG.G6.1202.1: D13/(P5 A11 C19) T26 and MB.f. 14894: D15/(P7 A16 C23) T28 
TABLE 1. Summary of the morphological features, which are useful to distinguish between the species of Eosemionotus.

\begin{tabular}{|c|c|c|c|c|c|}
\hline Morphological features & 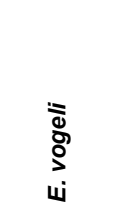 & 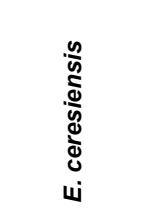 & 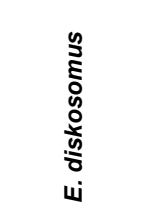 & 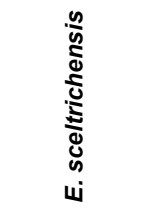 & 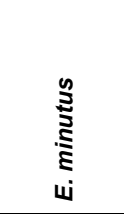 \\
\hline Body shape & fusiform & fusiform & deep & deep & fusiform \\
\hline Ornamented dermal skull bones & present & absent & absent & absent & absent \\
\hline Length frontal process & $?$ & short & long & long & long \\
\hline Relationship between frontal processes & $?$ & coalescent & coalescent & coalescent & separate \\
\hline Supraoccipital canal in parietals & present & present & absent & absent & present \\
\hline Parietals fused & absent & absent & absent & present & absent \\
\hline Number of extrascapulars & 1 pair & 5 & 3 pairs & 3 pairs & 3 pairs \\
\hline Maximal number of premaxillary teeth & 4 & 6 & $3-4$ & 4 & 6 \\
\hline Number of dentary teeth & 7 & $10-12$ & $?$ & $?$ & 11 \\
\hline Maxillary teeth & $?$ & present & absent & absent & present? \\
\hline Shape of maxilla & slender & slender & deep & deep & slender \\
\hline Position of lower jaw articulation relative to orbit & centre & anterior & anterior & centre & centre \\
\hline Depth to length ratio of opercle & $\sim 1$ & $\sim 1$ & $>1$ & $>1$ & $>1$ \\
\hline Length of interopercle & short & short & short & long & $?$ \\
\hline Number of branchiostegals & $6-7$ & $7-8$ & 5 & 6 & 5 \\
\hline Number of caudal fin rays & $12-15$ & $13-15$ & 13 & 12 & 12 \\
\hline Number of caudal fin rays below the lateral line & $7-8$ & $8-9$ & 7 & 8 & 8 \\
\hline Size of fringing fulcra & slender & small & large & large & slender \\
\hline Fringing fulcra on dorsal margin of caudal fin & present & present & present & present & absent \\
\hline Number of scales in marginal row of body lobe & $6-7$ & 5 & 4 & 2 & 4 \\
\hline Number of scales posterodorsal to the hinge-line & 4 & 5 & 4 & $4-5$ & 3 \\
\hline Number of dorsal caudal fulcra on the body lobe & $5-6$ & 5 & 4 & 4 & 4 \\
\hline Number of vertical rows of scales & $26-28$ & $27-28$ & $23-25$ & $23-25$ & 24 \\
\hline Dorsal precaudal scutes & $?$ & 10 & $7-8$ & absent & 1 \\
\hline Ventral precaudal scutes & absent & absent & absent & 4 & 3 \\
\hline Number of anal fin rays & 7 & 6 & $6-7$ & 7 & 5 \\
\hline Number of dorsal fin rays & $6-10$ & 6 & 9 & $6-7$ & 6 \\
\hline
\end{tabular}

Remarks. The holotype of Eosemionotus vogeli was first described by Stolley (1920). Additional specimens from Grebenberg bei Angerstein were referred to this species and described in great detail by Schultze and Möller (1986), and several unpublished specimens from Rüdersdorf bei Berlin also belong to this species. The Grebenberg specimens are all juveniles representing different ontogenetic stages and only the largest of them (GZG.G6.1202.1 with $24.5 \mathrm{~mm}$ SL; Figure 2.2) has a complete squamation comparable with the holo- type, in particular the distinctly high number of scales forming the marginal row of the body lobe. The Rüdersdorf specimens are adults and generally rather incompletely preserved, but among them, MB.f. 14894 (30 mm SL; Figure 2.3) is complete and, although the skull is badly preserved, the postcranium is well preserved showing distinctive features of the species.

Stolley (1920) described a total number of 28 vertical rows of scales in the holotype. Schultze and Möller (1986) counted 26, which agrees with 


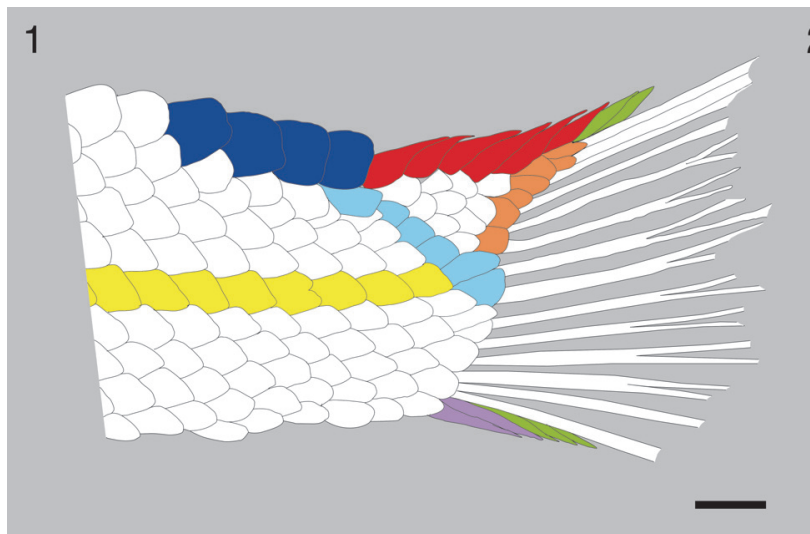

2

FIGURE 4. Caudal fin of Eosemionotus vogeli. 1, line drawing of the counterslab of the holotype (IGWuG L2) from Förderstedt bei Staßfurt, mirrored; all elements preserved as impressions. 2, line drawing of the specimen MBf 14894 from Rüdersdorf bei Berlin. Distinct dermal structures are indicated with colours: scales traversed by the lateral line (yellow), scales along the last vertical row at the hinge line (light blue), scales along the marginal row of the body lobe (orange), scutes (blue), dorsal caudal fulcra (red), ventral basal fulcra (purple), fringing fulcra (green). Note that the scutes in ' 1 ' are preserved as imprint and, thus, the rounded shape might be an artefact of preservation. Scale bars equal $2 \mathrm{~mm}$.

our observations. However, the squamation in MB.f. 14894 is very well preserved, including 28 vertical rows of scales; 27 scales are traversed by the lateral line and the 28th scale in this series has no sensory canal or pit line (Figure 3 ). Similarly, Stolley (1920) gave a total number of 13 caudal fin rays, but we count 14 in the holotype (Figure 4.1). The juveniles from Grebenberg have only 12 caudal fin rays, and there are 15-16 caudal fin rays in the three specimens from Rüdersdorf that are preserving the complete set of rays (MB.f. 14894, 14896a, b; Figure 4.2). The variation in the number of caudal fin rays might reflect differences between the three populations represented by the specimens. Instead, variation in the number of dorsal fin rays, $6-8$ in the juvenile specimens from Grebenberg vs. 10 in MB.f. 14894, might be due to different degree of ossification in the different ontogenetic stages (most posterior lepidotrichia not yet ossified in the juveniles).

Another important feature described by Stolley (1920) is the delicate ornamentation of the opercular bones, which is not clearly observable in the juveniles from Grebenberg, but it is well visible in MB.f. 14892. Similarly, a distinctive feature described and figured by Schultze and Möller (1986: figure 11C) and observed in the specimens MB.f. 14892 and 19800, is the presence of one to three spines in the posterior border of some flank scales, mainly in the area between the skull, the lateral line, and the dorsal fin.

\section{Eosemionotus ceresiensis Bürgin, 2004}

Figure 5

v 1998 Eosemionotus n. sp. A Bürgin, p. 7.

v 1999 Eosemionotus n. sp. A Bürgin, pp. 492-493.

$\mathrm{V}^{*} 2004$ Eosemionotus ceresiensis Bürgin, pp. 241247, figures 1-10.

Holotype. PIMUZ T 357. Complete fish preserved in left lateral view, in part and counterpart. SL $=39$ $\mathrm{mm}$ (Figure 5).

Paratypes. PIMUZ T 319, T 328, and T 329 from the type horizon and locality.

Type horizon and locality. Uppermost Besano Formation (Curionii Zone; lower Ladinian) at P. 902 (Mirigioli), Monte San Giorgio, Switzerland (Figure 1).

Additional specimens. PIMUZ T 236, T 245, T 334 , and $T$ 336, also from the type horizon and locality. From the lower Meride Limestone: MCSN 5628 from Acqua del Ghiffo (Cava inferiore beds; Switzerland); MCSN 5606, 5608, 5618, 5620, and 5672 from Acqua del Ghiffo (Cava superiore beds; Switzerland).

Differential diagnosis. Species of Eosemionotus differing from all other known species of the genus in the following features (Table 1): anteromedial frontal processes short; a total of five (one median and two pairs) of extrascapulars; marginal row of body lobe with five scales; presence of maxillary teeth; five scales posterodorsal to the hinge-line; 27-28 vertical rows of scales along the lateral line; pelvic and dorsal fins more posteriorly placed, 


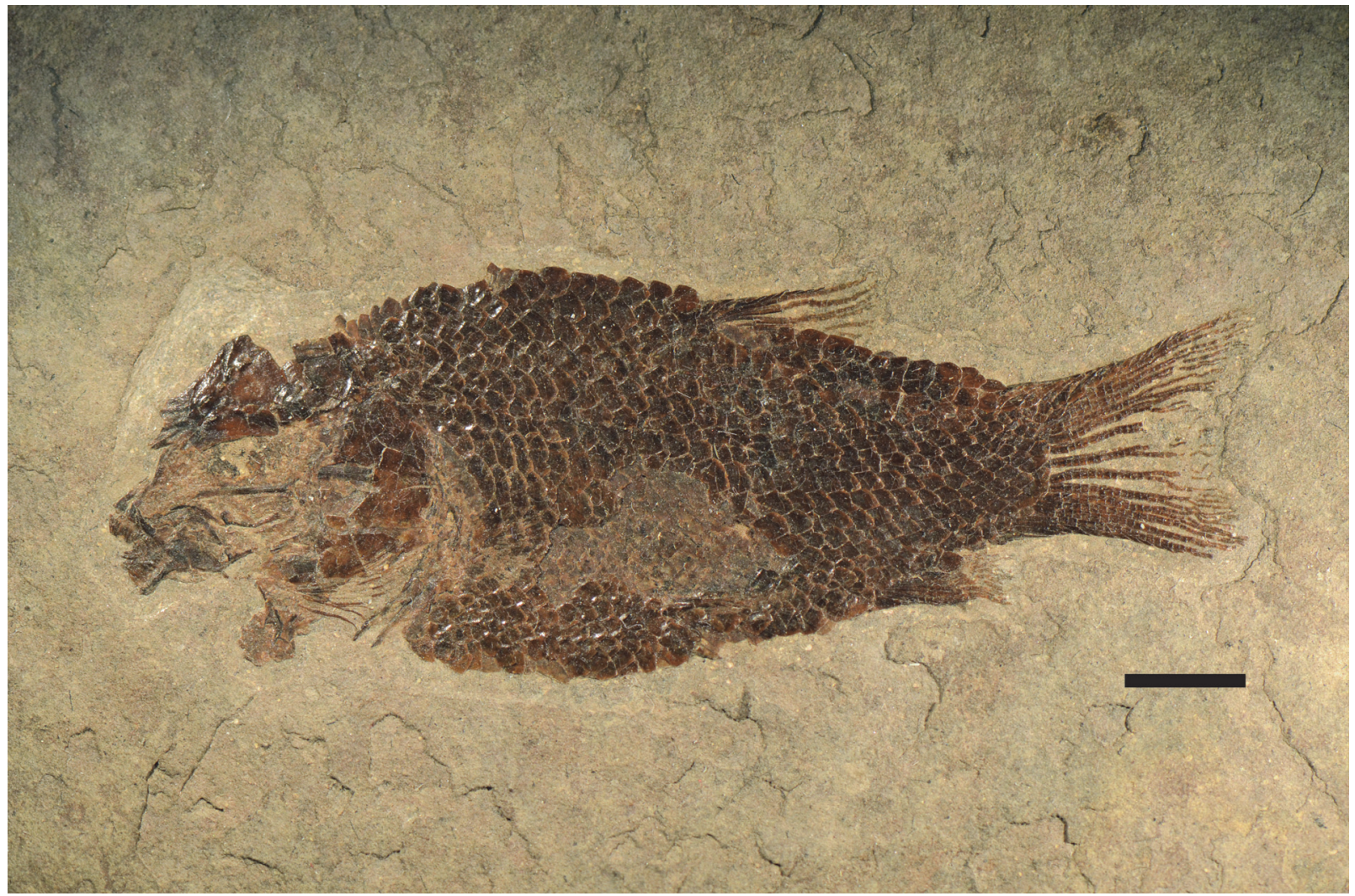

FIGURE 5. Eosemionotus ceresiensis. Holotype (PIMUZ T 357) preserved in left lateral view, in part and counterpart (39 $\mathrm{mm} \mathrm{SL}$ ). Scale bar equals $5 \mathrm{~mm}$.

started behind the 8th and 16th vertical rows of scales, respectively.

Additional characters (Table 1): fusiform body (deep disk-like in E. diskosomus and E. sceltrichensis n. spp.); dermal bones of the skull smooth (ornamented in E. vogeli); anteromedial frontal processes coalescent (separated in $E$. minutus n. sp.); supraoccipital canal in parietals present (absent in E. diskosomus and E. sceltrichensis n. spp.); 5-6 premaxillary teeth (four in $E$. vogeli); maxilla shallow (notably deeper in $E$. diskosomus and E. sceltrichensis n. spp.); 10-12 dentary teeth (seven in E. vogeli); lower jaw articulation at the anterior border of the orbit (at the centre of the orbit in $E$. vogeli and in E. minutus and $E$. sceltrichensis n. spp.); opercle approximately as deep as long (deeper than long in E. diskosomus, E. minutus and E. sceltrichensis n. spp.); 7-8 branchiostegals (6-7 in E. vogeli; six in E. sceltrichensis $\mathrm{n}$. sp.; five in $E$. diskosomus and $E$. minutus $\mathrm{n}$. spp.); five dorsal caudal fulcra on the body lobe (four in E. diskosomus, E. sceltrichensis and $E$. minutus n. spp.); $13-15$ caudal fin rays (12 in $E$. minutus and $E$. sceltrichensis n. spp. and 13 in $E$. diskosomus n. sp.); 8-9 of them below lateral line (seven in $E$. diskosomus and eight in $E$. minutus and $E$. sceltrichensis n. spp.); complete series of 10 rounded dorsal precaudal scutes present (dorsal precudal scutes absent in E. sceltrichensis and single in E. minutus n. spp.); absence of ventral precaudal scutes (present in E. minutus and $E$. sceltrichensis n. spp.).

Pterygial formula: D16/(P8 A14 C22) T28.

Remarks. Eosemionotus ceresiensis is described in detail in Bürgin (2004). Our new examination of the specimens studied by this author and additional material subsequently referred to this species (size range $22-42.5 \mathrm{~mm}$ ) confirms the original description and no further comments are necessary.

Eosemionotus diskosomus n. sp.

Figures 6-10

zoobank.org/B80D85A1-36C4-40E2-B213-7BC4935E6957

p. 1999 Eosemionotus n. sp. D-E Bürgin, p. 493.

2010 Eosemionotus sp. Stockar, figure 6d-e.

Etymology. the species epithet "diskosomus" from the Greek diskos "disk" and soma "body" recalls the general body shape of this fish. 


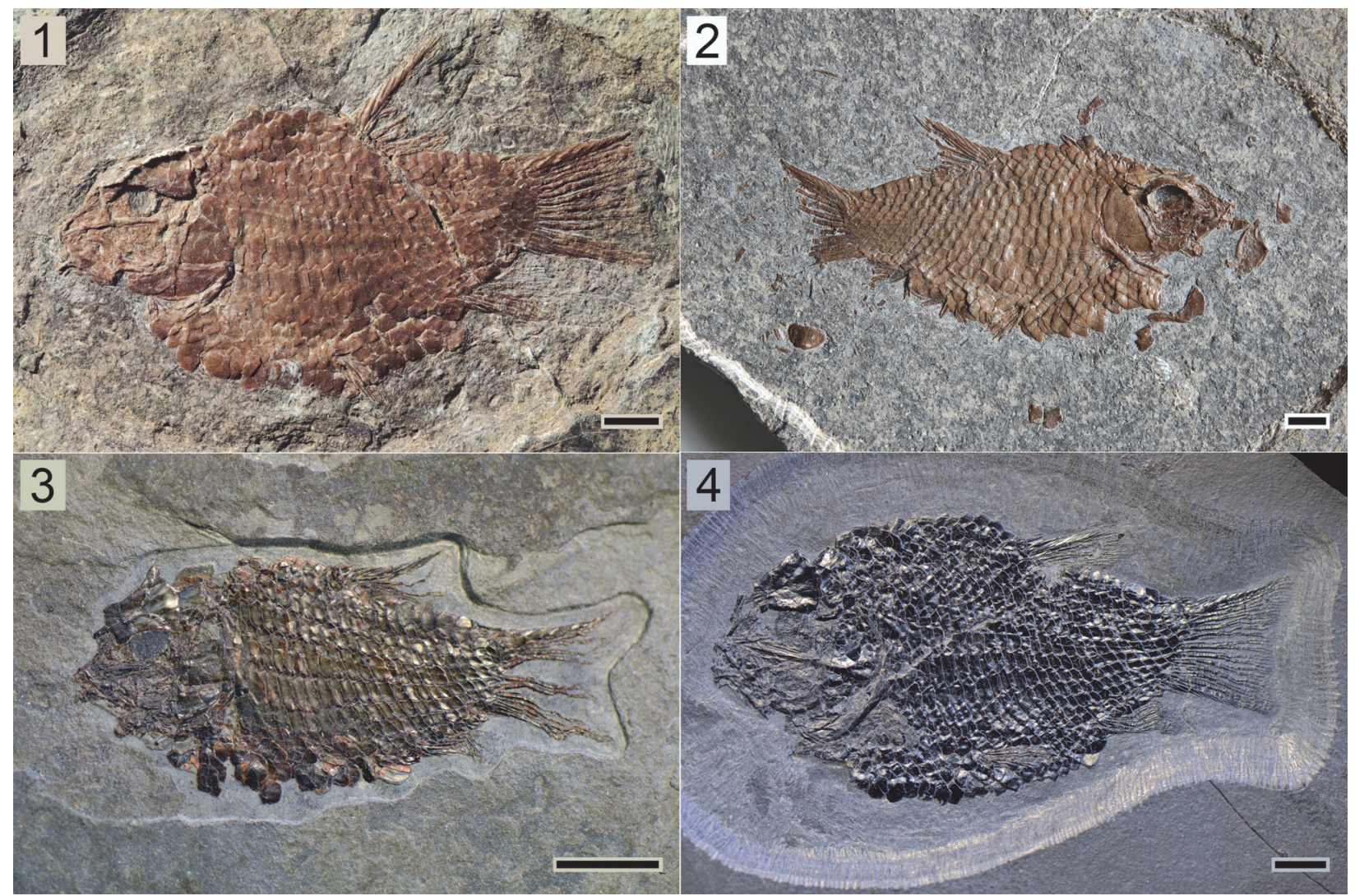

FIGURE 6. Eosemionotus diskosomus. Complete specimens. 1, holotype MCSN 8082 (45 mm SL); 2, MCSN 8006 (60.5 mm SL); 3, PIMUZ T 2924 (22.5 mm SL); 4, MCSN 5617 (46.7 mm SL). Scale bars equal $5 \mathrm{~mm}$.

Holotype. MCSN $8082(\mathrm{SL}=45 \mathrm{~mm})$. Complete and well-preserved specimen, exposed in left lateral view (Figure 6.1).

Type horizon and locality. Cassina beds, lower Meride Limestone (uppermost Gredleri Zone or transition interval between Gredleri and Archelaus Zones; lower Ladinian) at Cassina, Monte San Giorgio, Switzerland (Figure 1).

Paratypes. MCSN 8006 (Figure 6.2), 8078, PIMUZ T 4433, T 4434 from the type horizon and locality.

Additional specimens. From the uppermost Besano Formation (Curionii Zone; lower Ladinian): PIMUZ T 244 from P. 902 (Mirigioli; Switzerland). From the lower Meride Limestone: MCSN 5643, PIMUZ T 2924 (Figure 6.3) and T 2933 from Acqua del Ghiffo (Cava inferiore beds; Switzerland); PIMUZ T 2928 from upper Val Serrata, 'Cava Don Luigi', (Cava inferiore beds; Switzerland); MCSN 5617 (Figure 6.4), 5726 and 5741 from Acqua del Ghiffo (Cava superiore beds; Switzerland); MCSN 8099 from Costa (Cava superiore beds; Switzerland); PIMUZ T 2938 from 'Prà degli Spiriti' above Besano (Cassina beds; Italy), collected by B. Peyer from a poorly documented locality,
02.10.1936. From the upper part of the Rio dei Ponticelli, according to information provided by local people through Alberto Marchi (pers. comm., 12.06.2018).

Differential diagnosis. Species of Eosemionotus differing from all other known species of the genus in the presence of a series of median rounded scutes between the dorsal and caudal fin and only seven caudal fin rays below the level of the exit of the lateral line (Table 1).

Additional characters (Table 1): deep disk-like body (fusiform in E. vogeli, E. ceresiensis, and $E$. minutus n. sp.); dermal bones of the skull smooth (ornamented in E. vogeli); anteromedial frontal processes long (short in E. ceresiensis) and coalescent (separated in E. minutus n. sp.); no branch of supraoccipital canal in parietals (present in $E$. vogeli, E. ceresiensis, and in E. minutus n. sp.); three pairs of extrascapulars (one pair in $E$. vogeli, five extrascapulars in E. ceresiensis); 3-4 premaxillary teeth (5-6 in E. ceresiensis, six in $E$. minutus n. sp.); maxillary teeth absent (present in $E$. ceresiensis); maxilla deep (notably shallower in $E$. vogeli, E. ceresiensis, and in E. minutus n. sp.); 

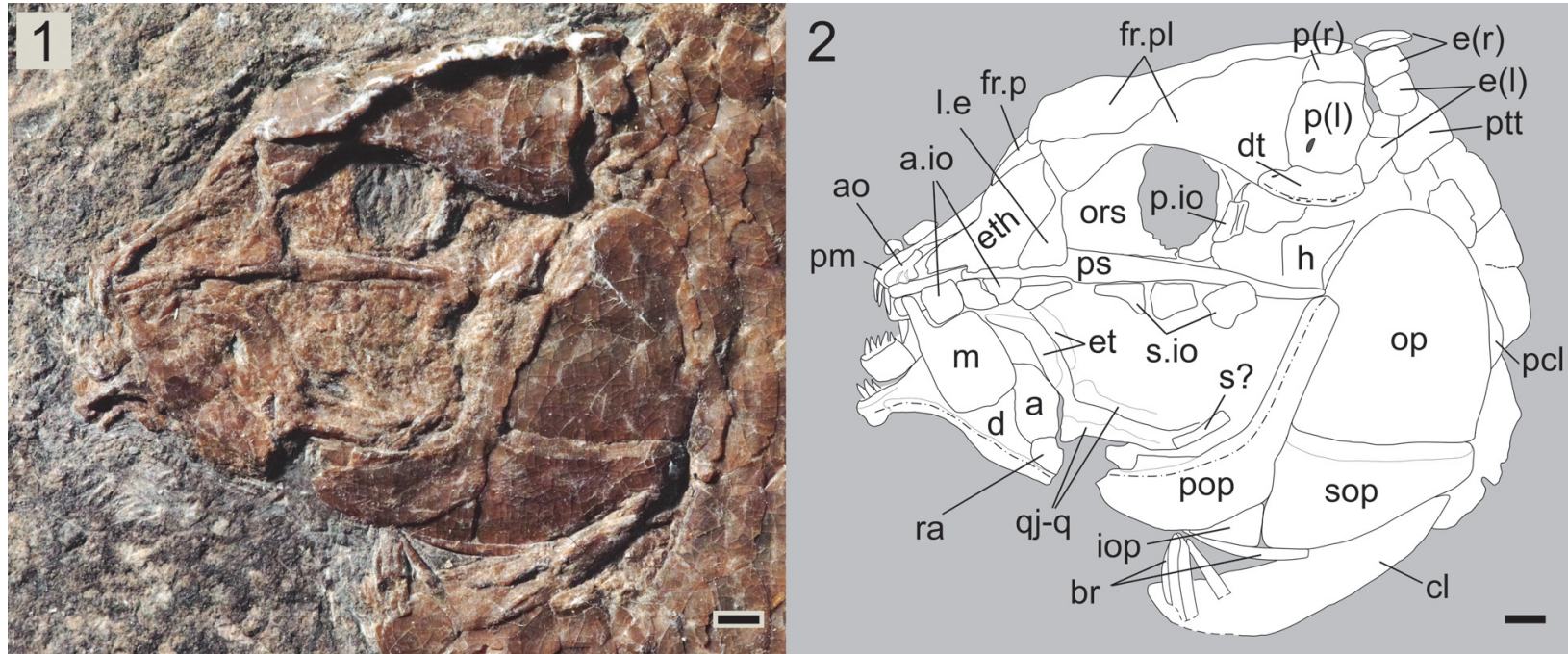

FIGURE 7. Eosemionotus diskosomus. Skull of the holotype MCSN 8082. 1, photograph. 2, line drawing. Dash-dotted lines indicate the trajectory of sensory canals. Scale bars equal $1 \mathrm{~mm}$.

lower jaw articulation at the anterior border of the orbit (at the centre of the orbit in E. vogeli and in $E$. minutus and E. sceltrichensis n. spp.); opercle deeper than long (approximately as deep as long in $E$. vogeli and E. ceresiensis); five branchiostegals (6-7 in E. vogeli; 7-8 in E. ceresiensi); large fringing fulcra (small in E. ceresiensis); marginal row of body lobe with four scales (two in E. sceltrichensis; five in E. ceresiensis; 6-7 in E. vogeli); four scales posterodorsal to the hinge-line (three in $E$. minutus n. sp; five in E. ceresiensis); four dorsal caudal fulcra on the body lobe (5-6 in E. vogeli, 5 in E. ceresiensis); complete series of $7-8$ rounded dorsal precaudal scutes present (absent in E. sceltrichensis and single in E. minutus n. spp.); absence of ventral precaudal scutes (present in E. minutus and $E$. sceltrichensis n. spp.); 13 caudal fin rays (12 in E. minutus and E. sceltrichensis n. spp.).

Pterygial formula: D11-14/(P3-4 A11-13 C18-21) T23-25.

\section{Description}

The specimens of Eosemionotus diskosomus n. sp. are generally very well preserved. The size range of the studied specimens varies between 22 and $60.5 \mathrm{~mm}$. The general shape of the body is
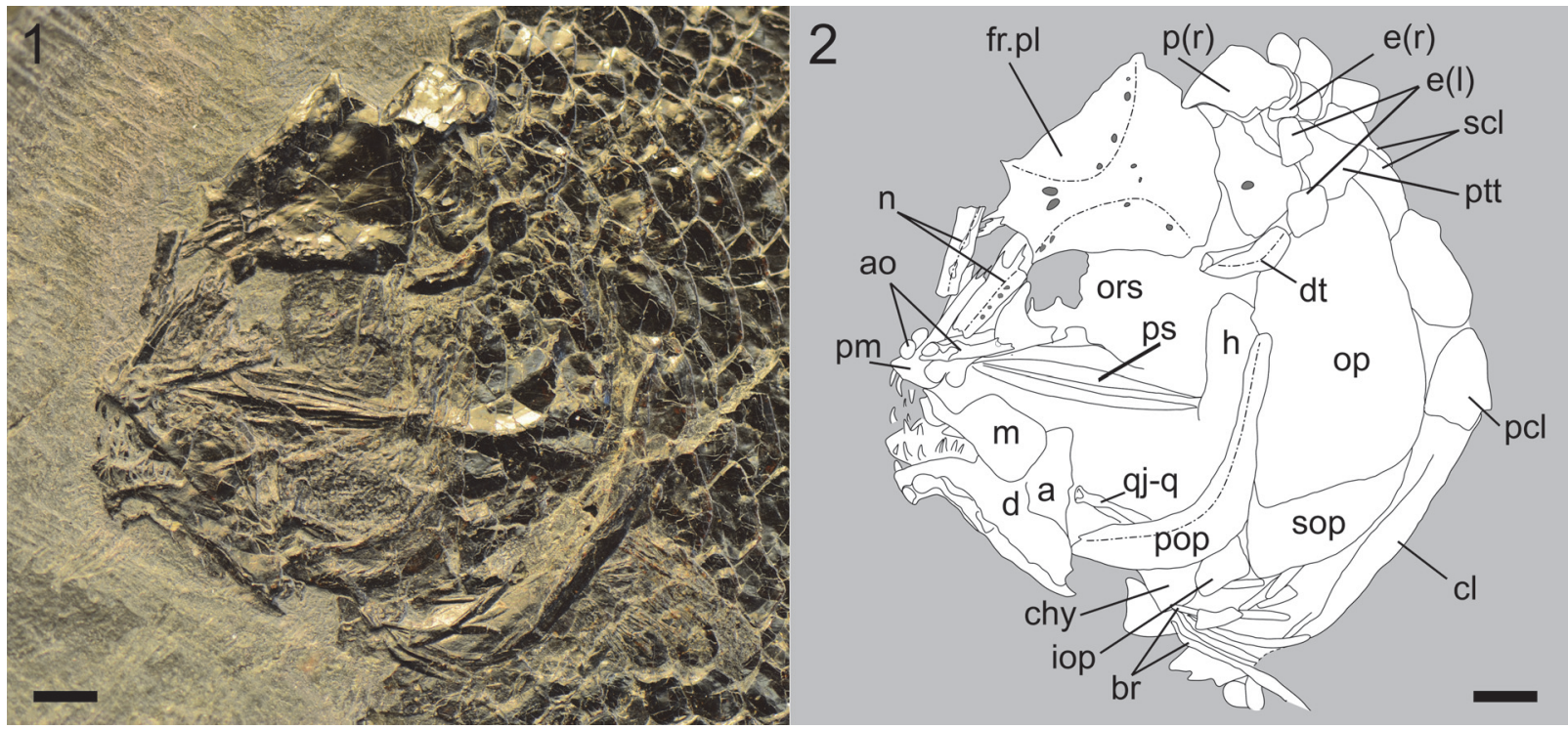

FIGURE 8. Eosemionotus diskosomus. Skull of MCSN 5617. 1, photograph. 2, line drawing. Dash-dotted lines indicate the trajectory of sensory canals. Scale bars equal $2 \mathrm{~mm}$. 

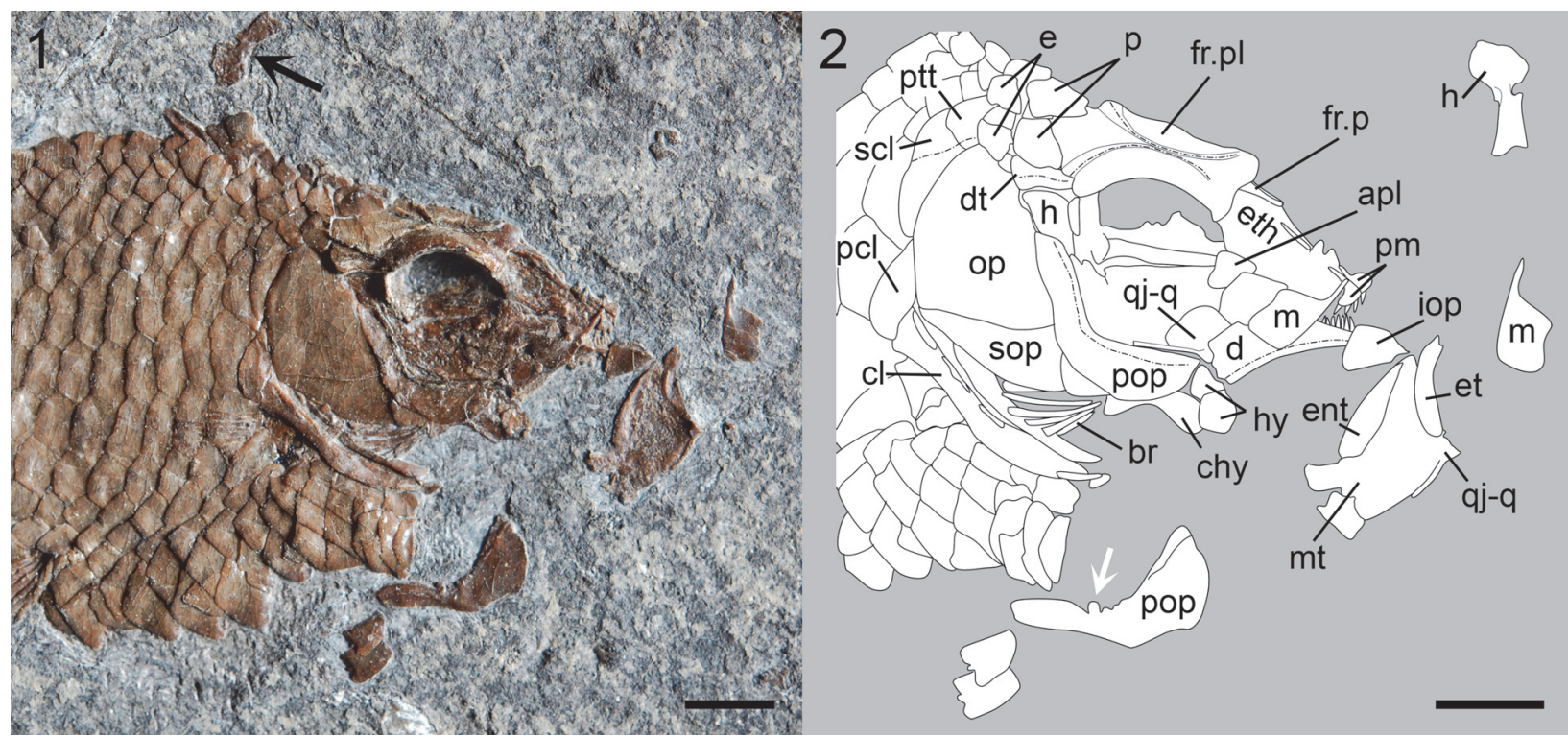

FIGURE 9. Eosemionotus diskosomus. Skull of MCSN 8006. 1, photograph. Black arrow points to the isolated hyomandibula. 2, line drawing. The line drawing of the isolated hyomandibula has been relocated and reoriented (anterior to the right). White arrow points to the small process at the base of the anterior border of the vertical arm of the preopercle. Dash-dotted lines indicate the trajectory of sensory canals. Scale bars equal $5 \mathrm{~mm}$.

deep and ovoid, with distinctly curved dorsal and ventral profiles. This feature makes the identification of most specimens rather easy (Figure 6). In the holotype, the maximal body depth is $51 \%$ of the $\mathrm{SL}$, but the body is deeper in other specimens (up to $61 \%$ of the SL in MCSN 5617) (Table 2). The dermal bones forming the roof of the skull, opercular series and several bones of the pectoral girdle, as well as the scales are completely covered with ganoine and have smooth surfaces. The jaw bones and preopercle are devoid of ganoine.

The shape of the parietals is somewhat variable, but they are generally trapezoidal, approximately as long as wide, with the lateral border slightly longer than the medial border, and perpendicular posterior and lateral borders (Figure 6). The supraorbital sensory canal does not pierce the parietals in this species. A rounded excavation is always present close to the anterolateral corner of the parietals, but it is not connected with the supraorbital sensory canal and might correspond to an isolated large pit organ. The dermopterotics are very narrow and elongated bones attached to the lateral borders of the parietals. They do not possess descending laminae or posterior processes and their lengths are approximately the same as the lateral borders of the parietals. A longitudinal series of pores indicates the passage of the temporal sensory canal. There are three small and approximately quadrangular extrascapular bones articulating with the posterior borders of the parietals and dermopterotics.

The two frontals are fully fused with each other forming a bell-shaped frontal plate, as is the case with the other species of the genus. The shape the frontal plate is variable including rela-

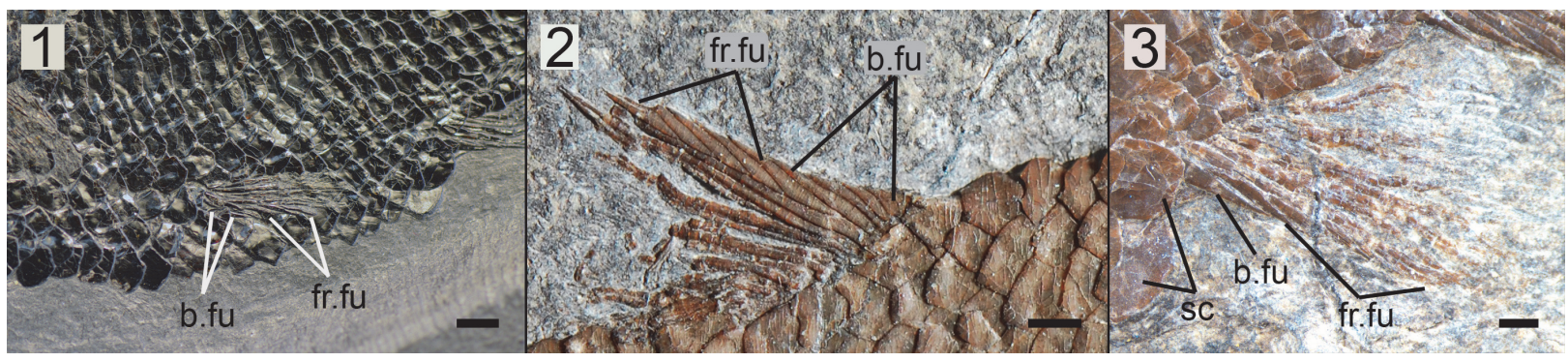

FIGURE 10. Eosemionotus diskosomus. Fins. 1, pelvic fin (MCSN 5617); 2, dorsal fin (MCSN 8006); 3, anal fin (MCSN 8082). Scale bars equal $2 \mathrm{~mm}$. 
TABLE 2. Body proportions based on measurements taken on well-preserved specimens. SL: standard length, HL: head length, BD: maximal body depth, CD: minimal depth of the caudal peduncle.

\begin{tabular}{|c|c|c|c|c|c|}
\hline Species & Specimen & SL & HL/SL & BD/SL & CD/SL \\
\hline \multirow[t]{4}{*}{ E. ceresiensis } & PIMUZ T357 & 39,00 & 0,35 & 0,33 & 0,13 \\
\hline & PIMUZ T236 & 38,00 & 0,30 & 0,41 & 0,15 \\
\hline & PIMUZ T319 & 42,50 & 0,32 & 0,42 & 0,18 \\
\hline & PIMUZ T329 & 36,50 & 0,33 & 0,42 & 0,18 \\
\hline \multirow[t]{4}{*}{ E. diskosomus } & MCSN 8082 & 45,00 & 0,37 & 0,58 & 0,20 \\
\hline & MCSN 8006 & 60,50 & 0,35 & 0,51 & 0,17 \\
\hline & MCSN 5617 & 46,70 & 0,36 & 0,61 & 0,20 \\
\hline & PIMUZ T2924 & 22,50 & 0,39 & 0,55 & 0,20 \\
\hline \multirow[t]{3}{*}{ E. sceltrichensis } & MCSN 8418 & 52,80 & & 0,48 & \\
\hline & MCSN 8497 & 39,14 & & 0,45 & \\
\hline & MCSN 8491 & 33,16 & & 0,53 & \\
\hline E. minutus & MCSN 8482 & 25,00 & 0,39 & 0,38 & 0,18 \\
\hline
\end{tabular}

tively straight (MCSN 5617; Figure 8) to deeply excavated (MCSN 8006, 8082, PIMUZ T 2924; Figures $6.3,7,9)$ orbital borders, straight (MCSN 8006, PIMUZ T 2924; Figures 6.3, 9) to concave (MCSN 5617; Fiugure 8) anterior borders, and from absent (MCSN 5617, 8082; Figures 6-8) to well-defined rounded (MCSN 8006, PIMUZ T 2924; Figures $6.3,9$ ) postorbital processes. The posterior border of the frontal plate is convex in MCSN 5617 , 8006, and 8082 (Figures 6-8), but it is triangular, pointing posteriorly, in PIMUZ T 2924 (Figure 6.3). The anteromedial frontal processes are relatively long when compared with E. ceresiensis, and both processes are tightly attached to each other along their entire length, tapering medially, but ending bluntly. The series of pores along the trajectories of the supraorbital canals are deeply curved, diverging anteriorly and posteriorly and exiting the frontal plate at its anterolateral and posterolateral corners.

Anterior to the frontal plate, the two nasals are only preserved in MCSN 5617 (Figure 8). They are rectangular, longer than broad, and medially separated and located lateral to the long nasal processes of the premaxillae and the anteromedial frontal processes. The right nasal in MCSN 5617 is exposed in mesial view showing a median groove for the supraorbital sensory canal. The left nasal in this specimen is exposed in external view, showing a series of pores adjacent to the lateral border of the bone, which are aligned with the pores of the supraorbital canal at the anterolateral corner of the frontal plate.

Several bones of the braincase are exposed, but no clear limits are visible among them, and only a few features can be described. There is a large ethmoidal ossification approximately triangular in lateral view, which is interpreted as the lateral ethmoids, and a median ethmoidal lamina (Figures 79). The orbitosphenoid is apparently a single unpaired bone and forms a large laminar septum (MCSN 5617, 8082; Figures 7-8), which is filling most of the orbital opening around the relatively large interorbital fenestra. The parasphenoid is best exposed in MCSN 5617 and PIMUZ T 2924, although only the portion anterior to the ascending processes is shown. The bone is narrow at the level of the posterior border of the orbit, but there are no distinct excavations for the carotid arteries. From this point, the parasphenoid broadens laterally up to a level within the anterior half of the orbit, before reaching the lateral ethmoids and then tapering to a pointed anterior end. The median longitudinal axis of the parasphenoid is elevated, gently sloping laterally. Ascending and basipterygoid processes are not distinguishable, but their possible presence cannot be excluded. Posteriorly, the parasphenoid extends at least up to the occipital condyle (MCSN 8082; Figure 7). Anterior to the parasphenoid, paired vomers bearing sharp peglike teeth, smaller than the premaxillary teeth, are partially exposed in MCSN 8082.

The circumborbital bones are generally poorly preserved. MCSN 8082 has the most complete series including three anterior infraorbitals, a fragment of the lachrymal and three subinfraorbitals, and one posterior infraorbital (Figure 7). This series of infraorbital bones conforms to the macrosemiid condition (Bartram, 1977). The anterior infraorbitals are approximately squared and the first of them is the largest. The lachrymal and first subinfraorbital are tubular, longer than deep, and the second and third subinfraorbital are approxi- 
mately rectangular, deeper than the anterior subinfraorbital and slightly longer than deep. The posterior infraorbital is tubular, four times deeper than long; it is best preserved in MCSN 8006 (Figure 9). A dermosphenotic is not preserved. The antorbital is best, though poorly preserved in MCSN 5617 (Figure 8) and a small median rostral is visible in this same specimen. Although the exact shape of these two bones remains obscure, the exposed portion of the antorbital is deep and narrow, traversed by the sensory canal medially, and expanded anteriorly. Suborbital and supraorbital bones are absent.

The upper jaw is formed by the paired premaxillae and maxillae. There is no supramaxillary bone. Each premaxilla has a relatively small toothed portion (only about $25 \%$ of the length of the nasal process) bearing only three peg-like teeth and a long nasal process extending posterodorsally and reaching close to the anteromedial frontal processes, though these elements do not articulate. The nasal processes are long and slender forming a kind of median keel and do not contribute to the floor of the nasal pit or include an olfactory foramen. The maxilla is edentulous, short and deep, with a long rod-like articular process, the length of which is almost $50 \%$ of the length of the maxillary plate. The maxillary plate is rectangular, with a depth of c. $70 \%$ of its length. The anterior, ventral, and posterior borders are straight and the dorsal border is sinuous. The posterior and ventral borders are almost perpendicular to each other and the anterior border is slightly inclined forming an angle of about $70^{\circ}$ respect to the ventral border of the bone. The anterodorsal, posterodorsal, and posteroventral corners of the bone are rounded.

The lower jaw is formed by the dentary, angular, surangular, retroarticular, and at least one coronoid bone. The presence of prearticular and articular bones cannot be evaluated. The toothed anterior portion of the dentary is shallow and curved ventrally. Seven dentary peg-like teeth are exposed in MCSN 8006 (Figure 9). The four most anterior dentary teeth are of similar size and about the same size as the premaxillary teeth. More posteriorly, the dentary teeth decrease in size gradually. There are remnants of coronoid bones bearing peg-like teeth similar to those of the dentary (MCSN 8082; Figure 7), but the exact number of coronoids or the arrangement of teeth cannot be established. The angular, surangular, and retroarticular are best observed in MCSN 8082. The laterally exposed portion of the angular is approximately rectangular, and the elongated surangular lays on its dorsal border. The retroarticular is approximately quadrangular and forms the posterodorsal corner of the lower jaw, participating of the lower jaw articulation at least laterally. The posterior and ventral borders of the lower jaw are almost perpendicular to each other, and the articular facet for the quadrate is oriented posteriorly.

The left palatoquadrate is well exposed in medial view, disarticulated and displaced, in MCSN 8006 (Figure 9). The dermal endo-, ectopterygoids, and quadratojugal are fused or firmly attached to a single chondral ossification including the quadrate and metapterygoid regions, but not the autopalatine, which is a separate ossification attached to the lateral ethmoids exactly as in Amia calva (compare Figure 8 with Grande and Bemis, 1998: figure $47 \mathrm{~A})$. The pars metapterygoidea projects posterodorsally, and the pars quadrata forms a slightly concave articular surface oriented anteroventrally. The quadratojugal is completely fused to the large chondral ossification, and it is tightly bound to the dorsal border of the horizontal arm of the preopercle. The endopterygoid is long and narrow, tapering anteriorly. The ectopterygoid is crescentshaped, convex dorsally, and concave ventrally, with rounded posteroventral and indented anterodorsal ends. There are no teeth on the endo- or ectopterygoid bones. Some peg-like teeth similar to those on the dentary, which are partially exposed medial to the articular process of the maxilla in some specimens (MCSN 5617, and 8082), might represent dermopalatine or vomerine teeth.

The left hyomandibula is isolated and displaced posterodorsal to the skull in MCSN 8006 (Figures 6.2, 9). The bone has a relatively narrow and slightly ventrally expanded shaft, with the hyomandibular foramen close to the anterior border, and a posteriorly expanded dorsal portion, but there is no distinct opercular process. The surface for the articulation with the neurocranium forms an angle of approximately $45^{\circ}$ with the main axis of the shaft. The anterior ceratohyals are well exposed in MCSN 8006 and MCSN 8082 (Figures $7,9)$. They are hourglass-shaped and strongly constricted in the middle. The relatively large left and right hypohyals are well preserved in the holotype.

The preopercle is L-shaped, with the vertical arm a little longer than the horizontal arm and widely separated from the dermopterotic. The vertical arm is uniformly broad and ends in a straight, slightly inclined dorsal border. The horizontal arm is 1.5 to 2 times broader than the vertical arm and has a generally convex ventral margin. The preopercular sensory canal runs close to the anterior 
border of the bone. The left preopercle is isolated and exposed in median view in MCSN 8006 showing a groove or elongated facet close to the dorsal margin of the horizontal arm, in the area of attachment of the quadratojugal (Figure 9). This facet is also visible in the holotype MCSN 8082 (Figure 7). There is also a small anteriorly directed process at the base of the anterior border of the vertical arm of the preopercle in MCSN 8006 (Figure 9). Similar processes are present in at least some specimens of Amia calva (e.g., Grande and Bemis, 1998; figure 47) and other species of Amia and Cyclurus, but the distribution and meaning of this feature are still unknown.

The opercle is about 1.3 times deeper than long, with straight ventral and anterior borders, and convex posterior border so that the bone is narrowing dorsally. The dorsal border of the opercle is rounded. The subopercle is sickle-shaped, tapering posterodorsally, with a straight anterior and dorsal margins and convex ventro-posterior margin. There is a tapered and small ascending process (PIMUZ T 2924). The base of the ascending process is about $10 \%$ of the maximal length of the bone at its dorsal border, and the height of the ascending process is about $30 \%$ of this same length. The interopercle is exposed in all the specimens. As is the case with several other left bones of the skull, the left interopercle is isolated in MCSN 8006 (Figure 9). The bone is short and triangular, but with rounded corners, and there is a groove at the posterior border for the attachment of the subopercle. The interopercle is slightly shorter than high, and its length is only about $40 \%$ of the length of the horizontal arm of the preopercle. The branchiostegal bones are very slender. Five branchiostegals are preserved in MCSN 8082 (holotype), MCSN 5617, and MCSN 8006 (Figures 7-9).

In the pectoral girdle, only the posttemporal, supracleithrum, and single postcleithrum are covered with ganoine. The posttemporal is approximately triangular with a rounded ventral border. The size and shape of the exposed portion of the supracleithrum closely resemble the adjacent lateral line scales, but differing from the scales, the supracleithrum tapers ventrally. The lateral line traverses the supracleithrum in anterodorsal to posteroventral direction, exiting the bone at the middle of its posterior border. The single postcleithrum is almost semicircular, but tapering dorsally, and it is tightly attached to the cleithrum forming an almost vertical suture. The cleithrum is very slender, without a median wing and with a narrow lateral wing. The cleithrum is generally devoid of ganoin, but only small and elongated patches of ganoine are present along the ridge between its branchial and lateral surfaces. Only badly preserved remains of the endochondral pectoral ossifications are exposed in the holotype. The pelvic bones are not exposed in any specimen.

The pectoral fins are badly preserved. They are best preserved in MCSN 5617, including numerous, though not countable, and delicate lepidotrichia (Figure 6.4). The presence or absence of basal or fringing fulcra in these fins cannot be established. The pelvic fins insert directly behind the third (MCSN 8006) or fourth (all other specimens) vertical row of scales and quite high in the fossil, thus indicating a broad ventrum. The fins are best preserved in MCSN 8006 and MCSN 5617, including two paired basal fulcra, five fringing fulcra, and five lepidotrichia (Figure 10.1). As usual in neopterygians, the basal segment is long, followed by short segments of similar size. The distal portion of the fin rays is not preserved and, thus, the bifurcation pattern is unknown.

The median fins possess strong basal and fringing fulcra (Figure 10.2-3). The dorsal fin is placed at the middle of the body, originating directly behind the 11th to 14th vertical row of scales. There are four paired basal fulcra and up to seven fringing fulcra counted in MCSN 8082. A maximum of nine fin rays was counted in MCSN 5617 and 8082. The anal fin originates directly behind the 11 th or 12 th vertical row of scales, usually at the same vertical scale row as the origin of the dorsal fin (MCSN 8006, 8082, PIMUZ T 2924) or two vertical rows of scales before the origin of the dorsal fin (MCSN 5617). There are two to three anal basal fulcra and up to five fringing fulcra counted in MCSN 8082 and PIMUZ T 4434. There are six (MCSN 8082) or seven (MCSN 5617) anal fin rays.

The caudal fin is hemiheterocercal with a rather short body lobe (Figures 11-12). Differing from the other species of the genus, in Eosemionotus diskosomus $\mathrm{n}$. $\mathrm{sp}$. there is a series of large, rounded scutes along the dorsal midline between the dorsal fin and the body lobe. The number of scutes varies between eight and nine. The series of scutes is followed by the large dorsal caudal and fringing fulcra typical of the genus Eosemionotus. The four paired dorsal caudal fulcra cover the dorsal margin of the body lobe from the hinge-line to the most distal scale, and there is a maximum of eight large fringing fulcra embracing the most dorsal caudal fin ray in the holotype (Figure 11). The ventral margin of the caudal fin possesses three paired basal fulcra and a maximum of 7 fringing ful- 


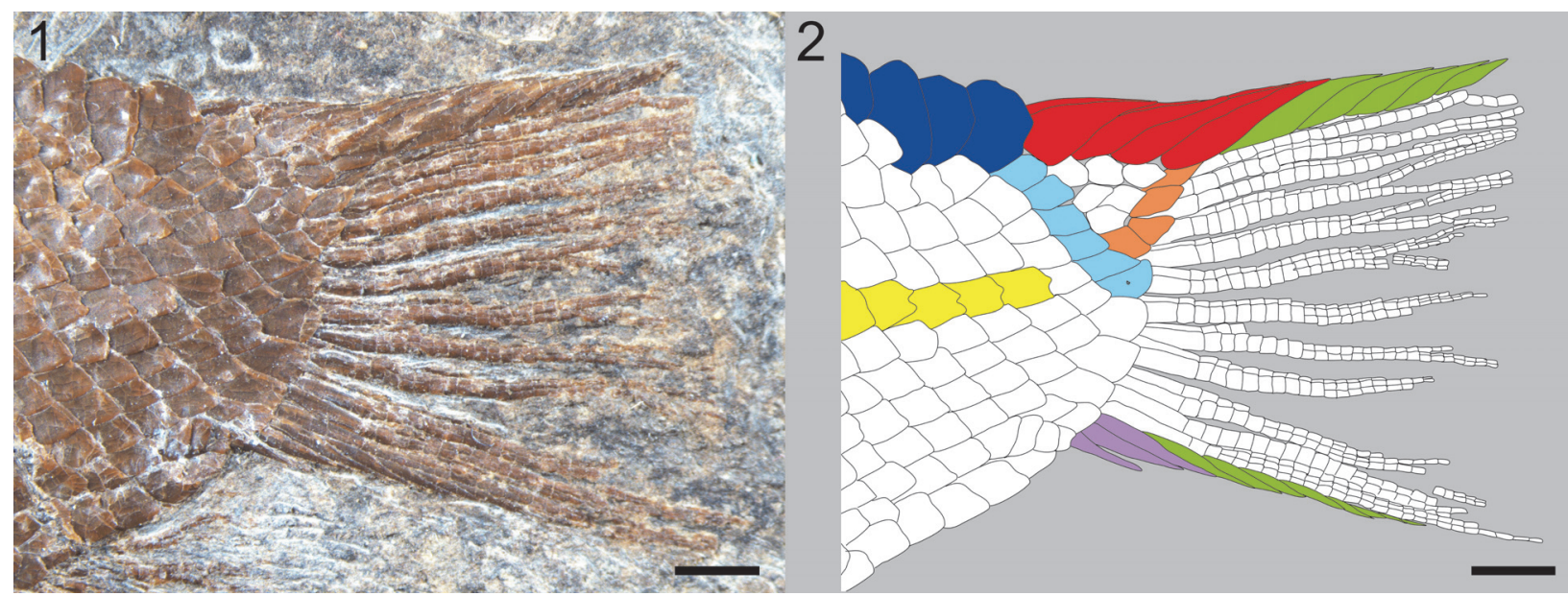

FIGURE 11. Eosemionotus diskosomus. Caudal fin of the holotype MCSN 8082. 1, photograph; 2, line drawing. Distinct dermal structures are indicated with colours: scales traversed by the lateral line (yellow), scales along the last vertical row at the hinge line (light blue), scales along the marginal row of the body lobe (orange), scutes (blue), dorsal caudal fulcra (red), ventral basal fulcra (purple), fringing fulcra (green). Scale bars equal $1 \mathrm{~mm}$.

cra in MCSN 5617 (Figure 12). The caudal fin web is made of 13 lepidotrichia, seven of them are placed below the level of the lateral line. All the caudal fin rays are segmented and branched at least once. The fin rays are best preserved in MCSN 5617. The most dorsal caudal ray is the slenderest in the fin and is mostly embraced by the large fringing fulcra. This ray branches only once close to its distal end. All other caudal rays branch two or three times, including the most ventral ray, which bears all the ventral fringing fulcra.

The body is covered with relatively large ganoid scales. There are 23-25 vertical rows of scales, counted along the lateral line, which traverses 2224 scales. The one or two last scales in this series, corresponding to the last vertical rows, only include isolated pit organs (Figures 11-12). There are normally 13 (10 in PIMUZ T 2924, which is the smallest specimen) scales along the vertical row directly before the origin of the dorsal fin. There are 6-7 scales in the last vertical row, four scales at the base of the body lobe along the hinge-line and four scales along the marginal row of body lobe (dorsal caudal fulcra excluded). A series of seven to eight large scutes cover the dorsal midline between the dorsal and caudal fins (Figure 6). There are no ventral precaudal scutes.

The scales have smooth surfaces and smooth posterior borders. There is a small peg for the pegand-socket articulation and there are no longitudinal processes (Figure 13). In the abdominal region, the lateral line scales and the scales of the horizontal row immediately ventral to them are deepened and notably deeper than the other scales of the body (Figure 13). Within these two rows, the anterior flank scales have a depth to width ratio of approximately 3 . From these deepest scales, the height of the scales decreases gradually in dorsal, ventral and posterior directions and only in the ventral portion of the caudal peduncle, below the lateral line, some scales are slightly longer than deep.

\section{Eosemionotus sceltrichensis n. sp.}

Figures 14-20

\section{zoobank.org/C42CD731-116C-4BFB-80AC-3480C879B807}

Etymology. The species epithet "sceltrichensis" refers to the type locality because this is so far the most abundant species of Eosemionotus in this locality and horizon, and the fish is furthermore exclusively known from there.

Holotype. MCSN 8418 (SL = $52.8 \mathrm{~mm})$. Complete and well-preserved specimen, exposed in right lateral view (Figure 14.1).

Type horizon and locality. Sceltrich beds, upper Meride Limestone (transitional interval Gredleri/ Archelaus Zones; lower/upper Ladinian) at Valle di Sceltrich, Monte San Giorgio, Switzerland (Figure 1).

Additional specimens. MCSN 8491, 8494, 8497 (Figure 14.2, 16) from the type horizon and locality. Differential diagnosis. Species of Eosemionotus differing from all other known species of the genus in the fusion of both parietal bones, very tight joint between opercle and subopercle and presence of a comparatively longer interopercle, which is more than two times longer than deep (vs. approximately as long as deep in the other species of the genus) (Table 1). 

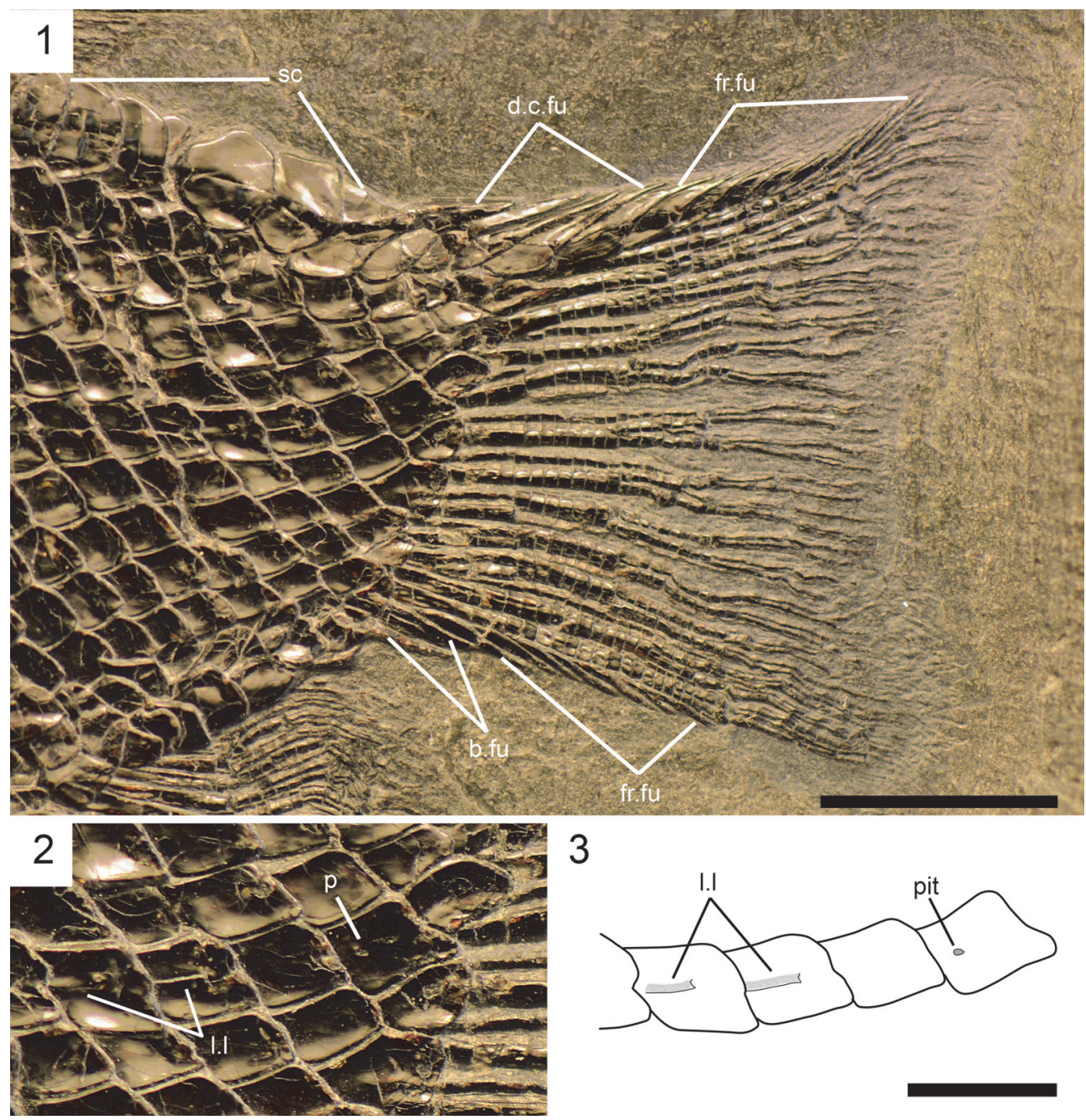

FIGURE 12. Eosemionotus diskosomus, specimen MCSN 5617. 1, photograph of the caudal fin; scale bar equals 5 $\mathrm{mm} .2$ and 3, detailed photograph (2) and line drawing (3) of the most posterior scales in the horizontal row along the lateral line; scale bar equals $2 \mathrm{~mm}$.

Additional characters (Table 1): deep diskshaped body (fusiform in E. vogeli, E. ceresiensis, and $E$. minutus n. sp.); dermal bones of skull smooth (ornamented in E. vogeli); anteromedial frontal processes long (short in E. ceresiensis) and coalescent (separated in E. minutus n. sp.); no branch of supraoccipital canal in parietals (present in $E$. vogeli, E. ceresiensis, and in E. minutus $\mathrm{n}$. sp.); three pairs of extrascapulars (one pair in $E$. vogeli, five extrascapulars in E. ceresiensis); 3-4 premaxillary teeth (5-6 in E. ceresiensis, six in $E$. minutus n. sp.); maxillary teeth absent (present in E. ceresiensis); maxilla deep (notably shallower in E. vogeli, E. ceresiensis, and in E. minutus n. sp.); lower jaw articulation at centre of orbit (at anterior border of orbit in E. ceresiensis, and in E. diskosomus n. sp.); opercle deeper than long (approximately as deep as long in $E$. vogeli and $E$. ceresiensis); large fringing fulcra (small in E. ceresiensis); marginal row of body lobe with two scales (four in E. diskosomus, E. sceltrichensis and $E$. minutus n. spp.; five in E. ceresiensis; $6-7$ in $E$. vogeli); 4-5 scales posterodorsal to hinge-line (three in E. minutus n. sp); four dorsal caudal fulcra on body lobe (5-6 in E. vogeli and E. ceresiensis); absence of dorsal precaudal scutes (present in $E$. ceresiensis and E. diskosomus n. sp.; single in $E$. minutus $\mathrm{n}$. sp.); four ventral precaudal scutes present (absent in E. vogeli, E. ceresiensis, and E. diskosomus n. sp.); 12 caudal fin rays (12-15 in $E$. vogeli, 13-15 in E. ceresiensis, and 13 in E. diskosomus $\mathrm{n}$. sp.), eight of them below lateral line (seven in E. diskosomus n. sp.).

Pterygial formula: D12-14/(P3-5 A12-13 C18-20) T23-25. 


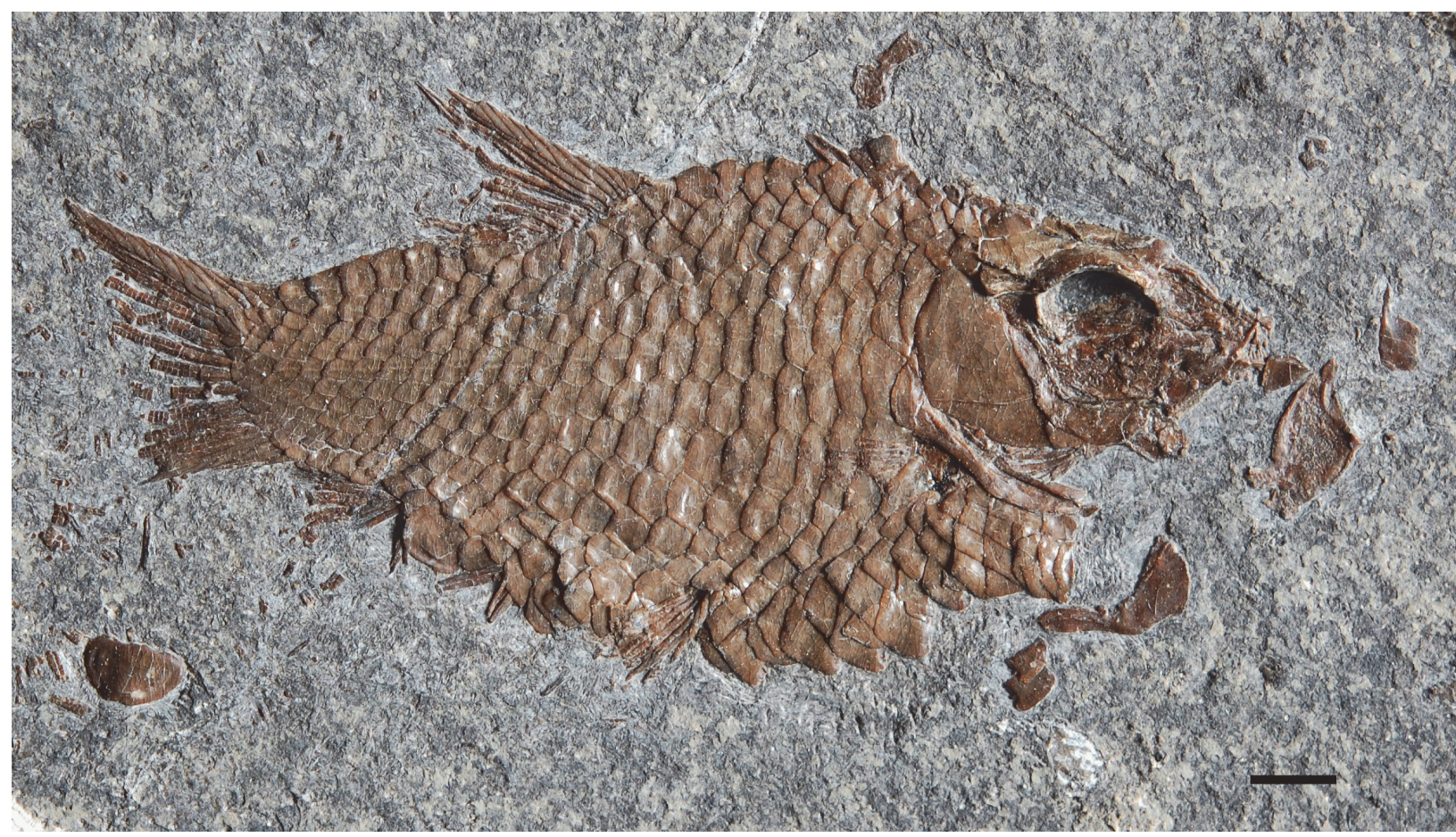

FIGURE 13. Eosemionotus diskosomus. Specimen MCSN 8006 showing the squamation pattern. Scale bar equals 5 $\mathrm{mm}$.

\section{Description}

At first glance, Eosemionotus sceltrichensis n. $\mathrm{sp}$. is very similar to $E$. diskosomus, mainly due to the also relatively deep body shape. However, differing from this latter species, the relative depth of the body decreases with the size of the specimens of E. sceltrichensis (Table 2, Figure 15). Although not remarkably different, the dorsal profile of the body is gently convex in E. diskosomus, but almost straight in E. sceltrichensis (compare Figure 6 with Figure 13). The size of the studied specimens ranges between 33.2 and $43.7 \mathrm{~mm}$.
Resembling the other species of the genus, the two frontals are also completely fused with each other in E. sceltrichensis. The anteromedial frontal processes are relatively short and tightly attached to each other along its entire length. The series of pores along the trajectories of the supraorbital canals are deeply curved, diverging anteriorly and posteriorly, and exiting the frontal plate at its anterolateral and posterolateral corners and, thus, not entering the parietals. Differing from the other species of the genus, the two parietals are also fused with each other forming a parietal plate. The parietal plate is not fused to the frontal plate in

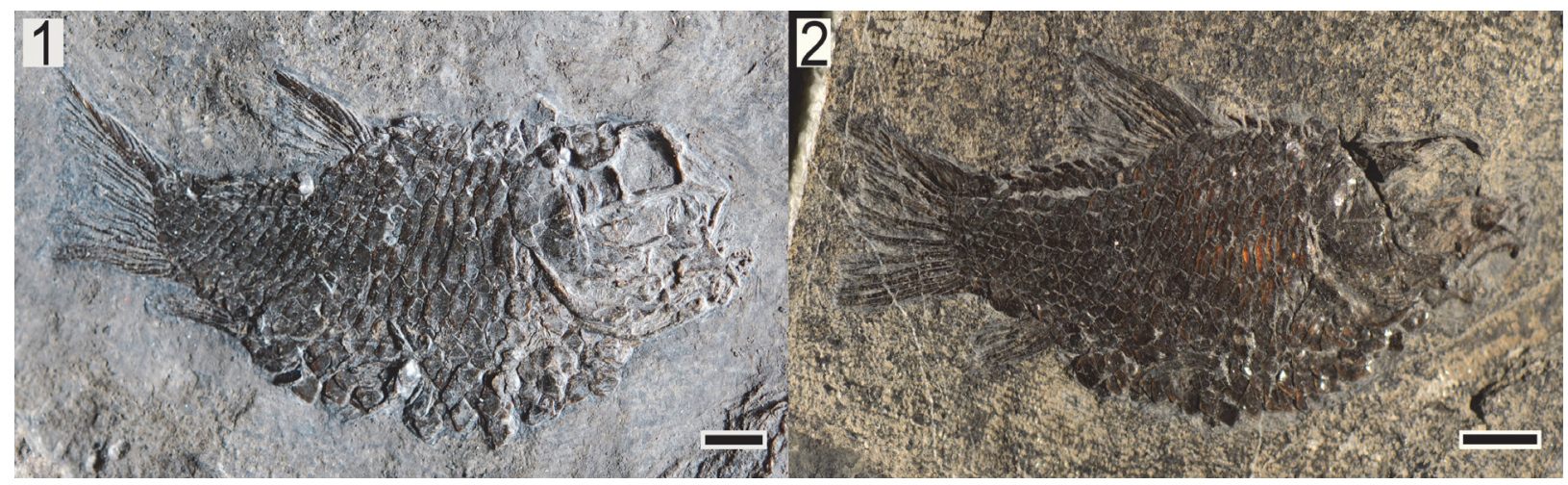

FIGURE 14. Eosemionotus sceltrichensis. 1, Holotype MCSN 8418 (52.8 mm SL) preserved in right lateral view. 2, MCSN 8497 (39.14 mm) preserved in right lateral view. Scale bars equal $5 \mathrm{~mm}$. 


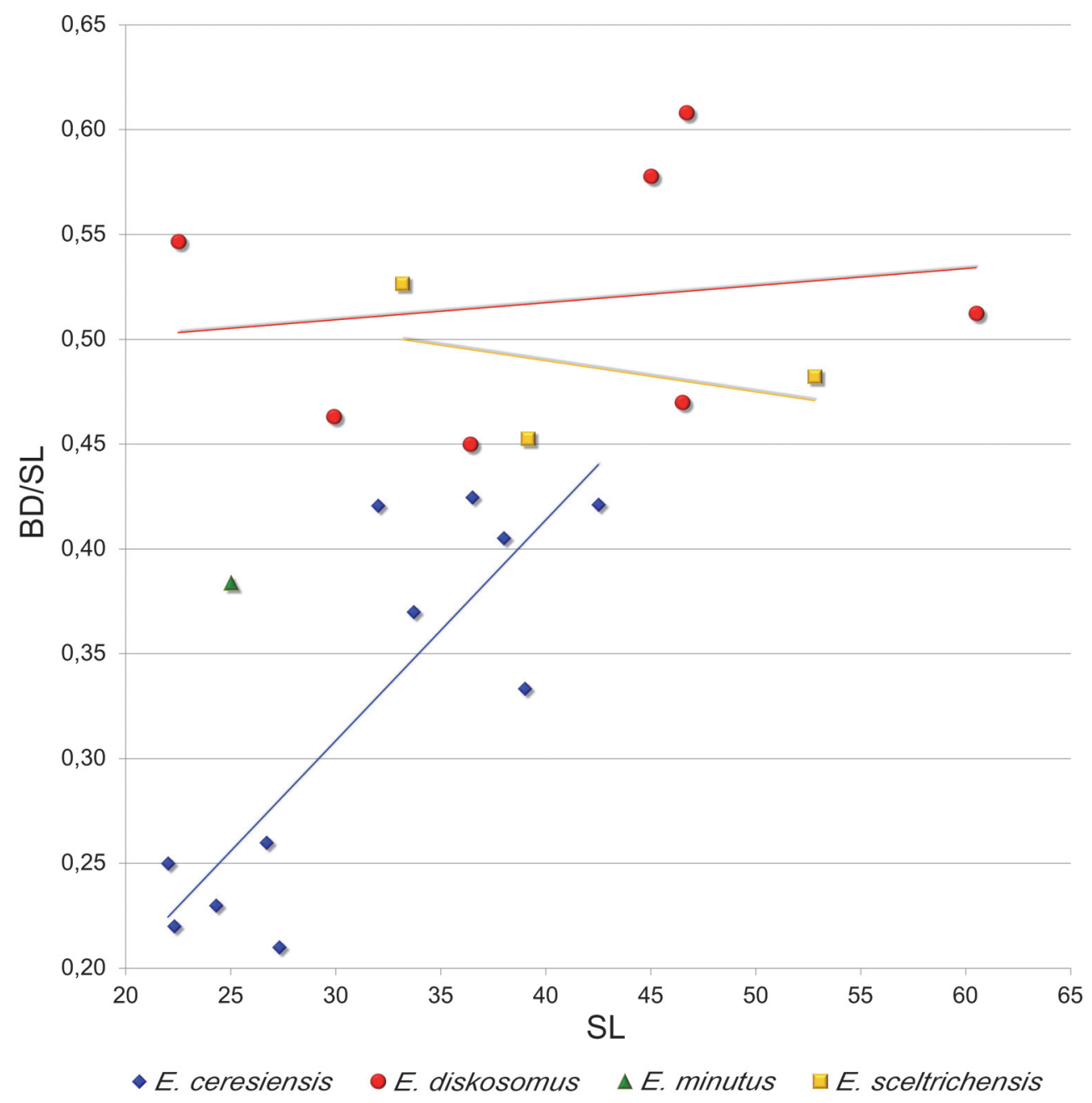

FIGURE 15. Ontogenetic changes in body proportions in the Monte San Giorgio species. Plot of the ratio between body depth (BD) and standard length (SL) in the y-axis vs. the standard length (SL) in the x-axis. Data in Table 2.

MCSN 8491 (SL $33.16 \mathrm{~mm}$; Figure 16.1), but the two plates are completely fused in the holotype MCSN 8418 (SL 52.80 mm; Figure 17). The parietal and frontal plates are also fused in the disarticulated specimen MCSN 8494 (Figure 16.2-3), which includes a skull roof preserved in right laterodorsal view. This skull roof is slightly larger than the skull roof of the holotype specimen and, although the bones are fused, the line of fusion between the parietal and frontal plates is still visible.

Each half of the fused parietals resembles a posteriorly inclined parallelogram with a somewhat variable length, which is maximal at the lateral borders and along the midline (Figure 16). On average, the parietal length is about one-third of the maximal length of the frontal plate. The dermopterotics are longitudinally elongated, mediolaterally broadest posteriorly and tapering anteriorly
(Figure 17). They are longer than the lateral border of the parietal plate, extending lateral to the frontal. Two small rectangular extrascapulars are preserved posterior to the parietals in the holotype MCSN 8418 (Figure 17). According to their position, a third lateral extrascapular might be missing posterior to the dermopterotic, but the series does not seem to reach the dorsal midline, where the extrascapulars are separated by the posterior extension of the parietal plate. The nasals are not well preserved and their description is not possible.

The exposed portions of the endochondral neurocranium are very similar to the corresponding bones in E. diskosomus. The lateral ethmoids are triangular in lateral view and there is a large median ethmoidal lamina extending from the parasphenoid to the premaxillary nasal processes and the anterior frontal processes (Figure 17). The 

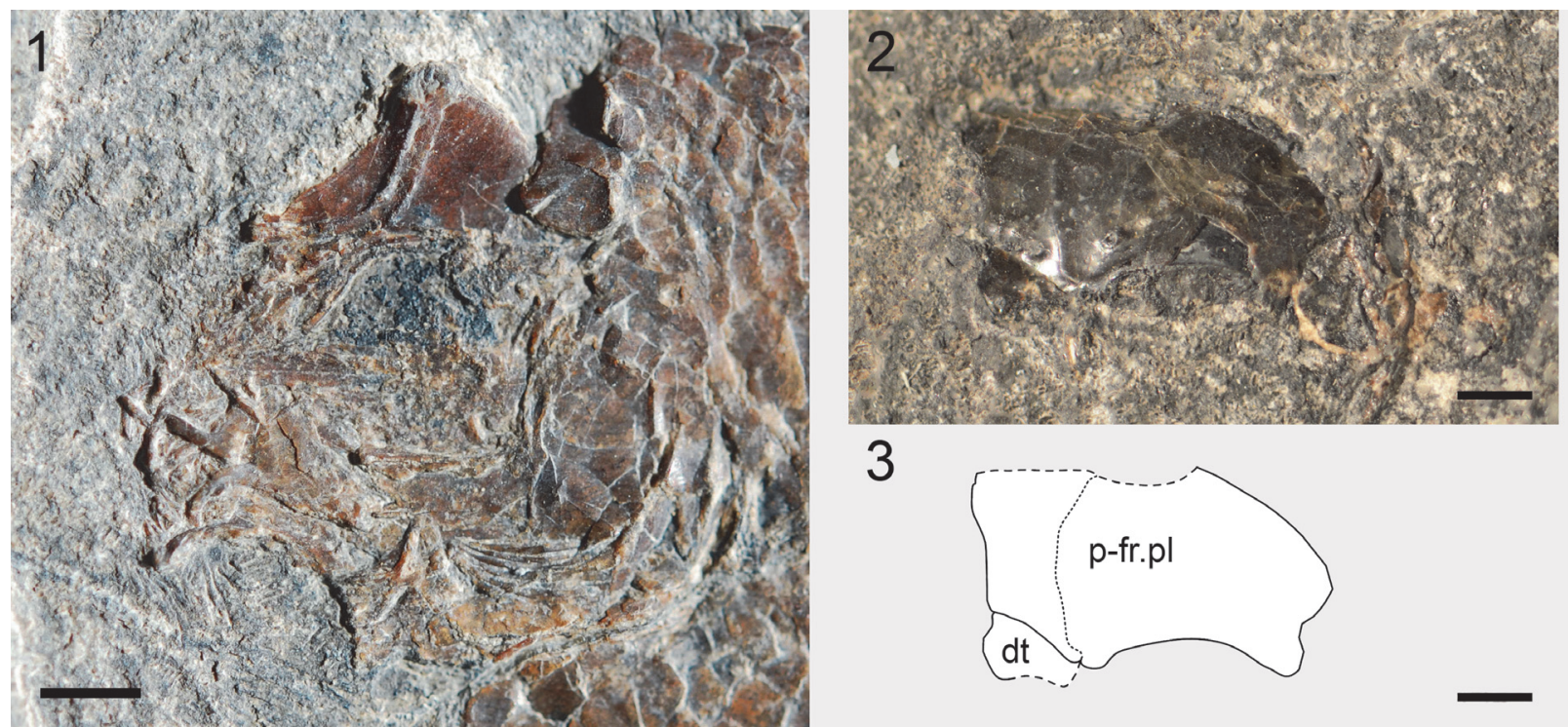

FIGURE 16. Additional specimens of Eosemionotus sceltrichensis: 1, photograph of the mostly disarticulated head of MCSN 8491 (33.16 mm SL); 2, photograph of the disarticulated and displaced skull roof in right latero-dorsal view of MCSN 8494; 3, line drawing of the latter specimen. Scale bars equal $2 \mathrm{~mm}$.

orbitosphenoid forms a large median laminar septum, which is filling most of the orbital opening around the relatively large interorbital fenestra. The parasphenoid is well exposed in lateral view in the holotype MCSN 8418 (Figure 17). The ascending processes are short and directed dorsally; basipterygoid processes are not distinguishable. Posteriorly, the parasphenoid extends along the occipital region and probably reaches the occipital condyle. The vomers are badly preserved and cannot be described.

The circumorbital bones are incompletely preserved. The poorly preserved lachrymal and two anterior infraorbitals are relatively large and rectangular (Figure 17). There is no evidence of suborbital or supraorbital bones.

The upper jaw is formed by the premaxillae and maxillae with no evidence of a supramaxillary bone. The displaced right premaxilla of the holo-
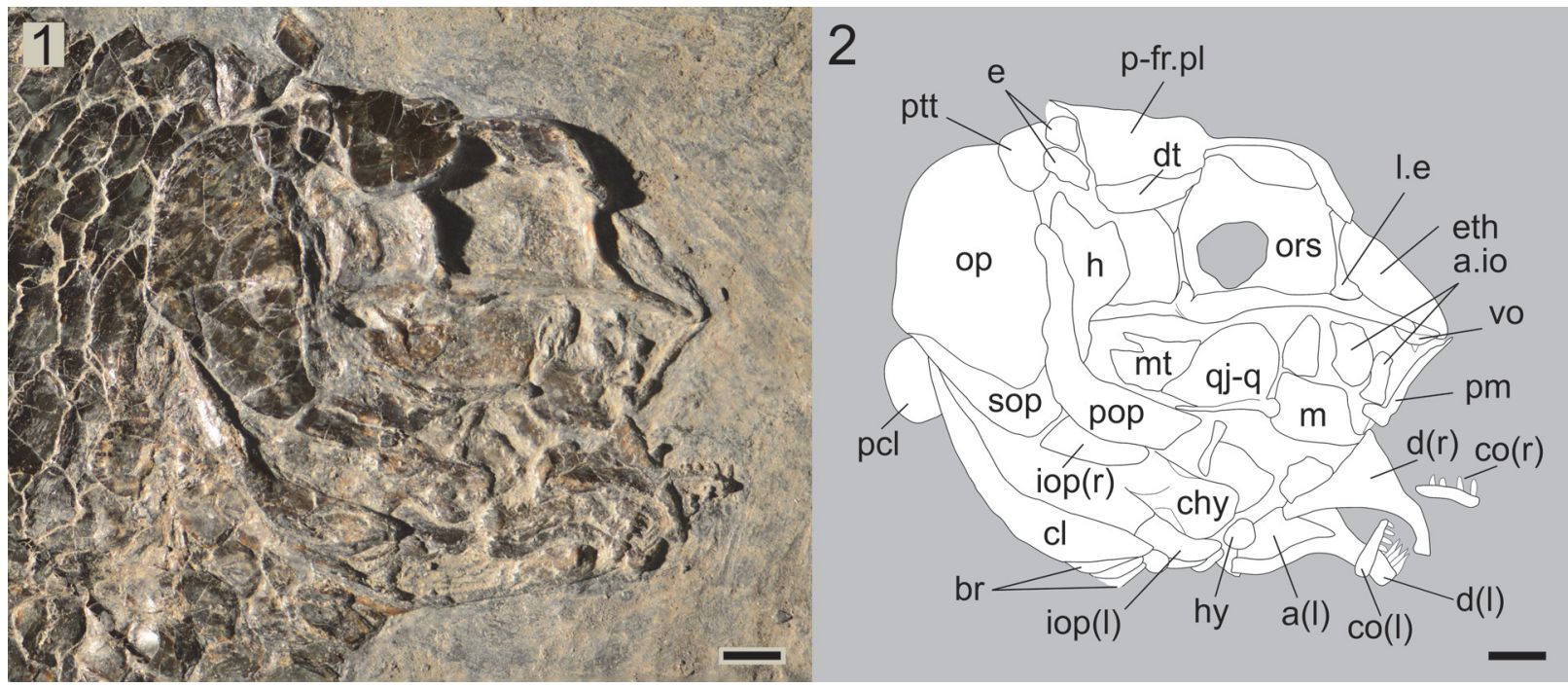

FIGURE 17. Eosemionotus sceltrichensis. Skull of the holotype MCSN 8418. 1, photograph. 2, line drawing. Scale bars equal $2 \mathrm{~mm}$. 

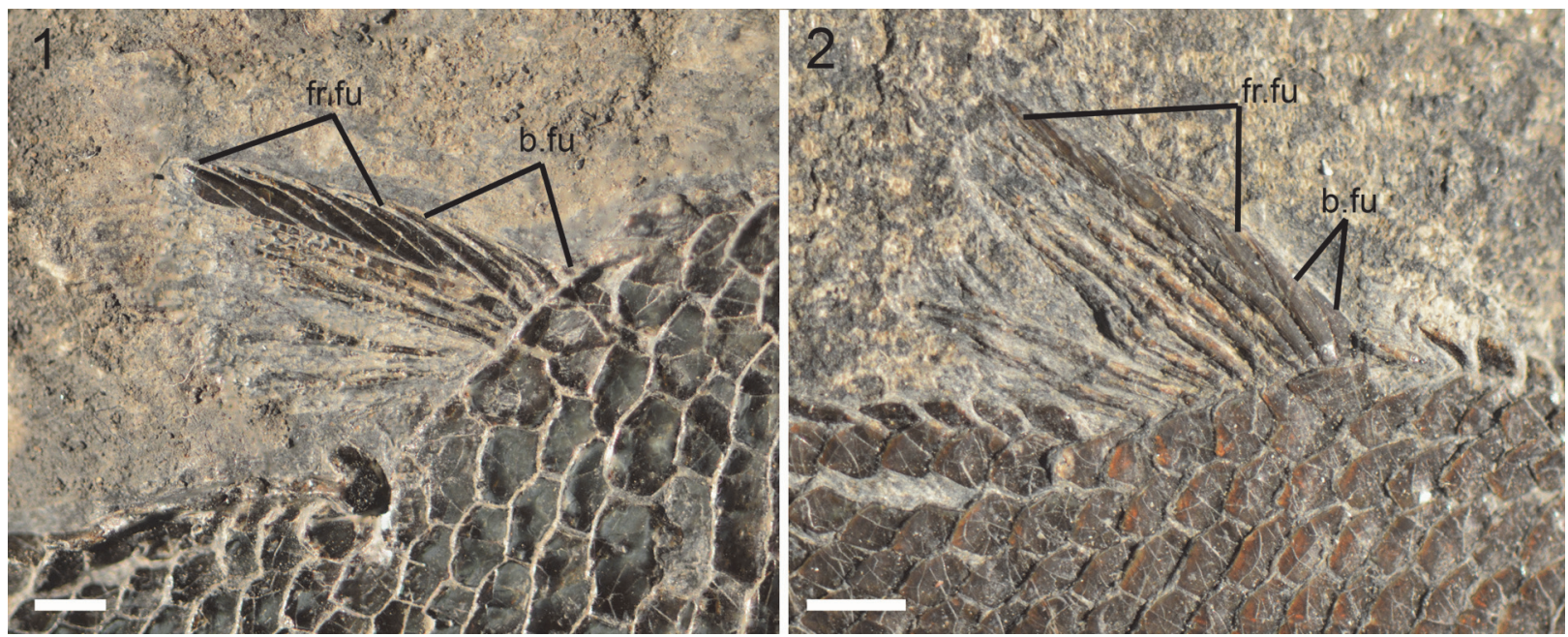

FIGURE 18. Eosemionotus sceltrichensis. Dorsal fin. 1, specimen MCSN 8418. 2, specimen MCSN 8497. Scale bars equal $2 \mathrm{~mm}$.

type MCSN 8418 (Figure 17) shows a very short dentigerous portion and a very high ascending process. Resembling E. diskosomus, the height of the ascending process is almost four times the maximal length of the dentigerous portion. Each premaxilla bears four peg-like teeth, which are best preserved in MCSN 8497. The maxilla is edentulous with a rectangular maxillary plate, the depth of which is c. $80 \%$ of its length.

In the lower jaws, only the dentaries, angulars, and coronoid bones are discernable. The toothed anterior portion of the dentary is shallow and curved ventrally. Four peg-like teeth are well preserved in the left dentary of the holotype MCSN 8418 (Figure 17), but the total number of dentary teeth is unknown. One coronoid bone bearing relatively large peg-like teeth similar to those of the dentary, is preserved on each jaw. There is no evidence of additional coronoid bones. The angular is best exposed in median view in the left lower jaw of the holotype MCSN 8418. It is relatively shallow and does not reach the tip of the coronoid process, which was probably formed by the dentary and surangular. The surangular is not preserved, but the shape of the coronoid process indicates that the bone was present posterior to the distal portion of the dentary and dorsal to the angular.

The posterior part of the right palatoquadrate is well exposed in lateral view in the holotype MCSN 8418 (Figure 17). The endo-, ectopterygoids, dermo-, and autopalatines are not preserved. The quadratojugal is at least partially fused to the ventral border of the chondral quadrate, which has rounded anterodorsal and posterodorsal borders. Part of the ventral margin of the quadrate is free and diverges from the distal end of the quadratojugal in a straight line directed posterodorsally. The complex quadrate-quadratojugal forms a
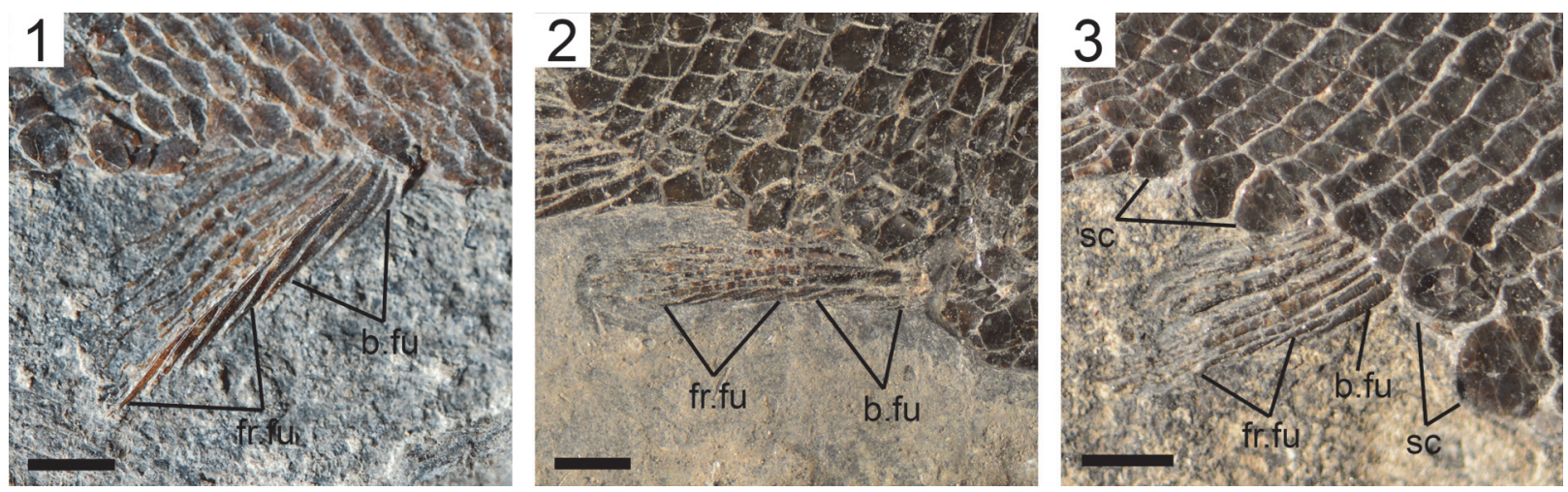

FIGURE 19. Eosemionotus sceltrichensis. Anal fin. 1, specimen MCSN 8491; specimen MCSN 8418; 3, specimen MCSN 8497. Scale bars equal $2 \mathrm{~mm}$. 


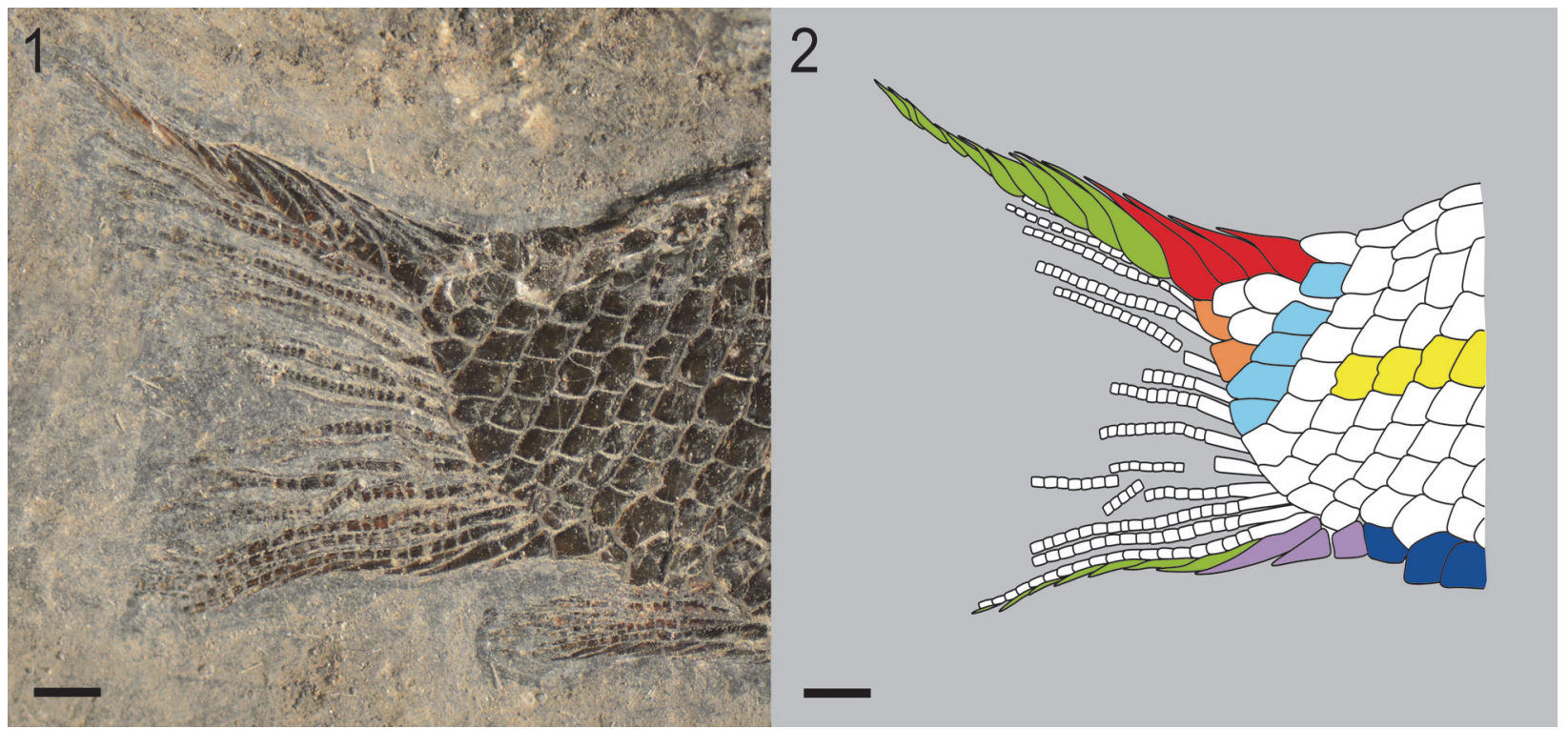

FIGURE 20. Eosemionotus sceltrichensis. Caudal fin of the holotype MCSN 8418 1, photograph. 2, line drawing. Distinct dermal structures are indicated with colours: scales traversed by the lateral line (yellow), scales along the last vertical row at the hinge line (light blue), scales along the marginal row of the body lobe (orange), scutes (blue), dorsal caudal fulcra (red), ventral caudal fulcra (purple), fringing fulcra (green). Scale bars equal $2 \mathrm{~mm}$.

very distinct round condyle and the free distal end of the quadratojugal is spine-like. The metapterygoid is firmly attached to the posterior margin of the quadrate. It is generally fan-shaped with a distinct dorsal process directed posteriorly.

The right hyomandibula is partially visible in the holotype MCSN 8418 (Figure 17), but no details can be described. A hatchet-shaped disarticulated bone, which is preserved ventral to the quadratojugal in the holotype, is interpreted as the symplectic. The anterior ceratohyals are well exposed in the four specimens (Figures 16.1, 17). They are approximately rectangular, with thickened ridges crossing, and forming a middle constriction. There is one pair of hypohyals.

The preopercle is L-shaped, with the vertical arm a little longer than the horizontal arm and well separated from the dermopterotic (Figures 16.1, 17). The vertical arm narrows dorsally very slightly ending in a rounded, finger-like distal tip. The horizontal arm is 1.5 to 2 times broader than the vertical arm and has a generally convex ventral margin. The preopercular sensory canal runs close to the anterior border of the bone. The dorsal border of the horizontal arm is strengthened forming an elongated facet, which is interpreted as an attachment area of the quadratojugal.

The opercle and subopercle are tightly bound to each other in all of the specimens (Figure 17). The opercle is only slightly deeper than long, widely ovate in shape, with convex ventral, antero- and posterodorsal borders. The subopercle is very large, deep, and sickle-shaped; its maximal depth is more than $80 \%$ of the maximal depth of the opercle. An ascending process is not visible. Differing from the other species of Eosemionotus, the interopercle in E. sceltrichensis is elongated, with a length of approximately $90 \%$ of the length of the horizontal arm of the preopercle, and, although the height cannot be measured with certainty in any of the specimens, the bone is evidently much longer than high. The complete series of slender branchiostegals, including six elements, is well preserved in MCSN 8491 (Figure 16.1).

The pectoral girdle is badly preserved and details cannot be described. In general terms the bones of the pectoral girdle are similar to those in $E$. diskosomus. The pelvic bone is not visible in any of the specimens. The pectoral fins are too incompletely preserved. The pelvic fins insert directly behind the third to fifth vertical row of scales. There are two basal fulcra and a series of fringing fulcra on the pelvic ray; the total number of rays in this fin is unknown.

The median fins are garnished with strong basal and fringing fulcra. The dorsal fin is placed at the middle of the body, originating directly behind the twelfth to fourteenth vertical row of scales (Figure 14). The dorsal fin has four paired basal fulcra and up to six fringing fulcra counted in MCSN 8418 and 8497 (Figure 18). There are seven dorsal fin rays in MCSN 8497 and six in MCSN 8491. The 
anal fin originates directly behind the twelfth or thirteenth vertical row of scales, at the same vertical scale row as the origin of the dorsal fin (Figure 14). There are three anal basal fulcra, which are only well preserved in MCSN 8491 (Figure 19.1), and up to five fringing fulcra counted in MCSN 8418 (Figure 19.2). Seven anal fin rays are preserved in MCSN 8497 (Figure 19.3).

The caudal fin is hemiheterocercal with a short body lobe (Figure 20). There are four paired dorsal caudal fulcra covering the dorsal margin of the body lobe from the hinge-line to the most distal scale, and there is a maximum of seven large fringing fulcra embracing the most dorsal caudal fin ray in the holotype. There are two ventral paired basal fulcra and four fringing fulcra in MCSN 8418 and 8497. The caudal fin web is made of 12 lepidotrichia, eight of which are placed below the level of the lateral line. All caudal fin rays are segmented and branched at least once. The most dorsal caudal ray is the slenderest in the fin and is mostly embraced by the large fringing fulcra.

The body is covered with relatively large ganoid scales. There are 23-25 vertical rows of scales, counted along the lateral line. The lateral line traverses 22-24 scales; there is no evidence of a pit organ in the last scale in this series, corresponding to the last vertical row (Figure 20). There are 12 scales along the vertical row directly before the origin of the dorsal and anal fins, five scales in the last vertical row, three scales in the marginal row of the body lobe, and four to five scales posterodorsal to the hinge-line. There are no dorsal precaudal scutes, but there is a series of four ventral precaudal scutes (Figures 14, 19.3, 20).

The scales have smooth surfaces and smooth posterior borders. There is a small peg for the pegand-socket articulation, but there are no longitudinal processes. The lateral line scales and the scales of the horizontal row immediately ventral to them are deepened and notably deeper than the other scales of the body. Within these two rows, the anterior flank scales have a depth to width ratio of approximately two. From these deepest scales, the height of the scales decreases gradually in dorsal, ventral and posterior directions and only in the ventral portion of the caudal peduncle, below the lateral line, very few scales are slightly longer than deep. There are large preanal scutes, apparently one median anteriorly followed by a posterior pair, all three of them almost circular and of similar size.

\section{Eosemionotus minutus n. sp.}

Figures 21-23

zoobank.org/DB46D7F4-CC99-4D7B-B85A-0A421EEAB000
Etymology. The species epithet from Latin minutus "little, small, minute" recalls the very small size of this fish when compared with the other species of the genus.

Holotype. MCSN 8482 (SL = $25 \mathrm{~mm})$. Complete and very well-preserved specimen, exposed in left lateral view (Figure 21).

Type horizon and locality. Sceltrich beds, upper Meride Limestone (transitional interval Gredleri/ Archelaus Zones; lower/upper Ladinian) at Valle di Sceltrich, Monte San Giorgio, Switzerland (Figure 1).

Differential diagnosis. Species of Eosemionotus differing from all other known species of the genus in the following features (Table 1): more posteriorly placed pelvic fins originating posterior to the origin of the dorsal fin; the presence of long and well separated anteromedial frontal processes, only three scales at the base of the body lobe posterodorsal to the hinge-line, long, but slender fringing fulcra, and the absence of fringing fulcra on the dorsal margin of the caudal fin.

Additional characters (Table 1): fusiform body (deep disk-like in E. diskosomus and E. sceltrichensis $\mathrm{n}$. spp.); dermal bones of the skull smooth (ornamented in E. vogeli); anteromedial frontal processes long (short in E. ceresiensis); short branch of supraoccipital canal in parietals (absent in E. diskosomus and E. sceltrichensis n. spp.); three pairs of extrascapulars (one pair in $E$. vogeli, five extrascapulars in $E$. ceresiensis); six premaxillary teeth (four in E. vogeli and E. sceltrichensis n. sp.; 3-4 in E. diskosomus n. sp.); maxilla triangular (deeply rectangular in E. diskosomus and E. sceltrichensis n. spp.); 11 dentary teeth (seven in E. vogeli); lower jaw articulation at the centre of the orbit (at the anterior border of the orbit in E. ceresiensis, and in E. diskosomus n. sp.); opercle deeper than long (approximately as deep as long in E. vogeli, E. ceresiensis and E. sceltrichensis n. sp.); five branchiostegals (six in $E$. sceltrichensis n. sp., 6-7 in E. vogeli, 7-8 in E. ceresiensis); 12 caudal fin rays (12-15 in E. vogeli, 13-15 in E. ceresiensis, and 13 in E. diskosomus n. sp.); eight caudal fin rays below the lateral line (seven in $E$. diskosomus $\mathrm{n}$. sp.); marginal row of body lobe with four scales (two in E. sceltrichensis; five in E. ceresiensis; 6-7 in E. vogeli); four dorsal caudal fulcra on the body lobe (5-6 in E. vogeli, five in $E$. ceresiensis); single dorsal precaudal scute (a series of several scutes present in E. ceresiensis and $E$. diskosomus n. sp.; single in $E$. minutus n. sp.; dorsal scutes absent in $E$. sceltrichensis); three ventral precaudal scutes 


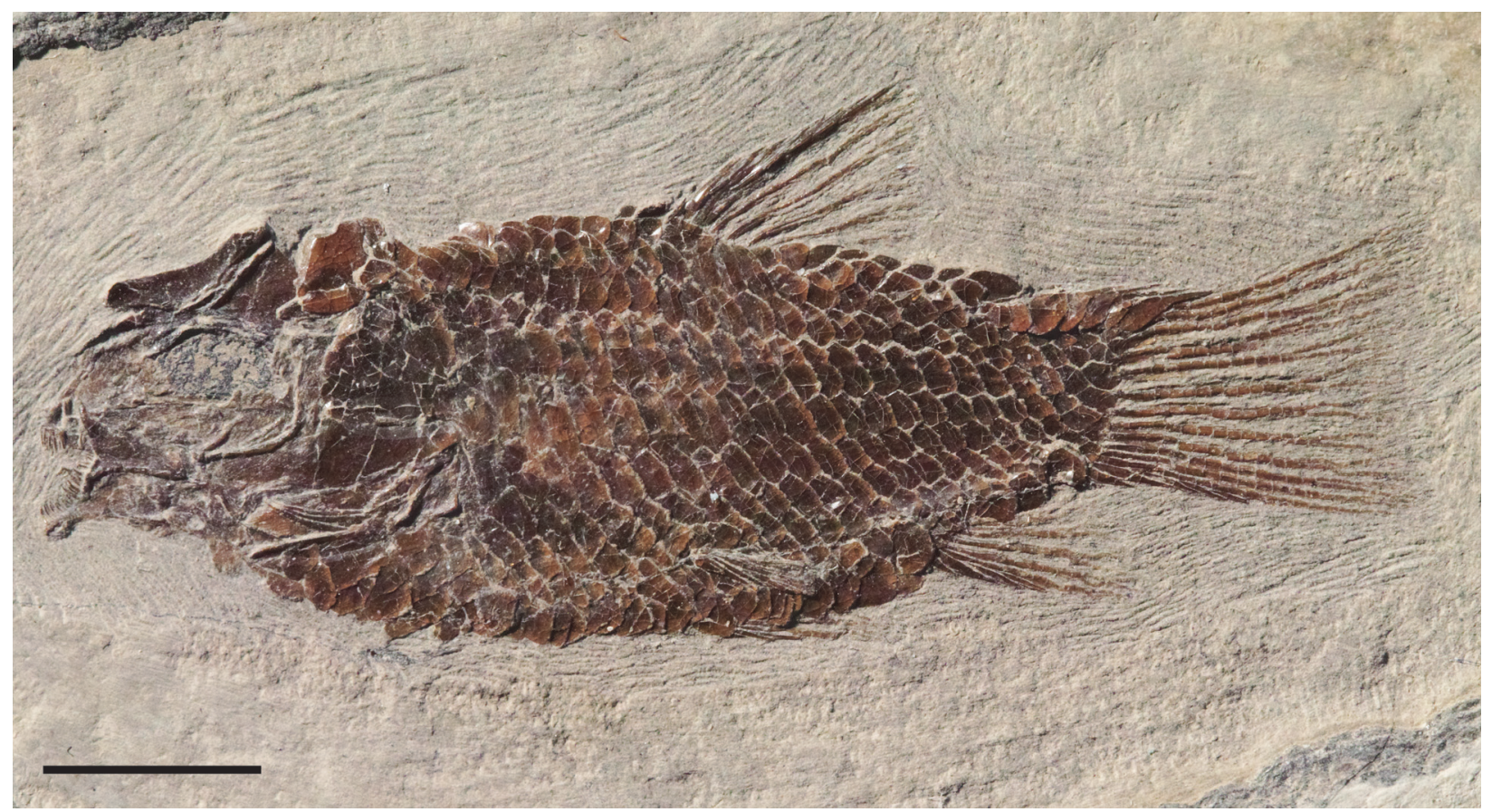

FIGURE 21. Eosemionotus minutus. Holotype MCSN $8482(25 \mathrm{~mm} \mathrm{SL})$, preserved in left lateral view. Scale bar equal $5 \mathrm{~mm}$.

present (absent in E. vogeli, E. ceresiensis and E. diskosomus n. sp.).

Pterygial formula: D11/(P5 A12 C20) T24.

\section{Description}

Only the holotype specimen (MSCN 8482) of Eosemionotus minutus $\mathrm{n}$. $\mathrm{sp}$. is known so far. Fortunately, the specimen is extraordinarily well preserved and complete. As indicated by its name, $E$. minutus $\mathrm{n}$. $\mathrm{sp}$. is notably smaller than the other species of the genus, with standard length of c. 25 $\mathrm{mm}$. The body is generally slender and the caudal fin is notably longer than in the sister species (Figure 21). Differing from the other species of Eosemionotus, the dorsal fin is opposite to the pelvic fins, originating anterior to the insertion of these fins and ending well anterior to the origin of the anal fin.

The frontal plate is deeply excavated at the orbits and forms distinct rounded and anteriorly oriented antorbital processes (Figure 22). In this species, postorbital processes are absent, and the anteromedial frontal processes are well separated, oriented parallel to each other, and tapering to a sharp acute distal end. The frontal plate is preserved in medial view and the trajectory of the supraorbital sensory canal is indicated by recurved grooves, contained by deep flat ridges. These grooves meet at the centre of the bone and diverge both anteriorly and posteriorly. Close to the posterolateral corners of the frontal plate, the grooves bifurcate in two branches towards the parietal and the temporal canal, respectively. In the parietal, the supraorbital sensory canal is represented by a very short groove or fenestra close to its anterior border.

Three small extrascapulars are preserved following the posterior border of the parietal (Figure 22). According to their shape, the most lateral extrascapular articulated with the posterior border of the dermopterotic and posteroventral border of the parietal and the other two extrascapulars articulated with the posterior border of the parietal reaching the dorsal midline. The parietals are trapezoidal, a little wider than long, with a maximal length at the lateral border equally the width at the posterior border and about 1.5 times the length of the medial border. The borders of the bone are gently curved or sinuous, the posterior and ventral border are perpendicular and the anterior border is about $60^{\circ}$ inclined with respect to the ventral border. The left dermopterotic is missing and only the anterior end of the right dermopterotic is exposed, protruding medially from the anterior border of the left parietal. Considering this exposed portion of the right dermopterotic together with the shape of the posterolateral border of the frontal plate, indicates that the posterolateral branch of the frontal supraorbital canal connected directly with the temporal canal within the anterior end of the dermopterotic and, thus, dermosphenotic bones were probably absent. 


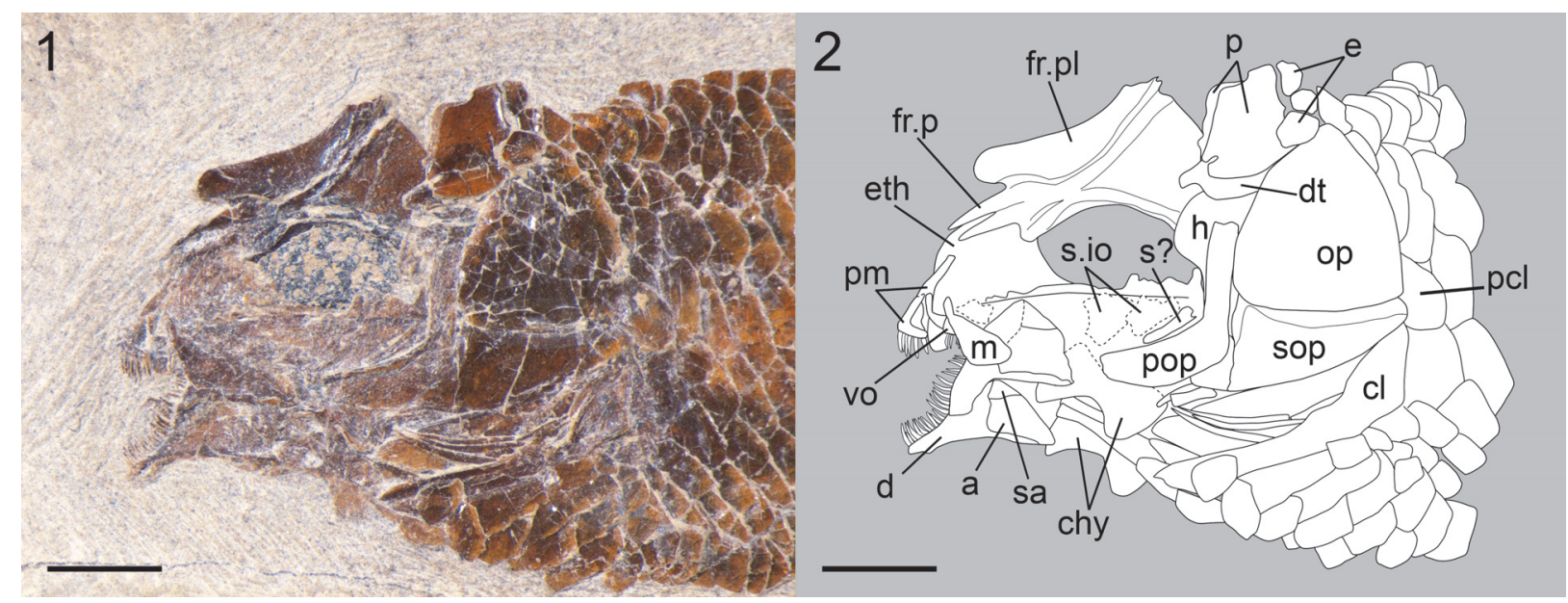

FIGURE 22. Eosemionotus minutus. Skull of the holotype MCSN 8482. 1, photograph. 2, line drawing. Scale bars equal $2 \mathrm{~mm}$.

The upper jaw is formed by the paired premaxillae and maxillae (Figure 22). There is no supramaxillary bone. The toothed portion of the premaxilla is about $32 \%$ of the length of the nasal process and bears six peg-like teeth. The long nasal process extends posterodorsally reaching the tip of the anteromedial frontal processes, though these elements are not sutured or seem to be articulating in any way. The nasal processes are very slender forming a median keel and do not contribute to the floor of the nasal pit or include an olfactory foramen.

The maxilla has a long rod-like articular process, the length of which is about $30 \%$ of the length of the maxillary plate, which is roughly triangular narrowest at the base of the articular process and deepest at the posterior end (Figure 22). Due to this triangular shape, the maxillary plate looks shallower than in the previously described species, but its maximal depth at the posterior margin is about $75 \%$ of its maximal length. The ventral and dorsal borders of the maxilla are almost straight, and the posterior border is convex. The posterodorsal and posteroventral corners of the bone are rounded. Two tiny conical teeth, much smaller than the other teeth on the jaws are preserved in the middle portion of the ventral border of the maxilla. The lower jaws are complete, but rather poorly preserved. The limits shown in Figure 22 between the dentary, angular, and surangular bones are not clear and have been interpreted based on the condition observed in the other species. The 11 slender peg-like dentary teeth are very well preserved on both the left and right dentaries.
The bones of the endocranium are poorly preserved (Figure 22). Resembling the other species of Eosemionotus, there is a large median ethmoidal ossification, but the lateral ethmoids are evidently not strongly ossified in E. minutus. The parasphenoid is partially visible, but no details can be described except for the relatively short ascending processes. Similarly, only the anteroventral toothed portion of a vomer can be identified with certainty. The bones of the palatoquadrate are not clearly discernable and in the hyoid arch only the two large anterior ceratohyals and the dorsal portion of the hyomandibula are visible. The anterior ceratohyals are hourglass-shaped, distinctly constrained in the middle. Similarly, the circumorbital bones are not preserved.

As in all other species of Eosemionotus, the preopercle is L-shaped, with the vertical arm a little longer than the horizontal arm and well separated from the dermopterotic (Figure 22). The vertical arm is uniformly broad ending in a straight dorsal border. The horizontal arm is almost two times broader than the vertical arm and has a slightly convex ventral margin. The preopercular sensory canal runs close to the anterior border of the bone. The dorsal border of the horizontal arm is strengthened forming an elongated facet, which is interpreted as an attachment area of the quadratojugal.

The opercle is only slightly deeper than long, widely ovate in shape, with convex ventral, anteroand posterodorsal borders (Figure 22). The subopercle is sickle-shaped, but with an only slightly concave dorsal border; its maximal depth is $47 \%$ of the maximal depth of the opercle. An ascending process is not visible. The interopercle is short, 


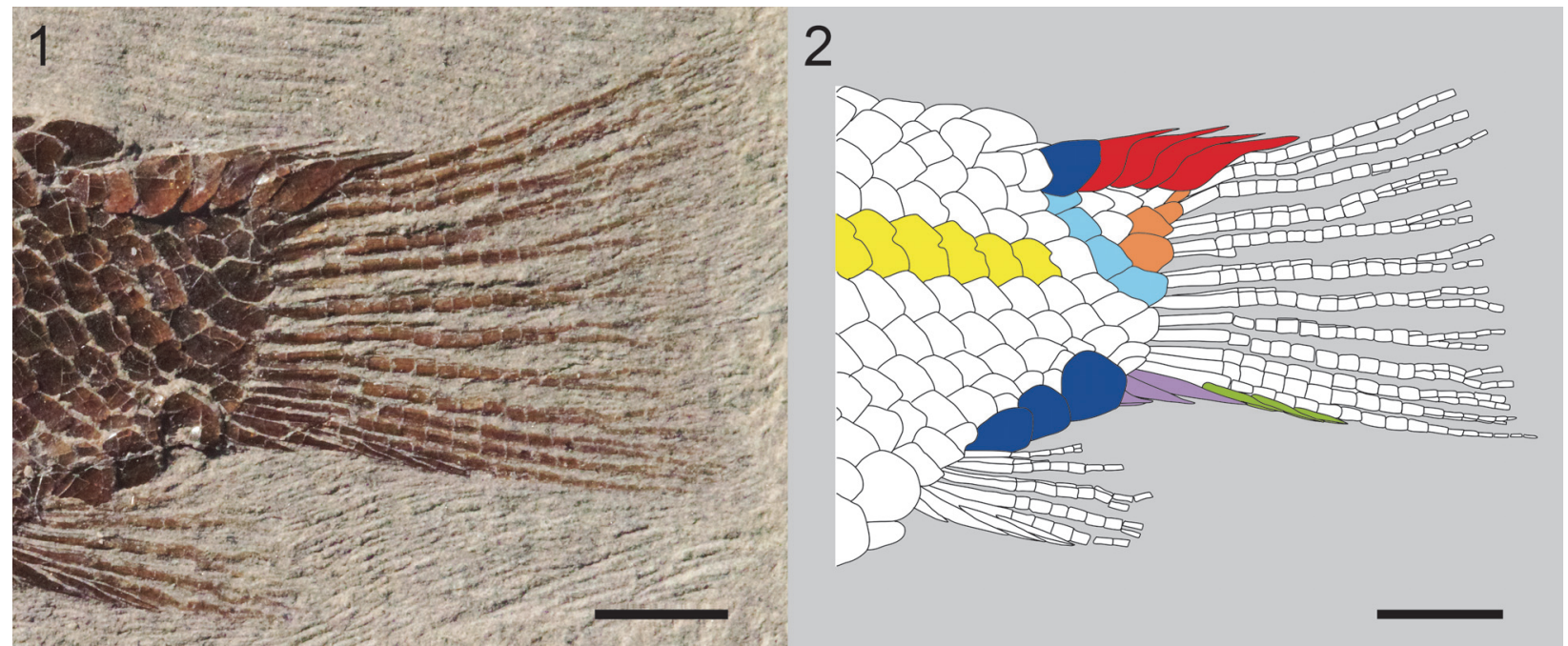

FIGURE 23. Eosemionotus minutus. Caudal fin of the holotype MCSN 8482. 1, photograph. 2, line drawing. Distinct dermal structures are indicated with colours: scales traversed by the lateral line (yellow), scales along the last vertical row at the hinge line (light blue), scales along the marginal row of the body lobe (orange), scutes (blue), dorsal caudal fulcra (red), ventral caudal fulcra (purple), fringing fulcra (green). Scale bars equal $2 \mathrm{~mm}$.

with rounded corners; it is almost 1.5 times higher than long, and its ventral length is only $35 \%$ of the length of the horizontal arm of the preopercle. Five very slender branchiostegals are preserved and these seem to represent the complete series.

The pectoral girdle is incompletely exposed, but generally the bones do not show significant differences from the bones of the pectoral girdle of $E$. diskosomus (Figure 22). The pelvic bones are not visible. The pectoral fins are too incompletely preserved. The pelvic fins insert directly behind the fifth vertical row of scales (Figure 21). There are three basal fulcra and relatively long fringing fulcra; three rays are well discernible, but the total number of rays in this fin is unknown.

The median fins are garnished with slender basal and fringing fulcra (Figure 21). The dorsal fin is placed at the middle of the body, originating directly behind the 11th vertical row of scales. There are three relatively high basal fulcra, the third of which is bearing a slender fringing fulcrum. Four additional fringing fulcra are laying on the first fin ray. The dorsal fin is small, including only six rays. The anal fin originates directly behind the 12th vertical row of scales and includes two basal fulcra followed by two slender fringing fulcra and five fin rays.

The caudal fin is hemiheterocercal with a short body lobe (Figure 23). There are four paired dorsal caudal fulcra covering the dorsal margin of the body lobe from the hinge-line to the most distal scale, and fringing fulcra are absent on the dorsalmost caudal fin ray, which is a very peculiar condi- tion of this species. There are two ventral basal fulcra and three slender fulcra fringing the ventral margin of the caudal fin. The caudal fin web is made of 12 lepidotrichia, seven of which are placed below the level of the lateral line. All caudal fin rays are segmented and branched at least once; the ventralmost ray is not branched, though its distalmost portion is missing.

There are 24 vertical rows of scales in the longitudinal series including the lateral line, which traverses 21 scales; there is an isolated pit organ in the 22nd scale and no evidence of sensory elements in the last two scales in this series (Figure 23). There are 10 scales along the vertical row directly before the origin of the dorsal fin, four scales in the last vertical row, four scales in the marginal row of the body lobe, and three scales posterodorsal to the hinge-line. There is only one large dorsal precaudal scute and a series of three large ventral precaudal scutes (Figures 21, 23).

The scales have smooth surfaces and smooth posterior borders. The lateral line scales and the scales of the horizontal row immediately ventral to them are deepened and notably deeper than the other scales of the body. Within these two rows, the anterior flank scales have a depth to width ratio of approximately 2:3. From these deepest scales, the depth of the scales decreases gradually in dorsal, ventral and posterior directions and only in the ventral portion of the caudal peduncle, below the lateral line, very few scales are approximately as long as they are deep. There are large preanal scutes, apparently one median anteriorly followed 
by a posterior pair, all three of them are almost circular and of similar size.

Remarks. Eosemionotus minutus is so far represented by a single specimen, the small size of which leads to the question of whether it represents an independent taxon or it might be representing a juvenile stage of any of the other species of Eosemionotus. However, the unique combination of characters summarized in the differential diagnosis (see also Table 1) makes it impossible to refer the specimen to any other known taxa, in particular the well-developed, long and separate anterior frontal processes. Furthermore, the fully ossified endo- (as far as visible) and exoskeleton indicates that, even when the species might have reached larger sizes, MCSN 8482 already represents the adult condition.

\section{PHYLOGENETIC ANALYSIS}

\section{Systematic position of Eosemionotus}

The phylogenetic relationships of Eosemionotus were explored through a cladistic analysis of ginglymodians (50 taxa and 192 characters). The following meristic characters were ordered a priori (additive): 130, number of branchiostegal rays; 144 , total number of principal caudal fin rays; 156 , maximal number of dorsal fin rays; 160 , maximal number of anal fin rays; 188, maximal number of premaxillary teeth; 189 , maximal number of scales in marginal row of body lobe; 190 , maximal number of scales posterodorsal to the hinge-line; 191, maximal number of dorsal caudal fulcra on the body lobe; 192, number of scales along the lateral line. Character 56, shape of the anterior portion of frontals, was ordered a posteriori, after noticing its ordered distribution in an earlier iteration of the analysis with this character unordered. The analysis resulted in 16 MPTs of 968 steps, with a consistency index $(\mathrm{Cl})$ of 0.380 and a retention index (RI) of 0.645 (both indexes calculated with Mesquite).

At a large scale, the relationships of ginglymodians in the strict consensus of the 16 MPTs (Figure 24) do not show significant differences in comparison with the results of López-Arbarello and Sferco (2018). The Middle Triassic genera Sangiorgioichthys, Ticinolepis and Kyphosichthys join the stem towards the Neoginglymodi, which includes monophyletic Lepisosteiformes and Semionotiformes. The clade Lepisosteiformes includes monophyletic Lepisosteoidei and Lepidotidae, and the clade Semionotiformes includes monophyletic Callipurbekiidae and Macrosemiidae. However, the three included species of Semionotus do not form a monophyletic group (Semionotidae in LópezArbarello and Sferco 2018) in the new topology. The new location of these taxa might be due to the inclusion of the three species of Lophionotus, which has been considered the sister taxon of Semionotus in previous cladistic analyses (Gibson, 2013b, 2016; López-Arbarello and Wencker, 2016). The inclusion of Lophionotus also produced a different location of the Early Cretaceous Neosemionotus, which was recovered as a lepisosteiform by López-Arbarello and Sferco (2018) and is now placed within Semionotiformes in agreement with Gibson (2016; also Cavin et al. 2018). Instead, in the new topology, Neosemionotus and the three species of Lophionotus are sister taxa forming a very interesting clade of freshwater fishes ranging from the Late Triassic to the Early Cretaceous, which is the sister group of all other semionotiforms.

Among the Tethyan semionotiforms, the five species of Eosemionotus form a monophyletic clade, which is the sister-group of all other macrosemiids. This sister-group relationship, as well as the monophyly of Eosemionotus and the clade formed by the other macrosemiid genera are very well supported with high Bremer and bootstrap values, and several synapomorphies. The clade Macrosemiidae, including Eosemionotus, is very strongly supported with a decay index of 8 , bootstrap value of 64 , jackknife value of 80 , and 14 unambiguous synapomorphies. Three of them are uniquely derived in macrosemiids within Ginglymodi: ch. 59(2), nasals narrow, rectangular, deeper than broad, to approximately tubular; ch. 83(1), absence of suborbital bones; ch. 91(2), premaxillary nasal processes spiniform, not enclosing the olfactory fenestra.

Also, within Ginglymodi, states 1 and 2 of character 56 are almost only found in Macrosemiidae, with ch. 56(2), anterior portion of frontals in the form of small processes, uniquely derived in Eosemionotus and ch. 56(1), anterior portion of frontals in the form of long tubular extensions, derived only the other macrosemiids and Paralepidotus ornatus. The absence of a supramaxilla might also be a unique synapomorphy of Macrosemiidae, but the condition is unknown in the closely related taxa Semionotus bergeri and $S$. capensis.

Character 6(0), the absence of longitudinal articulation of the scales of the body, is a reversal to the condition found in the stem-Neoginglymodi. Character 92(0), premaxillary nasal processes which are not sutured to the frontals is a plesiomor- 


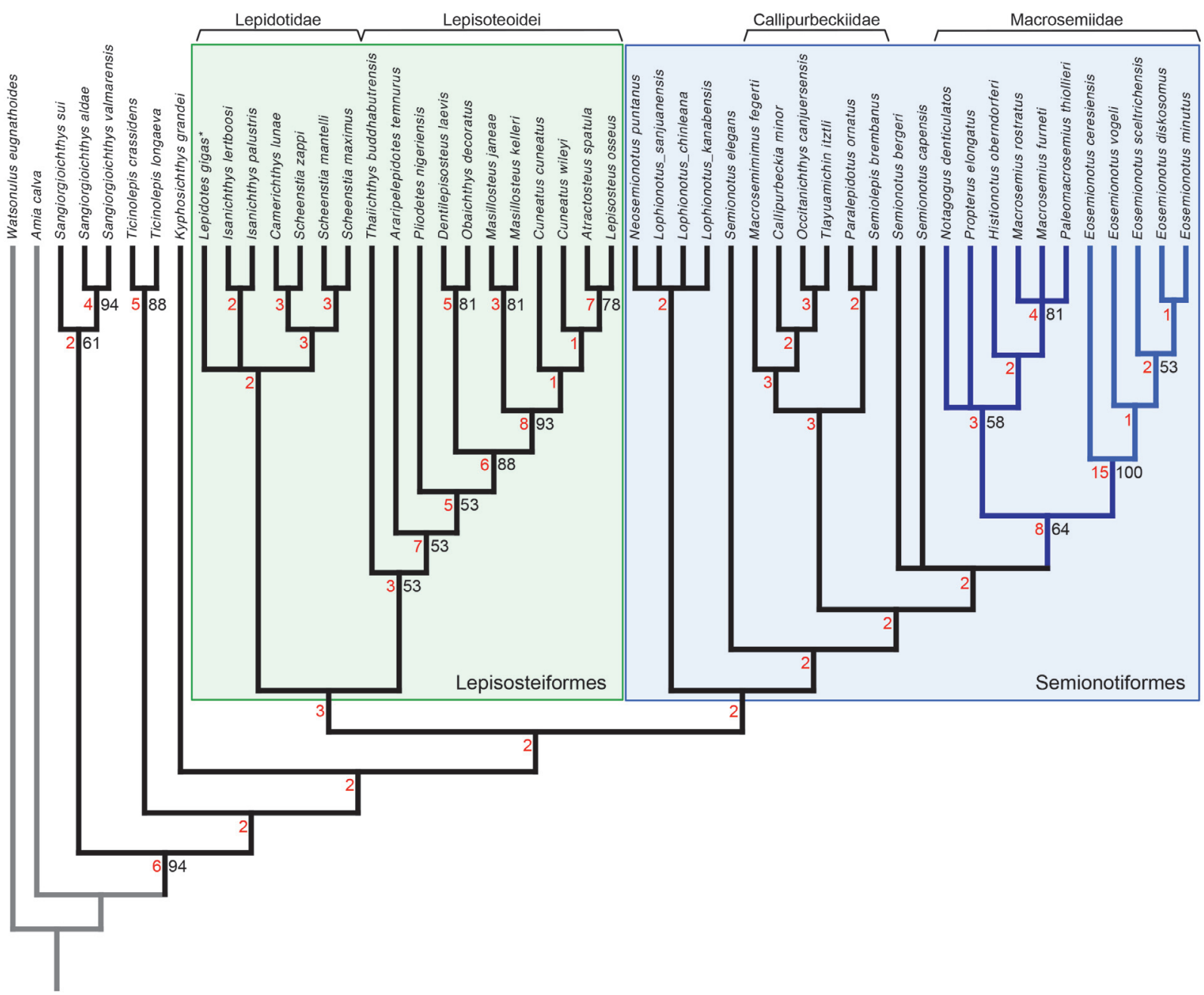

FIGURE 24. Strict consensus tree of 16 most parsimonious trees. Tree length $=968$ steps, consistency index $=0.380$ and retention index $=0.645$. Bremer indexes and bootstrap values larger than 50 are indicated with red and black numbers at the corresponding nodes, respectively. Macrosemiid branches are indicated in blue, with the branches corresponding to the five species of Eosemionotus in light blue.

phic condition among holosteans, also present in basal halecomorphs and Ticinolepis longaeva. Similarly, ch. 152(0), accessory row of scales adjacent to the ventral border of the body lobe, only occurs in Macrosemiidae within Neoginglymodi, but also in the stem taxa Sangiorgioichthys and Kyphosichthys, independently. The other synapomorphies are homoplastic: ch. 8(0), absence of dorsal ridge of scales between the skull and the dorsal fin, shared with Macrosemimimus fegerti among semionotiforms, but also Lepidotes gigas and the lepisosteoids except Thaiichthys buddhabutrensis, among lepisosteiforms, and with Ticinolepis among the stem Neogiglymodi; ch. 119(1), dorsal arm of preopercle does not reach the dermopterotic, also found in Sangiorgioichthys sui, Kyphosichthys grandei, Massillosteus kelleri, and Tlayuamichin itztli; ch. 128(1), interopercle remote from mandible, is a feature shared with the Neosemionotus-Lophionotus clade (except in L. kanabensis) and Semionotus brembanus, independently, amongst semionotiforms, and in the obaichthiids and Thaiichthys buddhabutrensis, also independently, amongst lepisosteiforms; ch. 187(1), frontal bones strongly constricted at the orbit, also occur only within Semionotiformes in Paralepidotus ornatus and Lophionotus kanabensis, independently. Finally, macrosemiids show a trend towards a reduction in some meristic features (characters 188, 190, and 191, maximal number of premaxillary teeth, scales posterodorsal to the hinge-line, and dorsal caudal fulcra, respectively), which is not mirrored in any other clade, but the dif- 
ferent character states independently occur in other terminal taxa.

The species of Eosemionotus form the best supported clade in the cladogram with a decay index of 15 , bootstrap value of 100 , jackknife value of 100 , and 18 unambiguous synapomorphies, three of which are uniquely derived in this genus (Figure 24; Appendix 3). As indicated above, ch. 56(2), anterior portion of frontals in the form of small processes, is uniquely derived in Eosemionotus. Distinctly large, deeply imbricated dorsal caudal fulcra forming a dorsal keel embracing the body lobe, ch. 151(2), is also a unique condition of Eosemionotus. Slender cleithra, without a medial wing, ch. 175(0), occur only in Amia calva and Eosemionotus among the studied taxa.

Other synapomorphies are homoplastic. Character 41(1), fusion between quadratojugal and quadrate, only occurs within Macrosemiidae, independently in Eosemionotus and Macrosemius rostratus. Widely separated nasal bones, ch. 60(2), are derived only in Eosemionotus and Sangiorgioichthys aldae among ginglymodians, and the complete absence of supraorbital bones, ch. 64(1), is only derived within Macrosemiidae in Eosemionotus and Macrosemius and Palaeomacrosemius among ginglymodians. Similarly, a median ethmoidal ossification, ch. 183(1), is known only in Eosemionotus and Histionotus oberndorferi. The fusion of the dermal bones forming the skull roof is very unusual amongst ginglymodians. So far, the fusion of the two frontals, ch. 186(1), is known only in Eosemionotus and Ticinolepis crassidens (polymorphic in this species). The relatively short frontals, with a length to width ratio lower than 3 , ch. 55(0), are widely distributed within Ginglymodi, but only occurs in Eosemionotus and the clade Neosemionotus-Lophionotus within Semionotiformes

Other homoplastic synapomorphies are: ch. $4(0)$, dermal bones of the skull smooth or very slightly ornamentated, is shared with Semionotus elegans and Neosemionotus puntanus among semionotiforms, with Isanichthyis, Thaiichthys buddhabutrensis and the lepisosteids except Atractosteus spatula, among lepisosteiforms, and with Ticinolepis crassidens among the stem-Neoginglymodi; ch. 53(1), broad parietals with a width to length ratio larger than 0.9 is shared with Histionotus oberndorferi and Semionotus elegans among semionotiforms, the feature is polymorphic in Lepidotes gigas, and it also occurs in the two species of Ticinolepis; ch. 58(0), preorbital portion of frontals less than $1 / 3$ of total length of frontal, is the plesiomorphic condition shown by the stem Neogingly- modi, which also occurs in Araripelepidotes temnurus and Pliodetes nigeriensis amongst lepisosteiforms, and the clade NeosemionotusLophionotus (except in L. kanabensis) within Semionotiformes; ch. 122(1), L-shaped preopercle, is independently derived in Lophionotus chinlea and the Lepisosteoidei; ch. 169(0), high posttemporal bones, reaching or almost reaching the dorsal midline, is the plesiomorphic condition shown by the stem Neoginglymodi, which reverses independently only in Eosemionotus and Lophionotus within that clade. Character 143(2), opercle approximately as deep as long, derives at the node Eosemionotus and reverses in the sister species $E$. diskosomus and E. minutus, and occurs independently in most lepisosteoids.

Although variable within the genus and homoplastic at the level of Ginglymodi, the low number of dorsal fin rays (10 or less; ch. 156 , states 0,1 , $3-4$ ) is uniquely derived in Eosemionotus from a much higher number of 18 rays (ch.156: $A \rightarrow 0$ ) within the Semionotiformes. The number of scales along the lateral line is also low in Eosemionotus (less than 30; ch. 192, states 4-5).

\section{Relationships between the species of Eosemionotus}

The phylogenetic relationships between the five species of Eosemionotus are fully resolved in the SCT (Figure 24). The lower Ladinian E. ceresiensis is the most basal taxon of the genus. Four unambiguous synapomorphies are shared between $E$. vogeli and the three species from the Meride Limestone: ch. 40(2), lower jaw articulation placed at the level of the centre of the orbit; ch. 109(1), edentulous maxilla; ch. 130(5), reduction in the number of branchiostegal rays from eight to seven; ch. 188(0), four premaxillary teeth. Also, four synapomorphies are shared by the species of the Meride Limestone (E. sceltrichensis, E. diskosomus, and E. minutus): ch. 130(6), further reduction in the number of branchiostegal rays from seven to six; ch. 189(8), four scales in the marginal row of the body lobe; ch. 191(7), four dorsal caudal fulcra embracing the body lobe; ch. 192(5), 20-25 scales along the lateral line.

Among the species from the Meride Limestone, despite the overall resemblance between Eosemionotus sceltrichensis and E. diskosomus, this latter taxon is more closely related to $E$. minutus than to the first species. E. diskosomus and $E$. minutus share one uniquely derived synapomorphy: ch. 174(1), sickle to L-shaped cleithrum with horizontal portion 1.5 to 2 times larger than vertical 
portion, which is a condition otherwise known in halecomorphs (López-Arbarello and Sferco 2018). Additionally, the two species share one feature that is derived uniquely in these species among semionotiforms, ch. 130(7), presence of only five branchiostegal rays, and a reversal, ch. 122(0), the opercle deeper than long.

\section{DISCUSSION}

\section{Phylogeny}

Due to the inclusion of the genus Ophiopsis in the family, the Macrosemiidae were first thought to be related to the amiiforms (see discussion in Bartram, 1977). After thorough revision of the Macrosemiidae, including extensive anatomical comparisons with halecomorphs and teleosts, Bartram (1977), according to the current ideas of neopterygian phylogeny at that time, placed the family at the base of Halecostomi. By then, Ginglymodi was limited to the Lepisosteidae and our knowledge of fossil ginglymodians was very incomplete. Our understanding of this group made an important step forward with the cladistic analysis of Olsen and McCune (1981), which resulted in a monophyletic Semionotiformes, including Semionotus, Macrosemiidae and Lepisosteidae. This clade Semionotiformes was equally retrieved as the sister group of teleosts or amiiforms, and in this hypothesis, Macrosemiidae is the sister group of Lepisosteidae.

More recent cladistic analyses have either retrieved the Macrosemiidae as the most basal Ginglymodi (Xu and Wu, 2012; Cavin et al., 2013; Deesri et al., 2014, 2016), or well nested within a monophyletic Semionotiformes to the exclusion of gars and other lepisosteiforms (López-Arbarello, 2012; López-Arbarello and Wencker, 2016; Sun and Ni, 2018; Cavin et al., 2018; López-Arbarello and Sferco, 2018). The inclusion of the five species of Eosemiontous in the cladistic analysis supports the second hypothesis encompassing two main ginglymodian subclades Lepisosteiformes and Semionotiformes, the latter including the macrosemiids.

Previous authors suggested that Eosemionotus was closely related to the Permian Acentrophorus (Bürgin, 2004) and included the genus in its own family Eosemionotidae (Bürgin et al., 2001; Bürgin, 2004). According to Bürgin (2004), Eosemionotus resembles Acentrophorus in general features, including the fused frontals, small body size, similar fin development, general pattern of squamation, the presence of basal and fringing fulcra, and the number and shape of the branchiostegal rays. However, this overall similarity is not enough evidence to support close phylogenetic relationships and the systematic position of Acentrophorus still has to be explored in a cladistic analysis. Furthermore, the numerous synapomorphies shared by Eosemionotus and the other macrosemiids are absent in Acentrophorus (Gill, 1923).

The results of our cladistic analysis strongly support the monophyly of the clade Eosemionotus and its sister-group relationships with a clade including all other macrosemiids. Including the genus Eosemionotus in the Macrosemiidae or classifying it in its own monogeneric family Eosemionotidae would be equally valid. Coining the family name Eosemionotidae Bürgin et al., 1991, was necessary to distinguish Eosemionotus from the taxa included in Semionotidae, which did not encompass macrosemiids, especially considering the relatively poor knowledge of ginglymodians at that time. However, according to our results, such a distinction of a monogeneric family is currently not necessary, and we prefer to classify Eosemionotus in the Macrosemiidae. The family name Eosemionotidae might become useful if any taxon is shown to be more closely related to Eosemionotus than to the other macrosemiids. For example, future research, including other Triassic macrosemiids (e.g., three species of Legnonotus; Egerton, 1854; Tintori and Renesto, 1983), might lead to the distinction of a family Eosemionotidae.

Eosemionotus differs from the other macrosemiid genera in several features, including the lack of 14 synapomorphies at the node directly above Eosemionotus in the macrosemiid clade: dorsal fin originating anterior to insertion of the pelvic fin and extending opposite to the anal fin (ch. 1(3)); absence of lateral ethmoid ossifications (ch. 22(1)); tubular extrascapular bones (ch. 48(1)); posterior extension of parietals median to the extrascapular bones (ch. 49(1)); length of parietals less than onethird the length of the frontals (ch. 54(2)); at least four anterior infraorbital bones (ch. 78(3)); slightly concave ventral margin of the maxilla (ch. 97(2)); posteroventral end of the dentary not particularly expanded forming a process extending beyond the coronoid process (ch. 102(0)); dentary tooth row extends over at least a third the length of the bone (ch. 111(0)); posterior border of the preopercle notched ventrally (ch. 120(1)); presence of a branchiopercle (ch. 129(1)); supraorbital sensory canal pierces the parietals (ch. 133(1)); bow-shaped dorsal fin (Macrosemius and Palaeomacrosemius), or dorsal fin divided in two sections (Propterus, 
Notagogus, Histionotus) (ch. 157(3 and 4)); anal fin bow-shaped or straight (ch. 161(2)). The posterior margin of the caudal (ch. 143) fin is concave in Eosemionotus, forked in Propterus, Notagogus, and Histionotus, and convex in Macrosemius and Palaeomacrosemius. Additionally, Eosemionotus differs from Macrosemius and Palaeomacrosemius because these genera lack fringing fulcra on the fins, except the caudal (chs. 167(1) and 180(1)).

Our new phylogenetic hypothesis does not support the monophyly of the family Semionotidae. A clade Semionotidae, including the type species of the genus Semionotus, S. bergeri Agassiz, 1832, has been retrieved in numerous cladistic analyses (López-Arbarello, 2012; Gibson, 2013b, 2016; López-Arbarello and Wencker, 2016; Sun and Ni, 2017; Cavin et al., 2018; López-Arbarello and Sferco, 2018). This clade Semionotoidae includes two additional species of Semionotus, $S$. capensis and $S$. elegans, and the three species of the genus Lophionotus. The incorporation of Eosemionotus in the cladistic analysis changed these relationships dramatically. In the new topology, $S$. bergeri, $S$. capensis, and $S$. elegans take different positions and there is neither a clade Semionotus nor a clade Semionotidae. Similarly, the genus Lophionotus is not monophyletic and its three species join Neosemionotus puntanus in a polytomy representing an unexpected clade, which is the sister-group to all other semionotiforms. The Early Creataceous $N$. puntanus from central Argentina has taken very different phylogenetic positions either as the sister-taxon to Lepisosteiformes (Sun and Ni, 2017; López-Arbarello and Sferco, 2018) or the sister-taxon of Semionotiformes (Deesri et al., 2016; Gibson, 2016; Cavin et al., 2018), or its relationships remained unresolved (López-Arbarello, 2012; Gibson, 2013b). These controversial results strongly indicate that more research is needed to achieve a more robust hypothesis of the phylogenetic relationships within Semionotiformes. Such study is beyond the scope of the present contribution.

\section{Stratigraphy and Palaeobiogeography}

The oldest named species of Eosemionotus, E. vogeli of late Anisian age (Middle Muschelkalk), is not the most basal taxon in the clade formed by the genus. Besides, E. vogeli, which is so far restricted to the Germanic Basin, is placed well nested between the species of the north-western Tethys. This pattern of relationships indicates that E. vogeli most probably evolved through dispersal from the Tethys into the Germanic Basin. Consider- ing the age of the known records of E. vogeli, migration must have occurred through the SilesianMoravian or the East Carpathian gates during the Anisian (Beutler and Szulc, 1999; Brack et al., 1999) before the opening of the Burgundy Gate in the late Anisian (Figure 25). All known records of Eosemionotus are remarkably close temporarily, but not geographically (Table 3; Figure 25), indicating a rapid dispersion during the Middle Triassic. Except for the species from Monte San Giorgio and the German Muschelkalk, all other fossils of Eosemionotus are not determined at the species level. Although not included in our analysis, besides Eosemionotus, the only other Triassic macrosemiid named taxon is Legnonotus, including three species: L. cothamensis Egerton, 1854, from Aust Cliff of Avon, UK, corresponding to the Rhaetian uppermost Westbury Formation (Gallois, 2009); L. krambergeri Bartram, 1977, from the Rhaetian of Hallein, Austria, and the Norian of Lombardy, Northern Italy (Tintori and Renesto, 1983); and $L$. obtusus Tintori and Renesto, 1983, from the Norian Zorzino Limestone in Lombardy, Northern Italy (Tintori and Lombardo, 2018). Furthermore, still undescribed macrosemiids have been reported from different stratigraphic levels of the Besano Formation and Meride Limestone of Monte San Giorgio (Bürgin, 1999). Therefore, the diversity of macrosemiids in the Western Tethys is very high and except for the three records of Eosemionotus in China (Table 3), no other Triassic macrosemiid has been reported from the Eastern Tethys so far.

Altogether, current evidence is not enough to elucidate whether the genus Eosemionotus or the clade Macrosemiidae have their origin in the Western or Eastern Tethys. They ostensibly originated and flourished rather rapidly during the Anisian and Ladinian (c. 10 m.y.a.) within the protected environments developed in the very rich marine platforms of the Tethys and dispersed from there into the Germanic Basin. This idea is further supported by the inferred palaeoecological requirements of these fishes, which most probably fed on algae, detritus, and/or small molluscs and crustaceans, and needed refuge from predators (Bartram, 1977; Bürgin, 2004), conditions that were certainly fulfilled in the tropical and subtropical marine platforms of both the Eastern and Western Tethys.

\section{CONCLUSIONS}

Confirming Bürgin's (2004) opinion, the diversity of Eosemionotus in the Middle Triassic of Monte San Giorgio is high and three new species from the Meride Limestone are here named and 


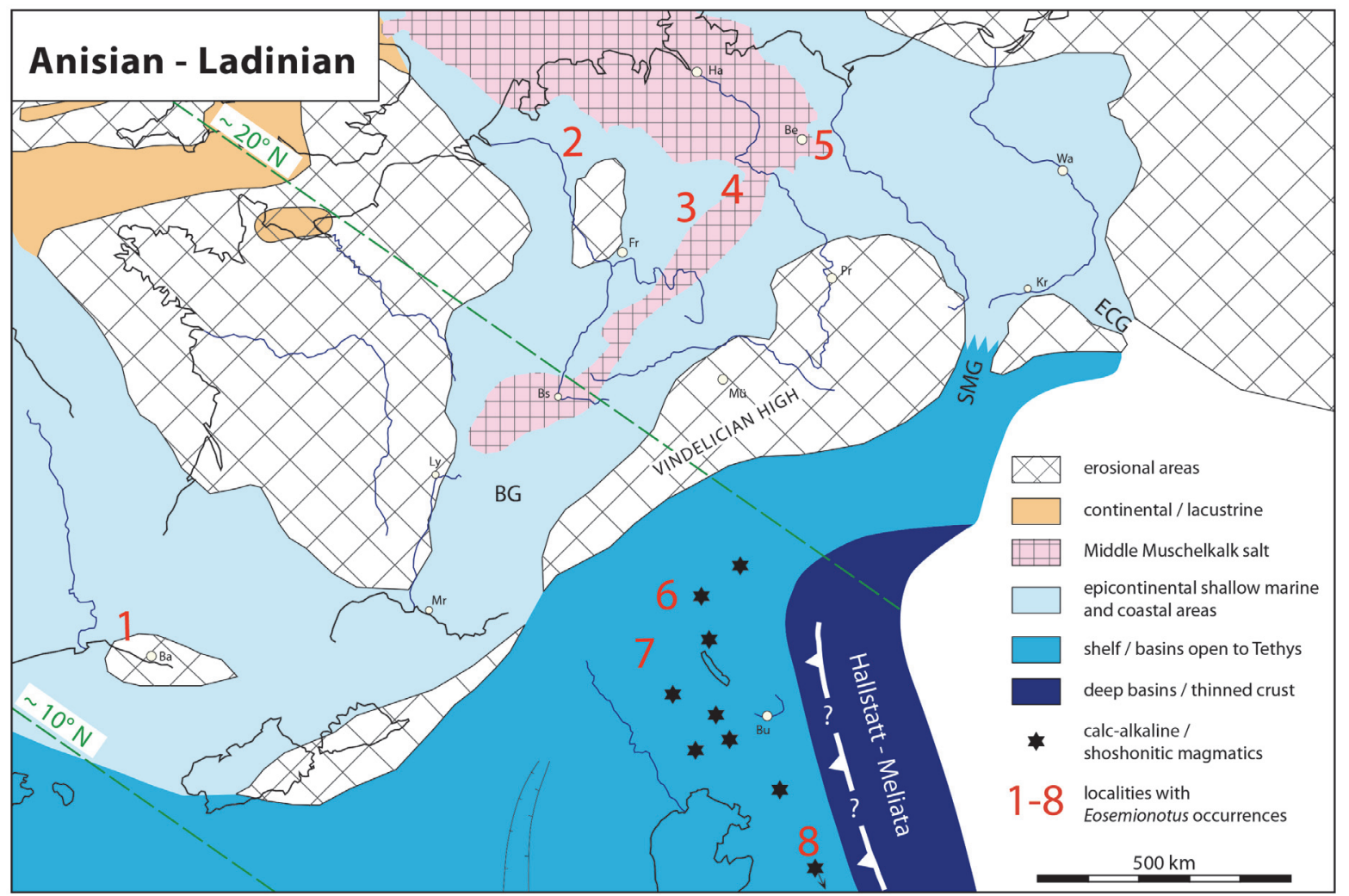

FIGURE 25. Simplified palaeogeography of the Alpine and the Germanic Triassic at the Anisian-Ladinian boundary with the Triassic position of the localities with Eosemionotus occurrences: 1 Alcover, Spain; 2 Winterswijk, The Netherlands; 3 Grebenberg, Germany; 4 Förderstedt, Germany; 5 Rüdersdorf, Germany; 6 Ducan and Landwasser areas, Switzerland; 7 Monte San Giorgio, Switzerland/Italy; 8 Velika Planina, Slovenia. BG Burgundy Gate; SMG SilesianMoravian Gate; ECG eastern Carpathian Gate (modified from Brack et al. 1999). Small letters indicate location of major cities: Ba, Barcelona; Be, Berlin; Bs, Basel; Bu, Budapest; Fr, Frankfurt am Main; Ha, Hamburg; Kr, Cracow; Ly, Lyon; Mr, Marseilles; Mü, Munich; Pr, Prague; Wa, Warsaw.

described: E. diskosomus, E. sceltrichensis, and E. minutus. Additional new species might be present in coeval sediments of the Prosanto Formation in the Ducan and Landwasser areas near Davos, Canton Graubünden, Switzerland (Bürgin et al., 1991; Bürgin, 1999; Herzog, 2003). Also, in agreement with previous ideas (Stolley, 1920; Schultze and Möller, 1984; Bürgin, 2004), Eosemionotus is a close relative of Semionotus and a member of the Semionotiformes. However, differing from previous hypotheses, Eosemionotus is more closely related to the macrosemiids than to any species of Semionotus, which lack the numerous synapomorphies of the macrosemiid clade. Pending further studies on Triassic macrosemiids, which might indicate the need to distinguish a family Eosemionotidae, according to the results of this study Eosemionotus is classified in the family Macrosemiidae within the order Semionotiformes.

A brief look at the palaeogeographic and stratigraphic context around the known fossil records of Eosemionotus indicate that the Muschelkalk species $E$. vogeli originated through dispersal of the genus from the Tethys into the Germanic Basin, most probably across the Silesian-Moravian or the East Carpathian gates before the late Anisian. Pending the taxonomic and phylogenetic study of the other known material of Eosemionotus and other Triassic macrosemiids, the origin of the genus and the family in the Western or Eastern Tethys cannot be established with certainty.

\section{ACKNOWLEDGEMENTS}

The excellent preparation of the fossil specimens has been done by A. Ceola, M. Hebeisen, and H. Lanz (all PIMUZ), C. Obrist (Rickenbach BL), and S. Rampinelli, H. Lanz, U. Oberli, L. Zulliger, and F. Magnani (MCSN). G. Aguirre (PIMUZ) helped with the illustrations. Special thanks are due to P. Brack, H. Hagdorn, and O. Rauhut for discus- 
TABLE 3. Fossil record of Eosemionotus.

\begin{tabular}{|c|c|c|c|}
\hline Taxonomy & Stratigraphic provenance & Geographic provenance & Reference \\
\hline Eosemionotus sp. & Carnian, Pyrenean basin & Vilanova de la Sal, Lleida, Spain & Fortuny et al., 2011 \\
\hline Eosemionotus sp. & $\begin{array}{l}\text { upper Ladinian, Falang Fm. (Zhuganpo } \\
\text { Member) }\end{array}$ & $\begin{array}{l}\text { Changdi, Luoping, Yunnan, } \\
\text { China }\end{array}$ & Jin, 2006 \\
\hline Eosemionotus sp. & upper Ladinian, Alcover unit & Alcover, Tarragona, Spain & Cartanyà, 1999 \\
\hline $\begin{array}{l}\text { E. ceresiensis, } \\
\text { E. diskosomus, } \\
\text { E. sceltrichensis, } \\
\text { E. minutus }\end{array}$ & Ladinian, Meride Limestone & $\begin{array}{l}\text { Several localities, Monte San } \\
\text { Giorgio, Switzerland }\end{array}$ & this work \\
\hline Eosemionotus sp. & lower Ladinian, Prosanto Fm. & $\begin{array}{l}\text { Ducan and Landwasser areas, } \\
\text { Graubünden, Switzerland }\end{array}$ & $\begin{array}{l}\text { Bürgin et al., 1991; } \\
\text { Herzog, } 2003\end{array}$ \\
\hline $\begin{array}{l}\text { E. ceresiensis, } \\
\text { E. diskosomus }\end{array}$ & lowermost Ladinian, Besano Fm. & $\begin{array}{l}\text { Several localities, Monte San } \\
\text { Giorgio, Switzerland }\end{array}$ & Bürgin, 2004; this work \\
\hline Eosemionotus sp. & $\begin{array}{l}\text { upper Anisian, Guanling Fm. (Member } \\
\text { II) }\end{array}$ & Xinmin, Panxian, Guizhou, China & Jin, 2006 \\
\hline E. vogeli & $\begin{array}{l}\text { upper Anisian, Diemel Fm. (Middle } \\
\text { Muschelkalk) }\end{array}$ & $\begin{array}{l}\text { Grebenberg bei Angerstein, } \\
\text { Germany }\end{array}$ & Schultze and Möller, 1986 \\
\hline E. vogeli & $\begin{array}{l}\text { upper Anisian, Heilbronn Formation, } \\
\text { 'blaue Fischmergel' of Rüdersdorf } \\
\text { (Middle Muschelkalk) }\end{array}$ & Rüdersdorf bei Berlin, Germany & $\begin{array}{l}\text { Siegel and Wischnewsky, } \\
\text { 2017; this work }\end{array}$ \\
\hline E. vogeli & $\begin{array}{l}\text { upper Anisian, Karlstadt Fm. (Middle } \\
\text { Muschelkalk) }\end{array}$ & $\begin{array}{l}\text { Förderstedt bei Staßfurt, } \\
\text { Germany }\end{array}$ & Fritsch, 1906 \\
\hline Eosemionotus sp. & upper Anisian, Strelovec Fm. & $\begin{array}{l}\text { Robanov kot valley, Kamnik- } \\
\text { Savinja Alps, Slovenia }\end{array}$ & Miklavc et al., 2016 \\
\hline Eosemionotus sp. & middle Anisian, Velika Planina Horizon & Kamnik-Savinja Alps, Slovenia & Hitij et al., 2010 \\
\hline Eosemionotus sp. & $\begin{array}{l}\text { middle Anisian, Upper Member, } \\
\text { Guanling Fm. }\end{array}$ & Dawazi site, Yunnan, China & Sun et al., 2009 \\
\hline Eosemionotus sp. & $\begin{array}{l}\text { middle - upper Anisian, Vossenveld } \\
\text { Fm. (Lower Muschelkalk) }\end{array}$ & $\begin{array}{l}\text { Steen- en Kalkgroeve } \\
\text { Winterswijk, The Netherlands }\end{array}$ & $\begin{array}{l}\text { Oosterink and Poppe, } \\
\text { 1979; Hagdorn and } \\
\text { Simon, 2010; Maxwell et } \\
\text { al., } 2016\end{array}$ \\
\hline
\end{tabular}

sions and assistance during the work and to Max Kuhn (Uster) for his permanent support to our research. We thank A. Gehler (GZG), N. Hauschke (IGWuG), J. Kriwet (University of Vienna), and T. Schossleitner and F. Witzman (MB.f) for their assistance and access to specimens under their care. Thanks are extended to three reviewers, I.
Kogan, G. Xu, and an anonymous referee, and the editor L. Wilson, for their helpful comments and suggestions. This study has been funded by the German Research Foundation through grant L01405/5-1 to A. López-Arbarello and by the Canton Ticino through the Museo Cantonale di Storia Naturale (Lugano).

\section{REFERENCES}

Arambourg, C. and Bertin, L. 1958. Super-ordre des Holostéens et des Halecostomi (Holostei et Halecostomi), p. 2173-2203. In Grassé, P.P. (ed.), Traité de Zoologie: Anatomie, Systématique, Biologie, 13 ed. Masson et Cie, Paris.

Bartram, A.W.H. 1977. The Macrosemiidae, a Mesozoic family of holostean fishes. Bulletin of the British Museum (Natural History), Geology, 29:137-234.

Beutler, G. and Szulc, J. 1999. Die paläogeographische Entwicklung des Germanischen Beckens in der Trias und die Verbindung zur Tethys, p. 81-80. In Hauschke, N. and Wilde, V. (eds.), Trias - Eine ganz andere Welt. Verlag Dr. Friedrich Pfeil, München. 
Brack, P., Rieber, H., and Urlichs, M. 1999. Pleagic successions in the Southern Alps and their correlation with the Gemanic Middle Triassic. Zentralblatt für Geologie und Paläontologie, Teil I, 1998/7-8:853-876.

Bürgin, T. 1998. Pesci fossili del Triassico medio del Monte San Giorgio (Svizzera meridionale) e della zona di Besano (Italia settentrionale). Geologia Insubrica, 3:1-9.

Bürgin, T. 1999. Middle Triassic marine fish faunas from Switzerland, p. 481-494. In Arratia, G. and Schultze, H.-P. (eds.), Mesozoic Fishes 2 - Systematics and Fossil Record. Verlag Dr. Friedrich Pfeil, München.

Bürgin, T. 2004. †Eosemionotus ceresiensis sp. nov., a new semionotiform fish (Actinopetygii, Halecostomi) from the Middle Triassic of Monte San Giorgio (Southern Switzerland), 239251. In Arratia, G. and Tintori, A. (eds.), Mesozoic Fishes 3 - Systematics, Pleoenvironments and Biodiversity. Verlag Dr. Friedrich Pfeil, München.

Bürgin, T., Eichenberger, U., Furrer, H., and Tschanz, K. 1991. Die Prosanto-Formation - eine fischreiche Fossil-Lagerstätte in der Mitteltrias der Silvretta-Decke (Kanton Graubünden, Schweiz). Eclogae Geologicae Helvetiae, 84:921-990. https://doi.org/10.5169/seals-166804

Cartanyà, J. 1999. An overview of the Middle Triassic actinopterygians from Alcover, Montral and El Pinetell (Catalonia, Spain), p. 535-551. In Arratia, G. and Schultze, H.-P. (eds.), Mesozoic Fishes 2 - Systematics and Fossil Record. Verlag Dr. Friedrich Pfeil, München.

Cavin, L., Deesri, U., and Suteethorn, V. 2013. Osteology and relationships of Thaiichthys nov. gen.: a Ginglymodi from the Late Jurassic-Early Cretaceous of Thailand. Palaeontology, 56(1), 183-208. https://doi.org/10.1111/j.1475-4983.2012.01184.x

Cavin, L., Deesri, U., Veran, M., Khentavong, B., Jintasakul, P., Chanthasit, P., and Allain, R. 2018. A new Lepisosteiformes (Actinopterygii: Ginglymodi) from the Early Cretaceous of Laos and Thailand, SE Asia. Journal of Systematic Palaeontology, 1-15. https://doi.org/ 10.1080/14772019.2018.1426060

Cope, E. 1887. Zittel's manual of palaeontology. American Naturalist, 21:e1019.

Cope, E.D. 1871. Observations on the systematic relations of the fishes. The American Naturalist, 5:579-593. https://doi.org/10.1086/270831

Deecke, W. 1926. Uber die Triasfische. Paläontologische Zeitschrift, 8:184-198. https://doi.org/ $10.1007 / \mathrm{bf03160419}$

Deesri, U., Lauprasert, K., Suteethorn, V., Wongko, K., and Cavin, L. 2014. A new species of the ginglymodian fish Isanichthys from the Late Jurassic Phu Kradung Formation, northeastern Thailand. Acta Palaeontologica Polonica, 59(2): 313-331. https://doi.org/10.4202/ app.2012.0013

Deesri, U., Jintasakul, P., and Cavin, L. 2016. A new Ginglymodi (Actinopterygii, Holostei) from the Late Jurassic-Early Cretaceous of Thailand, with comments on the early diversification of Lepisosteiformes in Southeast Asia. Journal of Vertebrate Paleontology, 36(6): e1225747. https://doi.org/10.1080/02724634.2016.1225747

Ebert, M., Lane, J.A., and Kolbl-Ebert, M. 2016. Palaeomacrosemius thiollieri, gen. et sp. nov., a new Macrosemiidae (Neopterygii) from the Upper Jurassic of the Solnhofen Archipelago (Germany) and Cerin (France), with a revision of the genus Macrosemius. Journal of Vertebrate Paleontology, 36:e1196081. https://doi.org/10.1080/02724634.2016.1196081

Egerton, P.G. 1854. On some new genera and species of fossil fishes: To the editors of the Annals of Natural History. Annals and Magazine of Natural History, 13:433-436. https:// doi.org/10.1080/03745485709495100

Fortuny, J., Bolet, A., Sellés, A.G., Cartanyà, J., and Galobart, À. 2011. New insights on the Permian and Triassic vertebrates from the Iberian Peninsula with emphasis on the Pyrenean and Catalonian basins. Journal of Iberian Geology, 37:65-86. https://doi.org/10.5209/ rev_JIGE.2011.v37.n1.5

Fritsch, K. 1906. Beiträge zur Kenntnis des Untergrundes von Lüneburg. Abh naturforsch Ges Halle, 24:217-285.

Gallois, R.W. 2009. The lithostratigraphy of the Penarth Group (late Triassic) of the Severn Estuary area. Goscience in South-West England 12:71-84.

Gibson, S.Z. 2013a. A new hump-backed ginglymodian fish (Neopterygii, Semionotiformes) from the Upper Triassic Chinle Formation of Southeastern Utah. Journal of Vertebrate Paleontology, 33:1037-1050. https://doi.org/10.1080/02724634.2013.758125

Gibson, S.Z. 2013b. Biodiversity and evolutionary history of †Lophionotus (Neopterygii: †Semionotiformes) from the western United States. Copeia 2013:582-603. https://doi.org/ $10.1643 / \mathrm{ci}-12-028$ 
Gibson, S.Z. 2016. Redescription and phylogenetic placement of †Hemicalypterus weiri Schaeffer, 1967 (Actinopterygii, Neopterygii) from the Triassic Chinle Formation, southwestern United States: New insights into morphology, ecological niche, and phylogeny. Plos One, 11:23. https://doi.org/10.1371/journal.pone.0163657

Giles, S., Xu, G.H., Near, T.J., and Friedman, M. 2017. Early members of 'living fossil' lineage imply later origin of modern ray-finned fishes. Nature, 549:265. https://doi.org/10.1038/ nature23654

Gill, E.L. 1923. The Permian fishes of the genus Acentrophorus. Proceedings of the Zoological Society of London, 93:19-40. https://doi.org/10.1111/j.1096-3642.1923.tb02170.x

Goloboff, P.A., Farris, J.S., and Nixon, K.C. 2008. TNT, a free program for phylogenetic analysis. Cladistics, 24:774-786. https://doi.org/10.1111/j.1096-0031.2008.00217.x

Grande, L. 2010. An empirical synthetic pattern study of gars (Lepisosteiformes) and closely related species, based mostly on skeletal anatomy. The resurrection of Holostei. American Society of Ichthyologists and Herpetologists, Special Publication, 10(2A):1-871.

Grande, L., and Bemis, W.E. 1998. A comprehensive phylogenetic study of amiid fishes (Amiidae) based on comparative skeletal anatomy: An empirical search for interconnected patterns of natural history. Memoirs of the Society of Vertebrate Paleontology, 4:I-X, 1-690. https://doi.org/10.2307/3889331

Hagdorn, H. and Simon, T.H. 2010. Vossenveld-Formation. LithoLex, Lithostratigraphisches Lexikon der Deutschen Stratigraphischen Kommission.

Herzog, A. 2003. Die Knochenfische der Prosanto-Formation (Mitteltrias, GR) - Systematik, Funktionsmorphologie und Paläoökologie. Unpublished PhD Thesis. Universität Zürich, Switzerland.

Hitij, T., Žalhohar, J., Celarc, B., Križnar, M., Renesto, S., and Tintori, A. 2010. The kingdom of the Tethys: The fossilized world of Triassic vertebrates from the Kamniško-Savinjske Alps. Scopolia, Suppl. 5:1-197.

Huxley, T.H. 1861. Preliminary Essay upon the Systematic Arrangement of the Fishes of the Devonian Epoch. Longman, Green, Longman, and Roberts, London.

Jin, F. 2006. An overview of Triassic fishes from China. Vertebrata PalAsiatica, 44:28-42.

Lehman, J.P. 1966. Traité de Paléontologie. Tome IV: L'origine des Vertébrés. Leur Expansion dans les Eaux Douces et le Milieu Marin. Volume 3: Actinoptérygiens, Crossoptéragiens, Dipneustes. Masson et Cie, Paris.

López-Arbarello, A. 2012. Phylogenetic interrelationships of ginglymodian fishes (Actinopterygii: Neopterygii). Plos One, 7. https://doi.org/10.1371/journal.pone.0039370

López-Arbarello, A. and Codorniú, L. 2007. Semionotids (Neopterygii, Semionotiformes) from the Lower Cretaceous Lagarcito Formation, San Luis Province, Argentina. Journal of Vertebrate Paleontology, 27:811-826. https://doi.org/10.1671/02724634(2007)27[811:snsft] 2.0.co;2

López-Arbarello, A. and Sferco, E. 2018. Neopterygian phylogeny: the merger assay. Royal Society Open Science, 5:172337. https://doi.org/10.1098/rsos.172337

López-Arbarello, A. and Wencker, L.C.M. 2016. New callipurbeckiid genus (Ginglymodi: Semionotiformes) from the Tithonian (Late Jurassic) of Canjuers, France. Paläontologische Zeitschrift, 90:543-560. https://doi.org/10.1007/s12542-016-0312-x

López-Arbarello, A., Bürgin, T., Furrer, H., and Stockar, R. 2016. New holostean fishes (Actinopterygii: Neopterygii) from the Middle Triassic of the Monte San Giorgio (Canton Ticino, Switzerland). PeerJ, 4:61. https://doi.org/10.7717/peerj.2234

Maddison, W.P. and Maddison, D.R. 2017. Mesquite: a modular system for evolutionary analysis. Version $3.31 \mathrm{http}: / /$ mesquiteproject.org.

Matthews, S.C. 1973. Notes on open nomenclature and on synonymy lists. Palaeontology, 16:713-719. https://www.palass.org/sites/default/files/media/publications/palaeontology/ volume_16/vol16_part4_pp713-719.pdf

Maxwell, E.E., Diependaal, H., Winkelhorst, H., Goris, G., and Klein, N. 2016. A new species of Saurichthys (Actinopterygii: Saurichthyidae) from the Middle Triassic of Winterswijk, The Netherlands. Neues Jahrbuch für Geologie und Palantologie - Abhandlunge, 280:119-134. https://doi.org/10.1127/njgpa/2016/0569

Miklavc, P., Celarc, B., and Šmuc, A. 2016. Anisian Strelovec Formation in the Robanov kot, Savinja Alps (Northern Slovenia). Geologija, 59:23-34. https://doi.org/10.5474/ geologija.2016.002 
Müller, J. 1844. Über den Bau und die Grenzen der Ganoiden, und über das natürliche System der Fische. Bericht Akademie der Wissenschaften Berlin, 1844:416-422.

Mundil, R., Palfy, J., Renne, P.R., and Brack, P. 2010. The Triassic timescale: new constraints and a review of geochronological data. In Lucas, S.G. (ed.), The Triassic Timescale. Special Publications of the Geological Society of London, 334:41-60. https://doi.org/10.1144/SP334.3

Obruchev, D.V. 1964. Osnovy paleontologii 2, Beschelyustnye, ryby. Izd. Nankâ, Moskow.

Olsen, P.E. and McCune, A.R. 1991. Morphology of the Semionotus elegans species group from the Early Jurassic part of the Newark Supergroup of Eastern North America with comments on the family Semionotidae (Neopterygii). Journal of Vertebrate Paleontology, 11(3): 269292. https://doi.org/10.1080/02724634.1991.10011398

Oosterink, H.W. and Poppe, W. 1979. Vissen en visresten uit de Onder-Muschelkalk van Winterswijk. Grondboor en Hamer, 3:95-112.

Patterson, C. 1982. Morphology and interrelationships of primitive actinopterygian fishes. American Zoology, 22:241-259. http://www.jstor.org/stable/3882658

Poyato-Ariza, F.J., Buscalioni, A.D., and Cartanyà, J. 1999. The Mesozoic record of osteichthyan fishes from Spain, p. 505-533. In Arratia, G. and Schultze, H.-P. (eds.), Mesozoic Fishes 2 Systematics and Fossil Record. Verlag Dr. Friedrich Pfeil, München.

Regan, C.T. 1923. The skeleton of Lepidosteus, with remarks on the origin and evolution of the lower neopterygian fishes. Proceedings of the Zoological Society of London, 1923:445-461. https://doi.org/10.1111/j.1096-3642.1923.tb02191.x

Schultze, H.-P. and Kriwet, J. 1999. Die Fische der Germanischen Trias, p. 239-250. In Hauschke, N. and Wilde, V. (eds.), Trias - Eine ganz andere Welt. Verlag Dr. Friedrich Pfeil, München.

Schultze, H.-P. and Möller, H. 1986. Wirbeltierreste aus dem Mittleren Muschelkalk (Trias) von Göttingen, West-Deutschland. Paläontologische Zeitschrift, 60:109-129. https://doi.org/ 10.1007/bf02989426

Schmidt, M. 1928. Die Lebewelt unserer Trias. Hohenlohesche Busvhhandlung Ferdinand Rau, Öhringen.

Schmidt, M. 1938. Die Lebewelt unserer Trias. Nachtrag. Hohenlohesche Busvhhandlung Ferdinand Rau, Öhringen.

Siegel, F. and Wischnewsky, L. 2017. Der „blaue Fischmergel“ von Rüdersdorf. Fossilien, Journal für Erdgeschichte, 34(6):4-14.

Stockar, R. 2010. Facies, depositional environment, and palaeoecology of the Middle Triassic Cassina beds (Meride Limestone, Monte San Giorgio, Switzerland). Swiss Journal of Geosciences, 103:101-119. https://doi.org/10.1007/s00015-010-0008-2.

Stockar, R., Baumgartner, P.O., and Condon, D. 2012. Integrated Ladinian biochronostratigraphy and geochrononology of Monte San Giorgio (Southern Alps, Switzerland). Swiss Journal of Geosciences, 105:85-108. https://doi.org/10.1007/s00015012-0093-5.

Stockar, R. and Kustatscher, E. 2010. The Ladinian flora from the Cassina beds (Meride Limestone, Monte San Giorgio, Switzerland): preliminary results. Rivista Italiana di Paleontologia e Stratigrafia, 116:173-188. https://doi.org/10.13130/2039-4942/5948

Stolley, E. 1920. Beiträge zur Kenntnis der Ganoiden des deutschen Muschelkalks. Palaeontographica Abteilung A, 63:25-96.

Sun, Z. and Ni, P. 2018. Revision of Kyphosichthys grandei Xu and Wu, 2012 from the Middle Triassic of Yunnan Province, South China: implications for phylogenetic interrelationships of ginglymodian fishes. Journal of Systematic Palaeontology, 16(1):67-85. https://doi.org/ 10.1080/14772019.2016.1269049

Sun, Z., Tintori, A., Jiang, D., Lombardo, C., Rusconi, M., Hao, W., and Sun, Y. 2009. A new perleidiform (Actinopterygii, Osteichthyes) from the Middle Anisian (Middle Triassic) of Yunnan, South China. Acta Geologica Sinica-English Edition, 83:460-470. https://doi.org/ 10.1111/j.1755-6724.2009.00067.x

Thiollière, V. 1858. Note sur les poissons fossiles du Bugey, et sur l'application de la méthode de Cuvier à leur classement. Bulletin De La Societe Geologique De France, 15:782-793.

Tintori, A. and Lombardo, C. 2018. The Zorzino Limestone actinopterygian fauna from the Late Triassic (Norian) of the southern Alps, p. 315-350. In Tanner, L.H. (ed.), The Late Triassic World: Earth in a Time of Transition, Topics in Geobiology 46. Springer, New York. https:// doi.org/10.1007/978-3-319-68009-5_9 
Tintori, A. and Renesto, S. 1983. The Macrosemiidae (Pisces, Actinopterygii) from the Upper Triassic of Lombardy (N. Italy). Rivista Italiana di Paleontologia e Stratigrafia, 89:209-222.

Wenz, S. 1999. †Pliodetes nigeriensis, gen. nov. et. sp. nov., a new semionotid fish from the Lower Cretaceous of Gadoufaoua (Niger Republic): phylogenetic comments, p. 107-120. In Arratia, G. and Schultze, H.-P. (eds.), Mesozoic Fishes 2 - Systematics and Fossil Record. Verlag Dr. Friedrich Pfeil, München.

Wenz, S. 2003. Lepidotes fishes (Actinopterygii, Semionotiformes) from the Lower Cretaceous (Barremian) of Las Hoyas (Cuenca Province, Spain). Geodiversitas, 25:481-499.

Westoll, T.S. 1944. The Haplolepidae, a new family of Late Carboniferous bony fishes. A study in taxonomy and evolution. Bulletin of the American Museum of Natural History, 83:1-121. https://doi.org/10.1086/an.78.779.2458295

Woodward, A.S. 1890. The fossil fishes of the Hawkesbury series at Gosford. Memoirs of the Geological Survey of New South Wales, Palaeontology, 4:1-55. https://doi.org/10.1080/ 00222939008694061

Xu, G. and Wu, F. 2012. A deep-bodied ginglymodian fish from the Middle Triassic of eastern Yunnan Province, China, and the phylogeny of lower neopterygians. Chinese Science Bulletin, 57(1):111-118. https://doi.org/10.1007/s11434-011-4719-1 


\section{APPENDIX 1}

Data matrix to "Taxonomy and phylogeny of Eosemionotus Stolley, 1920 (Neopterygii: Ginglymodi) from the Middle Triassic of Europe"

A nexus file including the complete data matrix is freely available in the MorphoBank (www.morphobank.org; Project 3211). The character matrix was compiled with the software Mesquite version 3.2 (Maddison and Maddison, 2017). Accordingly, the symbols $0-9$ and $\mathrm{A}-\mathrm{H}$ have been used for those multistate characters with more than 10 different states. Polymorphisms (e.g., state 0 and 2) are indicated by $0 \& 2$ in the nexus file available in Morphobank, but by "(0/2)" in this text file. A question mark "?" is used for completely unknown states and the dash symbol "-" indicates that a character is inapplicable to that taxon.

\section{Watsonulus eugnathoides}

10010??0--

0001000?100011000001100?1000100210100000?012011001?0001200300008020---020-----$0001010112110100000000001-$

00000?2?0101010000?00????01?0?0?20???0B???????00?000?1??2113000000-0005???0

Amia calva

300------0110110111000120010-10000100010-21022000210010010002101----1003(0/1)2020---

021-----11010100131001000000000020-0000121111011101000022010132020021-20-

F20172113301-000001011011000-0004????

Araripelepidotes temnurus

20110120-

121210?110000?3?????????2000??0?2???01004?001000051?0?012134002111010?00?020

00000??0221000100-?????1---??---

000004121100?02130?00?????322?100022201???3??0212021101???0??00000??00?3131

Atractosteus spatula

40011110-02110-1111-112211--

11101401111401033220040100110141011012114112031013011203020000111-------

002111101100043011000000300

0902100112211013232100022204200520011002200112106000110-200-???0

Callipurbeckia minor

000201211?2?????????0?1?100?0????10000030?04??0004??021101513100110030001700

122003010010-01101432001110110?00001??21-

00000113110?501000????????3?1?1010120070004?102?202110102?14?000000-0032233

Camerichthys lunae

00?1???10??????????????????????????00??1???????????????101????001201?0?21700

13210303100010??01430?01?101?0???0012?20-0-

010?110100?0?????????????????????????????????????????????????000??00?????

Cuneatus cuneatus

40000??0-?211??111??112211--10-

0140111130103??1004??030101410110121140?2031211011?03020000111-------

?0211??2?0000?3011?0010?200-

090?????12?1??1323?100022201??02???111022?0??????100110-200-???2 
LÓPEZ-ARBARELLO ET AL.: SYSTEMATICS OF EOSEMIONOTUS

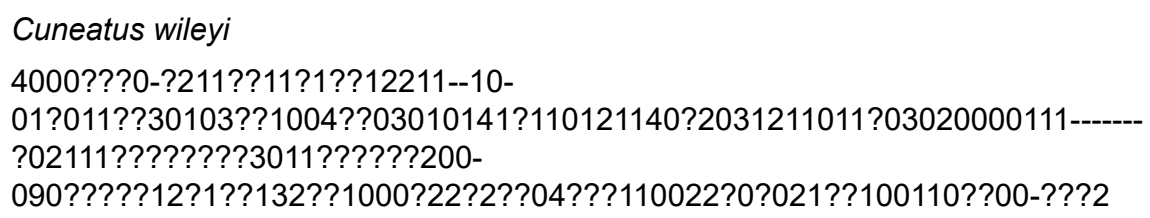


301100---?21010110?0?1?210010??0?1100004130??2011-??021201213101----

300017041300051------200141000?0001100000003320-011004111111400131-

010???1321?1000023?E20022003?11211000??1?1110002-011????

Masillosteus janeae

10001120-0??????1?1-

?1?????????0?3010??30?03??1004??01010141?11012114112031214310503020000111-----002111?2-010223011000000200-0?0??0??1221??1323?1?00-

22022?032?011102200112106100110??00-????

Masillosteus kelleri

1000???0-?????????1-

????????????????0??30?0???1004??0101014?211012114012031215310503020000111------00211??2-010223011100140?00-090?????1221??1323?1?00-

2202??02??011102200????05100110??00-???2

Neosemionotus puntanus

0010???11?????????00???????????0???00???03???32004??00000051??00121040?11402 1111030200(0/10)00120121000??1????000000?020-

0000041?111?50?00000?????2120?1?001001501140??2221211?1121??110000??0040053

Notagogus denticulatos

301100-0-

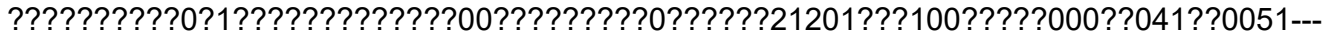
----??0141200?00???0?00000??20-

011004??1111?0???????????0321?1?00?0??D3??02??3????????????????000??0118553

Obaichthys decorates

11210110-?2120-?11-111?211--110??30101040103?2200401001101???1001?0-3101170015$10 ? 010000-$

01?02410001?021100?00100?31100001312111080?????1221???32??1?00???05???5???110 022001?-?-??001100-00????0

Occitanichthys canjuersensis

000101210?????????1000???????????1000003030???0004??000101513100?100300010014200?020000001101430001110110???0022221-

000001131101?010?0?0??????3?1?2?10?0?06??01?1?20?02110102114?000000-00?23?3

Paralepidotus ornatus

30010110-

??????????????????????0?10000030?????0004??021201????00000030???0021???0?00-10-0??0????????????????0??3?21-00000?12110?30??????0?-

??0130?2?201220?2??8???0?????????211??000000-01?2112

Pliodetes nigeriensis

20210110-

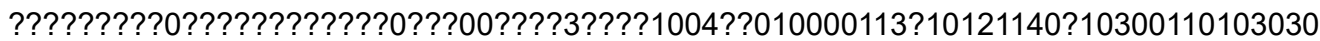
200001202410????041??001010?030000001311010?70?1?????00???????????????2?0?2? 1?1??021??1?21???00100??0037??3 
LÓPEZ-ARBARELLO ET AL.: SYSTEMATICS OF EOSEMIONOTUS

Propterus elongatus

301100-0-??????????0?1??10??0??0???000?1030???011-

??02120121?1000100300017041300051------2?0141200?00???0000000?020-

$00100411111140 ? 13000 ? ? ? 0 ? 0322 ? 10200231 E 31012 ? 033200110 ? ? 211 ? 0100002 ? 0112213$

Sangiorgioichthys aldae

00020010?????????0????????????????00??2?30???0004??00110052??00020030?0110310-$0 ? 031(0 / 1) 0101 ? ? 013100021120-0 ? 01010 ? ? 20-$ 00000011110130?0?0?0?????????????00????0??5???0??000?01?211310?000??00??2?3

Sangiorgioichthys sui 000100-10?????????0????????????001100001030??100(0/ 1)4??000000513?00020030?011(0/1)210--030(2/3)1010011?012100021120-0000000??2001000011110130003110?????0130?0020000060?150?1002000?010211?1000000-0012223

Sangiorgioichthys valmarensis

2001???10??????????????????????????00?????????000???001100????000(1/ 2)0030?0?103????0??3100001??0??10002?????0??0010??20-

000000111??1?0?0?0?0??????1??????00???????????0??000?01?211?10?000??00????3

Scheenstia mantelli

00011120-0210??0110000?210210???0??000?2?3???02004??0(0/2)(0/

1)101????0012114001130013?10?03100010110243?0011101?0???0123?20000001111100?0?000??1???????0???0020?0????????1??021201?2?14?0?000??00????3

\section{Scheenstia maximus}

000111210??????????????????????1????0??1??????2004??????01????00121040?21300 13?10?03100010????????????????00?013332000000111110??????????????1??0???0020?082?032?011?021201?2????00000??00-0222

\section{Scheenstia zappi}

0001???10????????????0??????????0??00???0?0???2004??000101113100121030?11302 $13 ? 10303100010110 ? ? ? ? ? ? ? ? 101 ? 0 ? 0 ? 0022 ? 20-$ 0001011?010??0100010?????21?0???00200060?15???0010212011??15??0000??00?1533

\section{Semiolepis brembanus}

000(0/

1)01111??????????????????????????00??30?????2004??02110111??00000030?0?100120 00300--10-0??0141000??1??????00??2?2100000412111?20???????????2130?2?201?0070??3???002???????211??00000??00?34?3

\section{Semionotus bergeri}

000101111?????????10???????????????00??3??0???0003??001101???1001100300027001 2000?00--10-01?0???????????????0010??20000000111100?0?0?000?????03?1??000???090??2???2?102??0??211??00000??00?3343

Semionotus capensis 
00??01111?????????10????????????01?00003030???1003??00110151?100010030000702 12?00300--10-0110????????1?????0?010??20-

000000111100?0?0?0?0?????0321??0001000E01030??220021?0??2????000000-0033343

Semionotus elegans

00100??111200111??10??1?102??13001?000020204100003101011015131001100300006001 1000300--10-0110241?0011101000000100020-0000041111004010?0000?$0 ? 032131 ? 00 ? 000701 ? 5 ? 1 ? 20 ? 021 ? 0 ? 0211 ? 0000000-0043123$

Thaiichthys buddhabutrensis

00?0?12100?10??011000?1?0???-

??????00??20?0?1?2003??01000111311012114002111012?00?010010-

0110241000101???0110010??301000004121110602000000?????120?1000?22060107??000 2021?0??21?4100000??00????2

Ticinolepis crassidens

000000-0-00????0000000??1000?????1-

0000200????000???120??0003?0001003000250211000303120000??0131000311???0?2000 23320-00000011110150?????0?????0210?012012207???3???0000000111211??000000-(0/ 1) $0 ? 3003$

\section{Ticinolepis longaeva}

000100-0-0????????00??1?10???0-001100??200011100011012001000300002003000(0/ 1) $5021100030312000000013100031101000200011120-$ 00000011110150110??0?????0110?0120122090?110?100200001102114100000??0020003

Tlayuamichin itztli

000201210?????????10???11????0-0?1000004030???(1/ 2)004??00110151?100000230002700162003020001001101430001110110021002?22101000113110150?03010??????331?2?001??07??02???212021101?2?14?0000?0-00?4223

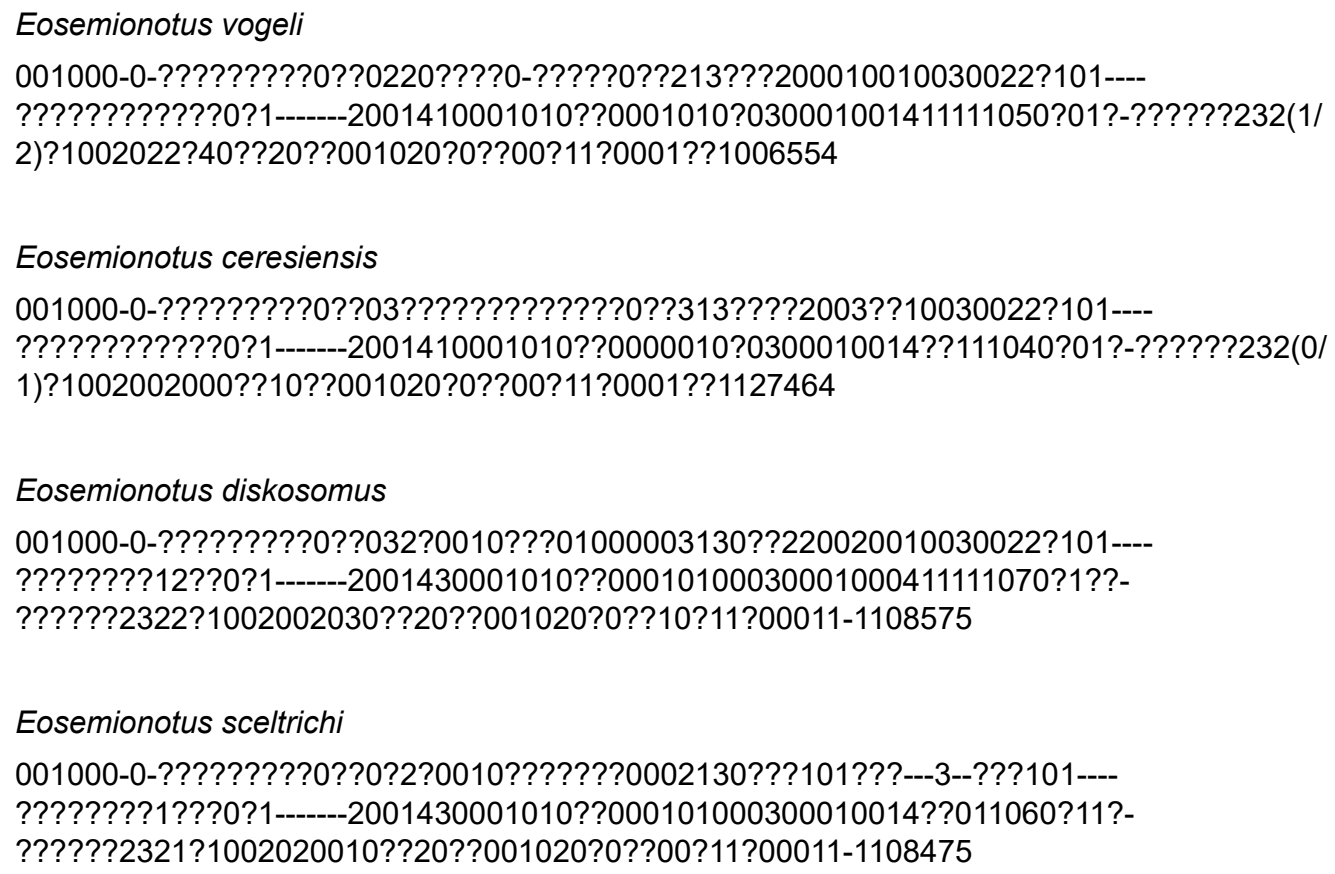




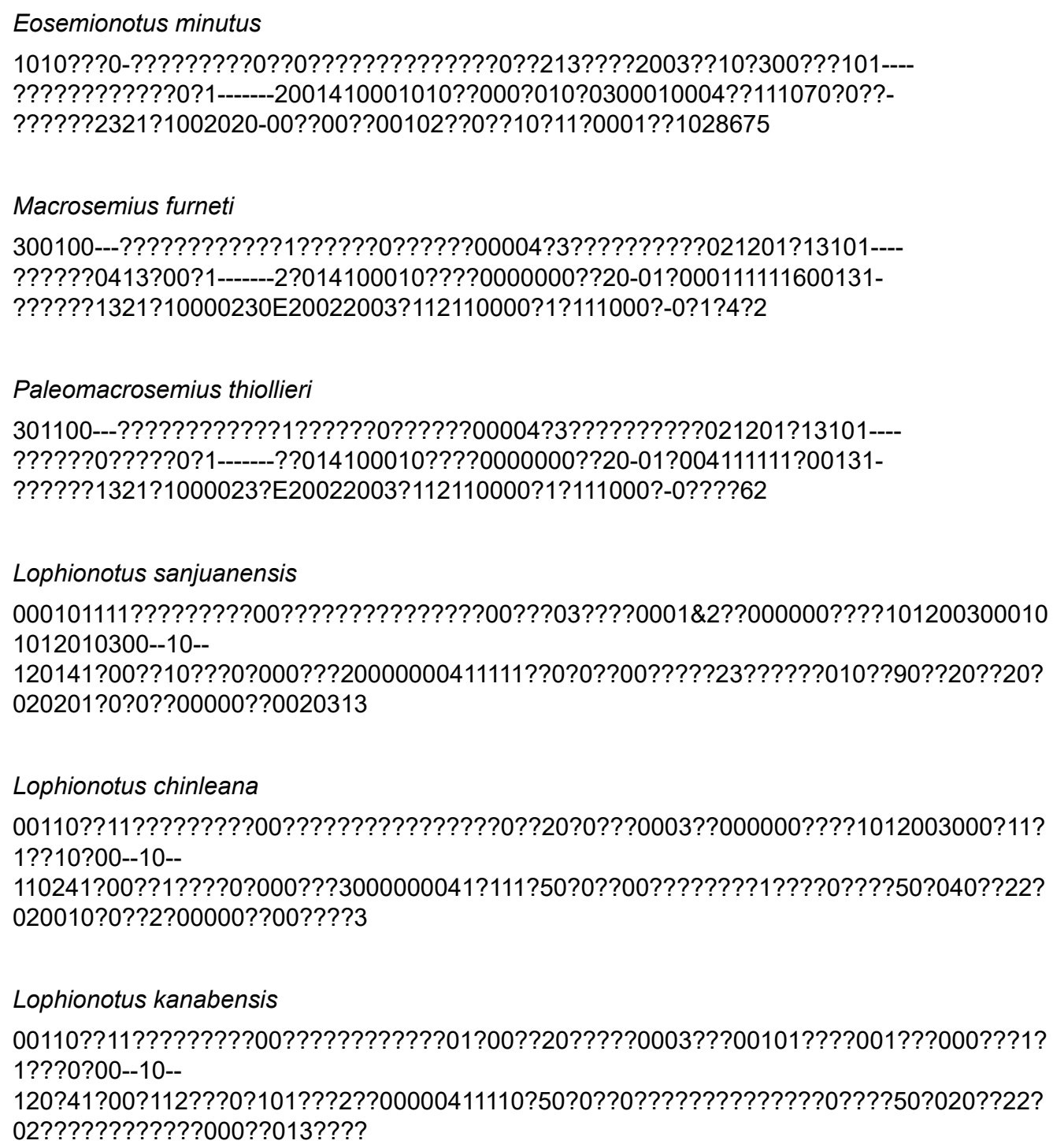

\section{REFERENCES}

Maddison, W.P. and Maddison, D.R. 2017. Mesquite: a modular system for evolutionary analysis. Version $3.31 \mathrm{http}: / /$ mesquiteproject.org. 


\section{APPENDIX 2}

List of phenotypic characters to "Taxonomy and phylogeny of Eosemionotus Stolley, 1920 (Neopterygii: Ginglymodi) from the Middle Triassic of Europe"

The 192 characters listed below have been used for the cladistic analysis to explore the phylogenetic relationships of the Middle Triassic genus †Eosemionotus. Characters 1-180 are taken from López-Arbarello and Sferco (2018). Among them, characters characters 39, 49, 56, 59, $91,130,151,154,156$, and 160 have been modified. Characters 181-182 are taken from LópezArbarello (2012) and characters 183 to 192 are new. The corresponding character number in our source literature is indicated in brackets with the following initials: LA, López-Arbarello (2012); LAS, López-Arbarello and Sferco (2018).

As explained in López-Arbarello and Sferco (2018), autapomorphic character states are not deleted because such states, though not informative for the tree search, are informative concerning the amount of homoplasy.

\section{General features of the body and squamation}

1. Relative position of the dorsal fin respect to the pelvic and anal fins (LAS1)

(0) originating posterior to insertion of pelvic and extending backwards not beyond middle of anal fin

(1) originating approximately at the level of the origin of the anal fin and extending opposite to it

(2) extending anterior to opposite of insertion of pelvic fins

(3) originating anterior to insertion of pelvic and extending opposite to anal fins

(4) originating posterior to the origin of anal fin

(5) originating posterior to insertion of pelvic and extending backwards up to end of anal fin

2. Elongation of the rostral region anterior to the lower jaw symphysis (LAS2)

(0) does not extend anterior to the dentary symphysis significantly

(1) extends well anterior to the dentary symphysis by more than $50 \%$ of mandibular length

3. Ornamentation of the dermal bones of the skull (LAS3)

(0) ornamented with tubercles or ridges

(1) smooth or very slightly ornamented

(2) ornamented with sharp tubercles resembling conical teeth

4. Posterior margin of ganoid anterior flank scales (LAS6)

(0) Smooth

(1) serrate or dentate

(2) spiny, with a few small spines

5. Vertical peg-and-socket articulation (LAS7)

(0) well developed

(1) reduced

6. Longitudinal articulation of the scales of the body (LAS8)

(0) absent

(1) present

7. Mode of longitudinal articulation of the scales (LAS9)

(0) small anterodorsal process

(1) strong anterior dorsal process

(2) double, anterior dorsal and ventral processes

8. Dorsal ridge of scales between the skull and the dorsal fin (LAS11)

(0) absent

(1) present

9. Shape of the dorsal ridge scales (LAS12)

(0) with a low spine

(1) with a high spine 


\section{Endocranium, parasphenoid and vomer}

10. Development of posterior process of epioccipital (LAS22)
(0) small
(1) large

11. Exit of the vagus nerve (X) placed (LAS24)
(0) through the fissura otico-occipitalis
(1) between intercalar and exoccipital
(2) in exoccipital
(3) between intercalar and opisthotic

12. Posterior extent of exoccipitals in adult-sized individuals (LAS25)

(0) reach posterior margin of occiput

(1) do not reach posterior margin of occiput

13. Exoccipital position relative to basioccipital (LAS28)
(0) dorsal
(1) anterodorsal
(2) anterior

14. Posterior myodome (LAS30)
(0) absent
(1) present

15. Relative size of posterior myodome (LAS31)
(0) not extending into basioccipital
(1) extending into basioccipital

16. Intercalar (LAS33)

(0) present
(1) absent

17. Opisthotic (LAS36)
(0) present
(1) absent

18. Pterotic (LAS37)

(0) present

(1) absent

19. Sphenotic with small dermal component (LAS41)

(0) absent

20. Sphenotic fused to dermosphenotic (LAS42)

(0) absent, the two bones are separate

(1) present

21. Basisphenoid (LAS43)

(0) present

(1) absent

22. Lateral ethmoid ossifications (LAS46)

(0) present

(1) absent

23. Width of parasphenoid anterior to the ascending processes (LAS49)

(0) the parasphenoid narrows towards its anterior end, but it is equally broad directly anterior and posterior to the ascending processes

(1) approximately uniformly broad, as wide or wider than posterior to the processes

(2) distinctly narrower than posterior to the processes

(3) the parasphenoid bar narrows directly in front of the ascending processes, but it broadens distinctly anteriorly 
24. Posterior extent of parasphenoid (LAS50)

(0) short, does not extend beyond the fissura oticalis-ventralis

(1) short, but extending beyond the fissura oticalis-ventralis

(2) long, reaching the occipital condyle or close to it

(3) very long, extending posterior to the occipital condyle

25. Basipterygoid processes of parasphenoid (LAS51)

(0) almost or totally absent

(1) well developed

26. Ascending processes of parasphenoid (LAS52)

(0) present

(1) absent

27. Orientation of the ascending processes of parasphenoid (LAS53)

(0) extend perpendicularly

(1) extend anteriorly

(2) extend posteriorly

28. Extent of the ascending processes of parasphenoid (LAS54)

(0) high, reaching the sphenotic

(1) low, sutured to the prootic only

29. Laterally sliding articulation between the metapterygoid and the parasphenoid basipterygoid process in adults (LAS55)

(0) absent

(1) present

30. Parasphenoid tooth patch (LAS56)

(0) absent

(1) present

31. Extent of parasphenoid tooth patch (LAS57)

(0) extends anterior and posterior to the ascending processes

(1) extends only anterior to the ascending processes

(2) extends only posterior to the ascending processes

(3) limited to the area between the ascending processes

32. Vomer in adults (LAS59)
(0) pair
(1) co-ossified

\section{Palatoquadrate}

33. Autopalatine bone (LAS60)

(0) present

(1) absent

34. Shape of ectopterygoid (LAS62)

(0) elongate, triangular, straight ventral border, deepest mid length

(1) approximately crescent shape, convex dorsally, concave ventrally

(2) approximately boomerang shape

(3) approximately triangular, deepest posteriorly, tapering anteriorly

(4) elongate, with bar-like anterior portion and deeply expanded posterior portion

(5) bar-like

35. Marginal row of teeth on ectopterygoid (LAS63)

(0) absent

(1) present

36. Ectopterygoid participation in palatal surface area (LAS64)

(0) ectopterygoid forms half or less of the palatal region

(1) ectopterygoid forms most of the palatal region 
37. Part of dorsal surface of ectopterygoid ornamented and forming part of skull roof (LAS65)

(0) absent

(1) present

38. Metapterygoid/quadrate relationship (LAS67)

(0) metapterygoid sutured or closely associated with the quadrate

(1) ectopterygoid separating metapterygoid from quadrate

39. Metapterygoid/ectopterygoid contact (LAS68)

(0) absent

(1) present

Character 68 of López-Arbarello and Sferco (2018) distinguishes three different modes in which the metapterygoid might be in contact with the ectopterygoid (states 1-3), but it considers only one way in which these bones might be separated by the endopterygoid (state 0 ). The metapterygoid in Eosemionotus is well separated from the ectopterygoid, but not by a large endopterygoid. Instead, there is a large quadrate or an extensive palatoquadrate chondral ossification, corresponding mainly to the quadrate, separating those two bones in this genus.

In macrosemiids (scored with question marks in López-Arbarello and Sferco, 2018), the endopterygoid does not extend backwards separating the meta- and ectopterygoid bones. In this case however, the quadrate is small and the meta- and ectopterygoid are separated by calcified cartilage or some kind of ossification, which still needs to be studied in detail.

In the light of these new observations, it was necessary to modified character 68 of LópezArbarello and Sferco (2018) to code for the presence or absence of contact between the metaand ectopterygoid bones, and to add two new characters (184 and 185) to code for the three different ways in which these bones might be separated or in contact, respectively.

40. Relative position of the lower jaw articulation at the level of (LAS69)

(0) posterior to the orbit

(1) around the posterior border of the orbit

(2) around the centre of the orbit

(3) around the anterior border of the orbit

(4) in front of the orbit

41. Quadratojugal fused to quadrate (LAS71)

(0) absent

(1) present

\section{Hyoid arch}

42. Shape of anterior ceratohyal (LAS81)

(0) deep, subrectangular

(1) elongate hourglass shape

(2) narrow anteriorly, more expansive and laterally compressed posteriorly

(3) deeply hourglass shape without Beryciform foramen

(4) deeply hourglass shape with Beryciform foramen

43. Symplectic relationship to lower jaw (LAS83)

(0) is not directly involved in the jaw joint

(1) participates directly in the jaw joint

44. Relation between symplectic and quadrate (LAS84)

(0) symplectic posteroventral to quadrate, the two bones are separate

(1) symplectic articulates with the inner, medial surface of quadrate

(2) symplectic attached into a groove formed by the posteroventral border of the quadrate

(3) symplectic posterodorsal and well separate from quadrate

(4) symplectic attached between the quadrate and quadratojugal

45. Shape of symplectic (LAS85)

(0) slightly curved tube or splint

(1) bar-like shaped

(2) hatchet shaped 
(3) L-shaped

46. Shape of hyomandibula (LAS89)

(0) rod like

(1) hourglass shaped, with a constriction between the shaft and the articular head

(2) shaft approximately as broad as hyomandibular head

(3) shaft notably narrower than hyomandibular head

\section{Dermal braincase}

47. Number of extrascapular bones (LAS90)
(0) one pair
(1) two pairs
(2) more than four extrascapulars

48. Shape of the extrascapular bone/s (LAS91)

(0) plate like, quadrangular to triangular

(1) tubular

(2) semicircular, expanded caudolaterally

(3) expanded rostrally

49. Posterior extension of parietals median to the extrascapular bones (LAS92)

(0) absent

(1) present

We have changed the enunciation of this character deleting "the single pair of laterally placed" from the definition in López-Arbarello and Sferco (2018). As defined by these authors, the character is too specific for the condition in macrosemiids, which have a single pair of extrascapulars. In Eosemionotus sceltrichi the parietal extends medially to two extrascapulars on each side of the head.

50. Dermopterotic (or pterotic) exposed surface extending anterior to parietal (LAS93)

(0) by more than $50 \%$ of its total length

(1) by more than $40 \%$ but less than $50 \%$ of its total length

(2) by more than $30 \%$ but less than $40 \%$ of its total length

(3) by less than $30 \%$ of its total length

(4) not extending anterior to parietal

51. Dermopterotic descending lamina (LAS96)
(0) absent
(1) present

52. Dermopterotic posterior projection(s) (LAS97)

(0) absent

(1) present and simple

(2) present, one or more, and notably large

53. Parietal width to length ratio (LAS99)

(0) not exceeding 0.90

54. Relative length of parietals respect to the length of the frontals (LAS100)

(0) less than one half but more than one third the length of frontals

(1) about half the length of frontals

(2) less than one third the length of frontals

(3) more than half the length of frontals

55. Length to width ratio of frontals in adult sized individuals (LAS101)

(0) lower than three

(1) equal or larger than three

56. Anterior portion of frontals (LAS102)

(0) subrectangular not significantly narrower anteriorly than posteriorly

(1) tapering gradually

(2) projected in the form of long tubular extensions 
(3) projected in the form of small processes

López-Arbarello and Sferco (2018) include the shape of the most anterior portion of the frontal bones and the depth of the interorbital constriction in a single character. We now separated these two features, which do not show any biological dependence. Consequently, we limit characer 102 to the shape of the most anterior portion of the frontals and added a new characrer state representing the condition in Eosemionotus (frontals projected in the form of small processes). The presence of a deep interorbital constriction is coded as a character (ch. 187).

57. Postorbital portion of frontal (LAS103)

(0) not significantly large

(1) large, more than $1 / 3$ of total length of frontal

58. Preorbital portion of frontal (LAS104)

(0) not significantly large

(1) large, more than $1 / 3$ of total length of frontal

59. Shape of nasal bones (LAS106)

(0) broad, approximately rectangular to oval or trapezoidal

(1) broad kidney shaped

(2) narrow, rectangular, longer than broad, to approximately tubular

(3) approximately tear-shape, broadest anteriorly, narrowing posteriorly

(4) small, approximately kidney shaped

(5) long and narrow, anterior end incurved laterally

(6) inverted Y-shaped

We have changed the enunciation of character state 2 to encompass a variation that we consider homologous.

60. Relationship between left and right nasal bones (LAS107)

(0) sutured to each other (1)

(2) close to each other

(3) widely separated

61. Posterior nostril relationship to nasal bone (LAS109)

(0) excavating the lateral margin of the nasals

(1) completely included in the posterior portion of the nasals

(2) cutting the posterolateral border of the nasals

(3) not indicated by the nasals

\section{Cheek and circumborbital bones}

62. Ossified sclerotic ring (LAS111)

(0) present

(1) absent

63. Quadrate laterally covered by infraorbital bones (LAS112)

(0) absent

(1) present

64. Supraorbital bones (LAS113)

(0) present

(1) absent

65. Circumborbital ring (LAS114)

(0) most anterior supraorbital does not contact infraorbitals

(1) most anterior supraorbital contacts infraorbital series

66. Number of supraorbital bones (LAS115)

(0) more than four

(1) three or four

(2) two

(3) one

67. Size of supraorbital bones relative to orbit (LAS117)

(0) small

(1) large 
(2) all supraorbitals small except the first, most anterior supraorbital, which is large, expanded anteriorly

68. Shape of most anterior supraorbital bone (LAS118)

(0) subrectangular to triangular, if the ring is closed, contacting only the antorbital or one infraorbital bone

(1) trapezoidal, longest ventrally, contacting more than one infraorbital bone

(2) pentagonal

(3) expanded anteroventrally, making the anterodorsal corner of the orbit

69. Size and shape of dermosphenotic (LAS119)

(0) extended and tapering rostrally

(1) extended and tapering caudally, ending at the level of the anterior margin of the dermopterotic (or pterotic)

(2) very large, extended and tapering caudally, reaching close to the level of the preopercular canal

(3) small, not distinctly extended rostrally or caudally

(4) large, keystone shaped

70. Position of dermosphenotic relative to orbital margin (LAS120)

(0) dermosphenotic participates in orbital margin

(1) dermosphenotic is excluded from orbital margin

71. Dermosphenotic/sphenotic association (LAS121)

(0) closely associated with each other (i.e. contacting or fused to each other)

(1) not in contact with each other

72. Shape of the postinfraorbital bones (jugal not included) (LAS123)

(0) deeper than long, sometimes almost tubular

(1) approximately quadrangular

(2) longer than deep, expanded posteriorly, not longer than the orbital diameter

(3) very large, longer than the orbit

(4) approximately triangular, tapering dorsally

(5) subrectangular and elongated in posterodorsal to anteroventral direction

73. Number of postorbital bones (infraorbital bones forming the posterior rim of the orbit (jugal not included) (LAS124)

(0) one

(1) two

(2) three

(3) none

74. The largest circumborbital bone is (LAS125)

(0) the jugal (infraorbital placed at the posteroventral corner of the orbit), and it is not much larger than other infraorbital bones

(1) the jugal (infraorbital placed at the posteroventral corner of the orbit), and it is notably larger than other infraorbitals

(2) a postorbital occupying the posteroventral and posterior rim of the orbit (in some cases this area is occupied by one or more bones of similar size)

(3) the dermosphenotic or a supraorbital (all these bones being of similar size)

(4) one of the supraorbitals (the dermosphenotic is notably smaller than the supraorbitals)

(5) the infraorbital placed at the centre of the ventral margin of the orbit

(6) the lachrymal or infraorbital placed at the anteroventral corner of the orbit

(7) 'one of the anterior infraorbitals

(8) the jugal or the lachrymal, both with similar size

75. Contact between preopercle and jugal or lower postinfraorbital (LAS126)

(0) absent

(1) present

76. General shape of the subinfraorbital bone(s) (Infraorbital bones forming the ventral border of the orbit between the lachrymal and the jugal) (LAS127)

(0) subrectangular to triangular, about 1,5 to 2,5 times deeper than long 
(1) subtriangular, longer ventrally, more than 3 times deeper than long

(2) quadrangular to longer than deep, notably smaller than the orbit

(3) subrectangular, a quarter to half the size of the orbit

(4) scroll-like

77. Anterior infraorbitals (LAS130)

(0) absent

(1) present

78. Number of anterior infraorbitals (LAS131)

(0) one

(1) two or more

(2) three or more

(3) four or more

(4) five or more

(5) six or more

(6) seven or more

The number of anterior infraorbital bones is variable in several taxa. This variation is intraspecific, but not ontogenetic. For this reason, we decided to score the minimal number of anterior infraorbitals for each species.

79. Shape of most anterior anterior-infraorbital (LAS132)

(0) not distinct than adjacent infraorbital

(1) rectangular dorsal portion, ventrally expanded and higher than adjacent infraorbital

(2) narrowing dorsally, expanded ventrally, further ventral than the adjacent anterior infraorbitals

(3) approximately rectangular, deeper than adjacent anterior infraorbital

80. Ventral border of infraorbital series (LAS133)

(0) follows a straight line or a gentle curve

(1) flexes abruptly dorsally at the anterior margin of the orbit

81. A series of toothed infraorbitals bordering the snout (LAS134)

(0) absent

(1) present

82. Shape of antorbital bone (LAS136)

(0) approximately triangular or drop-like, narrowing posterodorsally

(1) rectangular

(2) clavate

(3) sickle- to L-shape

(4) approximately triradiated, Y-shape

(5) tubular

(6) splint-like

83. Suborbital bones (LAS143)

(0) present

(1) absent

84. Number of suborbital bones (LAS144)

(0) one

(1) two

(3) three

(4) four or more, usually numerous suborbitals

85. Distribution of suborbital bones (LAS145)

(0) suborbitals limited to the area between the infraorbitals and preopercle posterior to the orbit

(1) suborbitals occupy the area between the infraorbitals and preopercle posterior and below the orbit

86. Arrangement of suborbital bones (LAS146)

(0) one row 
(1) two rows

(2) mosaic of numerous suborbitals

87. Independent of the total number, there is a large suborbital covering almost the whole area between the infraorbital bones and the preopercle (LAS147)

(0) absent

(1) present

88. Independent of the total number, there is a suborbital bone between the dermopterotic and preopercle (LAS148)

(0) absent

(1) present

89. Relative size of the most anterior and most dorsal suborbitals (LAS149)

(0) of similar size than the other suborbitals

(1) notably larger than the other suborbitals

90. Suborbitals covering the quadrate laterally (LAS150)

(0) present, suborbitals within a series or mosaic, no distinct shape

(1) present, one or two suborbitals forming a triangular plate

\section{Jaws and dentition}

91. Premaxillary nasal processes (= lateral dermethmoids) (LAS152)

(0) small lining the nasal pits, without or only partially surrounding the passage of the olfactory nerve

(1) large completely enclosing the olfactory fenestra

(2) spiniform, not forming an olfactory fenestra

We added character state two representing the condition in the species of Eosemionotus. We revised the scorings for this character in the light of the newly recognized condition and consequently made several changes.

92. Premaxillary nasal process relationship to frontal (LAS153)

(0) does not suture to the frontal

(1) sutures to the ventral surface of the frontal

(2) sutures to the anterior border of the frontal

The definition of character state 2 because in some taxa (e.g., Neosemionotus) the nasal process of the premaxilla sutures to the anterior border of the frontal, but it does not participate of the skull roof. This later condition is not coded in an independent character (ch. 181) taken from López-Arbarello (2012).

93. Maxilla (N154)

(0) present and independent

(1) fused to toothed infraorbital bones

94. Length of maxilla relative to coronoid process (LAS156)

(0) very long, extends beyond the coronoid process

(1) extends backwards partially covering the coronoid process laterally

(2) very short, does not reach the coronoid process

95. Posterior extent of maxilla relative to orbit (LAS157)

(0) beyond posterior orbital margin

(1) up to posterior orbital margin

(2) up to centre of the orbit

(3) up to anterior orbital margin

(4) in front of the orbit

96. Shape of maxilla (LAS158)

(0) elongate, broad posteriorly, stretches well behind the orbit

(1) elongate, shallow

(2) maxilla extremely slender

(3) deep, depth $>0,5$ of its length

97. Ventral margin of maxilla (LAS159)

(0) straight or almost straight 
(1) slightly convex

(2) slightly concave

(3) bends downwards posteriorly

98. Shape of posterodorsal corner of maxilla (LAS160)

(0) rounded to straight angle

(1) acute angle

99. Postmaxillary process (LAS161)
(0) absent
(1) present and small
(2) present and notably large, posterior border of maxilla deeply excavated

100. Shape of dorsal margin of maxilla (LAS162)

(0) straight or concave infraorbital and convex postorbital portions

(1) generally straight or convex

(2) gently concave allocating supramaxilla

(3) with a distinct supramaxillary notch

101. Supramaxilla (LAS163)

(0) absent

(1) present, single bone

(2) present, two bones

102. Posteroventral end of the dentary (LAS166)

(0) not particularly expanded

(1) forming a well-developed process extending beyond the coronoid process

103. Coronoid process (LAS168)

(0) made up by the dentary and surangular

(1) made up by the dentary only

(2) made up by the surangular only

(3) made up by the surangular and angular

(4) made up by the dentary and angular

104. Retroarticular (LAS174)

(0) absent

(1) present and separate

(2) present and fused to angular only

(3) present and fused to articular only

(4) present and fused to angular and articular

105. Retroarticular and quadrato-mandibular joint (LAS175)

(0) retroarticular excluded from the joint facet for quadrate

(1) retroarticular included in the joint facet for quadrate

106. Plicidentine structure in teeth (LAS177)

(0) absent

(1) present

107. Organization of teeth on premaxilla (LAS178)

(0) single row

(1) more than one row

(2) single row plus anterior fang

108. Relative size of largest premaxillary teeth (LAS179)

(0) of similar size of dentary teeth

(1) larger than dentary teeth

(2) smaller than dentary teeth

109. Maxillary teeth (LAS180)

(0) present

(1) absent

110. Tooth organization on dentary (LAS182)

(0) teeth in a single row and of similar size 
(1) in addition to a lateral single row of similar sized teeth, there is a medial row of much larger fangs

(2) teeth of similar size arranged in two or more rows

111. Extent of teeth on dentary (excluding coronoid toothplates) (LAS183)

(0) tooth row extends over at least a third the length of dentary

(1) tooth row is present on only the anterior one third or less of dentary

112. Morphology of dentary teeth (LAS184)

(0) conical

(1) pointed pencil like

(2) high, bluntly pencil like

(3) molariform, broader than high

(4) conical with labiolingually compressed, sharply carinate (keeled) caps

113. Morphology of teeth on anterior coronoids (LAS185)

(0) conical

(1) pointed pencil like

(2) high, blunt, flattened or broadly rounded

(3) 'molariform, broader than high

114. Morphology of vomerine teeth (LAS186)

(0) conical

(1) pointed pencil like

(2) blunt, flattened or broadly rounded

(3) molariform

(4) heterogeneous sharply pointed fangs

\section{Opercular bones, branchiostegals and gular}

115. Shape of preopercle (LAS187)

(0) long, angularly bent, with almost horizontal anterodorsal and vertical (1) posteroventral portions

(2) plate-like, broad dorsally, narrowing ventrally

(3) comma-shape

(4) roughly L-shape

116. Anterior/anteroventral end of preopercle (LAS189)

(0) broadly tapered

(1) finely tapered

117. Relative length of preopercular arms (LAS190)

(0) vertical arm is longer than horizontal arm

(1) horizontal arm is longer than vertical arm

118. Exposure of dorsal limb of preopercle (LAS194)

(0) infraorbital or suborbital bones do not overlap, but only the anterior rim of preopercle

(1) suborbital bones completely overlap the dorsal limb of preopercle

119. Preopercle to dermopterotic relationship (LAS195)

(0) preopercle reaches at least close to dermopterotic

(1) preopercle and dermopterotic are well separated

120. Posterior border of the preopercle notched ventrally (LAS196)

(0) absent

(1) present

121. Suprapreopercle (LAS197)

(0) absent

(1) present

122. Shape of the opercle width/length (LAS198)

(0) deeper than long

(1) approximately as deep as long

(2) tapering anteroventrally 
(3) longer than deep

123. Opercle ornamentation in adult-sized individuals (LAS199)

(0) densely arranged low tubercles and/or ridges

(1) well-defined tubercles

(2) pattern of ridges radiating from the anterodorsal corner

(3) denticles

(4) ornamentation weak or absent

124. Base of ascending process of the subopercle (LAS201)

(0) broad, more than $30 \%$ of the maximal length of the bone

(1) narrow, between 10 and $30 \%$ of the maximal length of the bone

(2) tiny, less than $10 \%$ of the maximal length of the bone

125. Height ascending process of the subopercle (LAS202)

(0) low, $20 \%$ of the maximal length of the bone

(1) medium, $20-40 \%$ of the maximal length of the bone

(2) high, approximately $50-60 \%$ of the maximal length of the bone

(3) very high, approximately $70 \%$ or more the maximal length of the bone

126. Subopercle maximal depth (excluding ascending process) (LAS203)

(0) more than half the depth of the opercle

(1) less than half the depth of the opercle

(2) deeper than the opercle

127. Interopercle (N204)

(0) absent

(1) present

128. Relationship between interopercle and the lower jaw (LAS205)

(0) anterior end of interopercle close to mandible

(1) interopercle remote from mandible

129. Branchiopercle (LAS206)

(0) absent

(1) present

130. Maximal number of branchiostegal rays (LAS207 modified)

(0) fourteen

(1) twelve

(2) ten

(3) nine

(4) eight or

(5) seven

(6) six

(7) five

(8) four

(9) three

This character is coded as discrete character using ranges in López-Arbarello and Sferco (2018). Instead, we use multiple states representing the raw counts directly. The intraspecific variation in the number of branchiostegal rays reported for several taxa is usually due to incomplete preservation. For this reason, we decided to score the maximal observed number of rays.

131. Median gular (LAS208)

(0) absent

(1) present

\section{Sensory canals}

132. Position of junction of supraorbital and temporal canals (LAS215)

(0) exclusively within frontal bone

(1) exclusively within dermosphenotic bone

(2) exclusively within dermopterotic bone 
133. Supraorbital sensory canal in parietal (LAS216)

(0) present

(1) absent

134. Middle pit line (LAS217)

(0) leaving a groove or pore-line on the parietal and dermopterotic

(1) leaving a groove or pore-line on the parietal only

(2) in the dermopterotic only

(3) leaving no trace on the bones

135. Position of the supratemporal commissure (LAS218)

(0) pierces extrascapulars

(1) pierces extrascapulars and parietals

(2) pierces parietals only, or parietals and supraoccipital

(3) pierces dermopterotics

136. Orbital canal (LAS219)

(0) absent

(1) present

137. Posttemporal penetration by lateral line canal (LAS222)

(0) present

(1) absent

\section{Vertebral column}

138. Arcocentrum (LAS225)

(0) absent

(1) present and thin, ring-like centra

(2) present and forming solidly ossified centra

139. Large parapophyses (LAS231)

(0) absent

(1) present, not fused to the centra

(2) present, fused to the centra

140. Relationship between the abdominal neural arches and vertebral centra (LAS234)

(0) neuual arches attached to the centra but not fused to them

(1) all or most of the neural arches fused to the centra

141. Distribution of supraneural bones (LAS238)

(0) extend below dorsal fin

(1) the series of supraneurals ends anterior to dorsal fin

142. Neural arch on preural centrum 1 (Pu1) (LAS255)

(0) with neural spine

(1) without neural spine

\section{Median fins}

143. Shape of posterior margin of caudal fin (LAS278)

(0) forked

(1) convexly rounded

(2) concave

144. Total number of principal caudal fin rays (LAS282)

(0) variable, more than 50

(1) variable, between 19 and 50

(2) stable at 19

(3) variable, up to 19

145. Number of rays forming the dorsal margin of the caudal fin (LAS283)

(0) more than two (branched or not)

(1) two, at least the first unbranched

(2) one branched 
(3) one unbranched

146. Number of principal caudal fin rays below lateral line (LAS284)

(0) more than eight

(1) eight

(2) seven

(3) $\operatorname{six}$

147. Number of principal caudal fin rays associated to the preural skeleton (LAS285)

(0) more than nine

(1) seven or eight

(2) four to six

(3) one to three

148. Number of rays forming the ventral margin of the caudal fin (LAS286)

(0) two or more (branched or not)

(1) one branched

(2) one unbranched

149. Dorsal processes of the bases of innermost principal caudal fin rays (LAS287)

(0) absent

(1) present

150. Number of hypaxial procurrent (segmented) caudal fin rays (LAS290)

(0) none

(1) one

(2) two to five

(3) six to eleven

151. Epaxial basal fulcra (not segmented) (LAS291)

(0) present and scale-like

(1) present as procurrent rays

(2) distinctly large, deeply imbricated forming a dorsal keel embracing the body lobe

We added character state two representing the condition in the species of Eosemionotus.

152. Accessory row of scales adjacent to the ventral border of the body lobe (LAS293)

(0) absent

(1) present, one row

(2) present, two or more rows

153. Dorsal scute(s) preceding caudal fin (LAS296)

(0) present, more than one

(1) present, single

(2) absent

154. Ventral scute(s) preceding caudal fin (LAS297)

(0) present, more than one

(1) present, single

(2) absent

López-Arbarello and Sferco (2018) considered characters 296 and 297 inapplicable for those taxa with a complete series of dorsal caudal fulcra because of the unclear homology between the isolated dorsal and ventral scutes preceding the caudal fin of teleosts and many halecomorphs. Reviewing this topic, we now follow López-Arbarello and Codorniú (2007) in their distinction between scutes (characters 296 and 297), which are laying on the caudal peduncle, and basal fulcra (characters 291), which are laying in the body lobe. This distinction is supported by the independent development of the squamation of the body and the body-lobe. The precaudal scutes of teleosts are distinct from the series of epaxial basal fulcra and, thus, are most probably homologous with the scutes of other neopterygians. Based on these hypotheses of homology it has been possible to score these characters for most of the taxa included in the analysis. Additionally, we added the state three to the character 297, representing the peculiar condition of the ventral scutes preceding the caudal fin in macrosemiids. 
155. Number of fringing fulcra on the first principal caudal fin ray (LAS299)

(0) numerous

(1) one to five

156. Maximal number of dorsal fin rays (LAS301 modified)

(0) 6

(1) 7

(2) 8

(3) 9

(4) 10

(5) 11

(6) 12

(7) 13

(8) 15

(9) 16

(A) 18

(B) 20

(C) 21

(D) 24

(E) 28

(F) $\quad 30-40$

(G) 50 or more

This character is coded as discrete character using ranges in López-Arbarello and Sferco (2018). Instead, we use multiple states representing the raw counts directly. The intraspecific variation reported for several taxa is usually due to incomplete preservation. For this reason, we decided to score the maximal number observed.

157. Shape of dorsal fin (LAS302)

(0) triangular

(1) anterior rays distinctly higher forming a sickle-shaped margin

(2) bow-shaped

(3) divided in two sections

158. Relationship between first dorsal proximal pterygiophore and fin rays (LAS304)

(0) articulates with procurrent rays or basal fulcra and first principal ray

(1) articulates with procurrent rays or basal fulcra only

159. First principal dorsal ray (LAS305)

(0) branched

(1) unbranched

160. Maximal number of anal fin rays (LAS306 modified)

(0) 5

(1) 6

(2) 7

(3) 8

(4) 9

(5) 10

(6) 11

(7) 12

(8) 15

This character is coded as discrete character using ranges in López-Arbarello and Sferco (2018). Instead, we use multiple states representing the raw counts directly. The intraspecific variation reported for several taxa is usually due to incomplete preservation. For this reason, we decided to score the maximal number observed.

161. Shape of anal fin (LAS307)

(0) triangular

(1) anterior rays distinctly deeper forming a sickle-shaped margin

(2) bow-shaped or straight 
162. Relationship between first anal pterygiophore and fin rays (LAS308)

(0) articulates with procurrent rays or basal fulcra and first principal ray

(1) articulates with procurrent rays or basal fulcra only

163. First principal anal fin ray (LAS310)

(0) branched

(1) unbranched

164. Relative size of the basal fulcra in the dorsal fin (LAS312)

(0) slender, equalling or more slender than the basal segment of the first dorsal fin ray

(1) stout and short, shorter than the basal segment of the first dorsal fin ray

(2) stout and increasing up to relatively high, higher than the basal segment of the first dorsal fin ray

(3) ray-like

165. Relative size of the basal fulcra in the anal fin (LAS313)

(0) slender, equalling or more slender than the basal segment of the first anal fin ray

(1) stout and short, shorter than the basal segment of the first anal fin ray

(2) stout and increasing up to relatively high, higher than the basal segment of the first anal fin ray

(3) ray-like

166. Preanal scute (LAS314)

(0) absent

(1) present, smooth surface and borders

(2) present, smooth surface, indented border

167. Fringing fulcra on dorsal and anal fins (LAS315)

(0) present

(1) absent

168. Pattern of fringing fulcra on median fins (LAS316)

(0) formed by a combination of small, spiny bony fringing fulcra positioned between the terminal segments of the procurrent and/or marginal rays

(1) formed by a combination of small, spiny bony fringing fulcra positioned between the terminal segments of the procurrent and subsequently lying on the surface of the marginal ray(s)

(2) formed of small, paired, spine-like elements lying on the surface of the marginal ray(s) only

\section{Paired girdles and fins}

169. Relative height of the posttemporal bone (LAS317)

(0) high, reaching or almost reaching the dorsal midline

(1) low, approximately as high as the dermopterotic

(2) posttemporals very small

170. Anterior process of posttemporal bone (LAS318)

(0) absent

(1) present, blunt

(2) present, large and knob-like

171. Presupracleithrum (LAS320)

(0) absent

(1) present

172. Supracleithrum with a concave articular facet for articulation with the posttempo-

ral (LAS321)

(0) absent

(1) present

173. Relationship between lateral line system and supracleithrum (LAS322)

(0) emerging at the middle 
(1) emerging at its upper half

(2) emerging at its lower half

174. General shape of cleithrum (LAS323)

(0) sickle to L-shape with approximately equally large vertical and horizontal portions

(1) sickle to L-shape with horizontal portion 1,5 to 2 times larger than vertical portion

(2) sickle without clearly distinct vertical and horizontal portions

175. Medial wing of cleithrum (LAS324)

(0) absent

(1) present

176. Ornamentation of the cleithrum (LAS325)

(0) absent

(1) one or more series of toothed ridges on the anterolateral surface

177. Number of postcleithra (LAS326)

(0) none

(1) one

(2) two

(3) three

(4) four

(5) five

(6) six or more

178. Clavicles (LAS327)

(0) present

(1) absent

179. Fringing fulcra on pectoral fin (LAS334)

(0) present

(1) absent

180. Fringing fulcra on pelvic fin (LAS337)

(0) present

(1) absent

\section{Characters from López-Arbarello (2012)}

181. Premaxillary nasal processes form external dermal components of the skull roof (LA48)

(0) absent

(1) present

182. Supraorbital sensory canal in premaxillary nasal processes (LA49)

(0) absent

(1) present

\section{New characters}

183. Median ethmoidal ossification

(0) absent

(1) present

184. Bone separating the metapterygoid from the ectopterygoid

(0) endopterygoid

(1) quadrate or a large palatoquadrate endochondral ossification

$\mathrm{t}(2)$ he bones were probably separated by cartilage

185. Contact between metapterygoid/ectopterygoid is due to

(0) metapterygoid placed anteriorly

(1) metapterygoid expanded anteriorly

(2) ectopterygoid enlarged posteriorly 
186. Frontal bones

(0) independent

(1) fused to each other

187. Frontal bones strongly constricted at the orbit; minimal interorbital width less than half of maximal width in the temporal region

(0) absent

(1) present

188. Maximal number of premaxillary teeth

(0) four

(1) five

(2) six

(3) seven

(4) eight

(5) nine

This character includes multiple states representing the raw counts directly. The intraspecific variation reported for several taxa is usually due to incomplete preservation. For this reason, we decided to score the maximal number observed.

189. Maximal number of scales in marginal row of body lobe

(0) 14

(1) 12

(2) 11

(3) 10

(4) nine

(5) eight

(6) seven

(7) five

(8) four

This character includes multiple states representing the raw counts directly. The intraspecific variation reported for several taxa is usually due to incomplete preservation. For this reason, we decided to score the maximal number observed.

190. Maximal number of scales posterodorsal to the hinge-line

(0) nine

(1) eight

(2) seven

(3) six

(4) five

(5) four

(6) three

This character includes multiple states representing the raw counts directly. The intraspecific variation reported for several taxa is usually due to incomplete preservation. For this reason, we decided to score the maximal number observed.

191. Maximal number of dorsal caudal fulcra on the body lobe

(0) 12

(1) Ten

(2) nine

(3) eight

(4) six

(5) five

(6) four

This character includes multiple states representing the raw counts directly. The intraspecific variation reported for several taxa is usually due to incomplete preservation. For this reason, we decided to score the maximal number observed.

192. Number of scales along the lateral line

(0) more or equal 60

(1) more or equal 50 
(2) more or equal 40

(3) more or equal 30

(4) 26-29

(5) 20-25

This character includes multiple states representing the raw counts directly. The intraspecific variation reported for several taxa is usually due to incomplete preservation. For this reason, we decided to score the maximal number observed. 
LÓPEZ-ARBARELLO ET AL.: SYSTEMATICS OF EOSEMIONOTUS

APPENDIX 3.

List of synapomorphies to "Taxonomy and phylogeny of Eosemionotus Stolley, 1920 (Neopterygil: Ginglymodi) from the Middle Triassic of Europe".

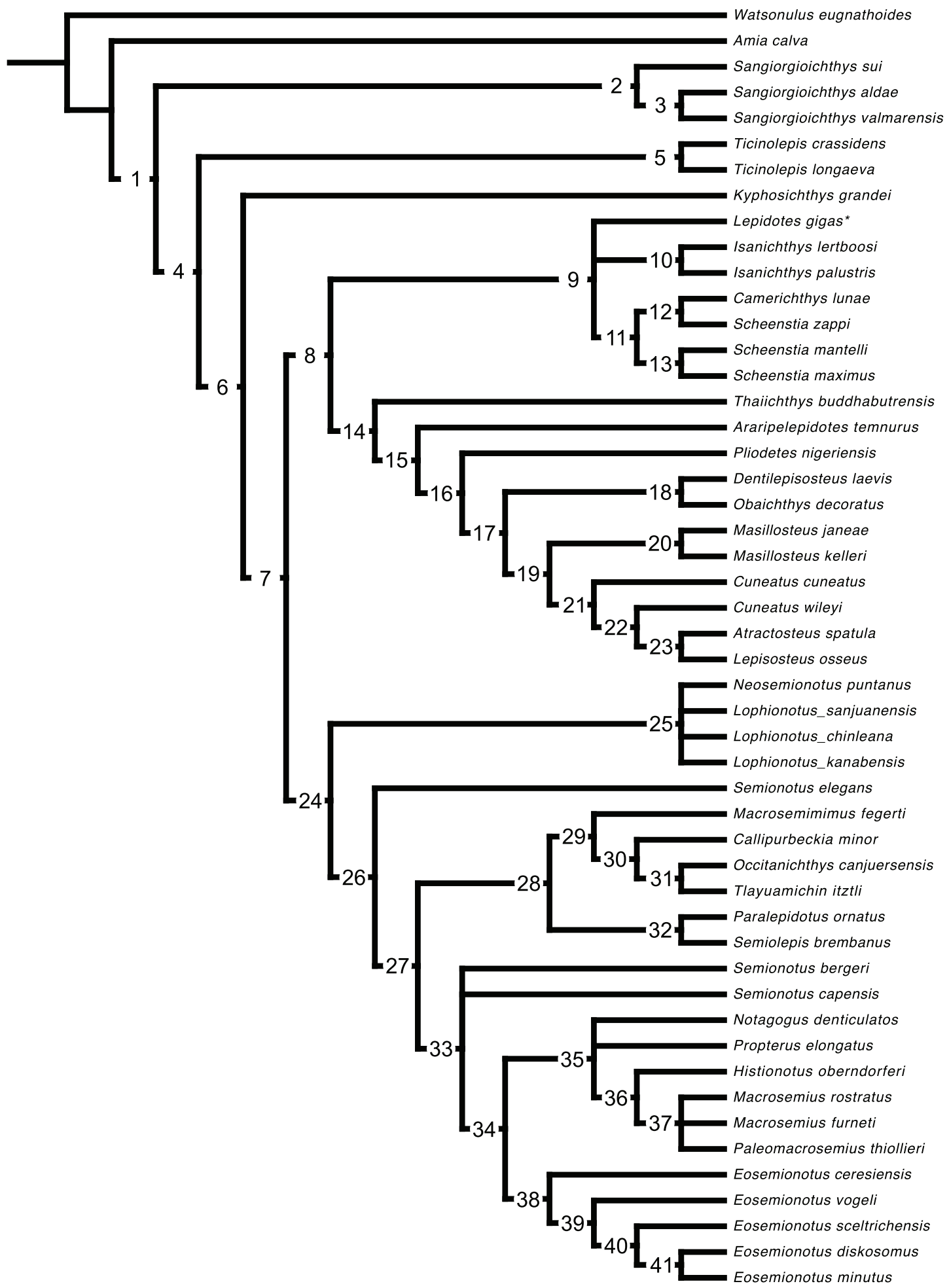

64 